
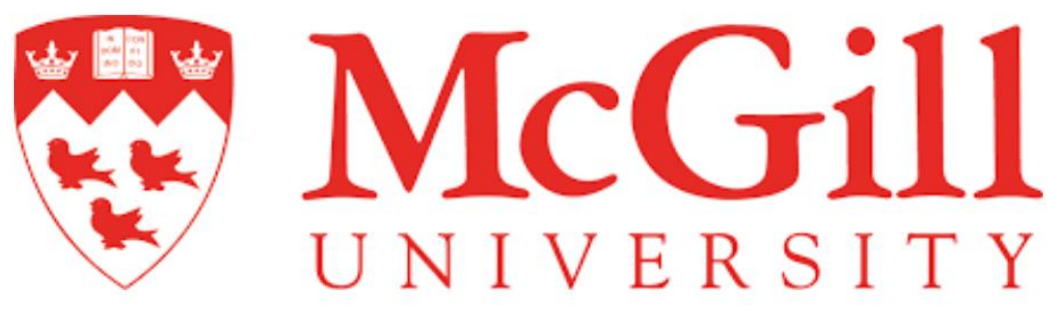

\title{
Strategies for surface crown pillar design using numerical modelling - A case study \\ Tuo Chen
}

\author{
Department of Mining and Materials Engineering \\ McGill University
}

August 2020

\begin{abstract}
A thesis submitted to McGill University in partial fulfillment of the requirements of a degree of Master of Engineering in the Department of Mining and Materials Engineering.
\end{abstract}

(OTuo Chen 2020 


\begin{abstract}
The extraction of shallow ore deposits using underground mining methods rather than open pit mining is not uncommon nowadays, especially with the increased environmental constraints such as maintaining surface ecology and/or protecting overlying infrastructure. The role of surface crown pillar - the rock cover consisting of ore rocks that are left above the uppermost stopes - is to separate the overlying surface from the underground mining operation. Although the problem of surface crown pillar design has been researched for more than 30 years, the underlining stability mechanisms and design guidelines are still limited. This is largely because of the wide variety and complexity of site-specific conditions. Thus, empirical and analytical methods are only used for preliminary design and more comprehensive methods such as numerical modelling must be adopted for the final design.
\end{abstract}

This thesis investigates strategies for the design of a surface crown pillar at a gold mining operation having a new, shallow, steeply dipping gold vein orebody that extends underneath an existing tailings storage facility. The orebody is in the vicinity of two regional faults. In this study, numerical modelling approaches are developed using the finite difference code FLAC3D 7.0. Critical factors such as in-situ stress regime, major geological structures, mining sequences, slanted surface topography and surcharge load due to the tailings storage facility are considered using 3-dimensional, elastoplastic analysis with Hoek-Brown failure criterion. A model parametric study is carried out to investigate the effect of fault properties and horizontal-to-vertical in-situ stress ratio on surface crown pillar stability. Mining-induced surface subsidence is then analyzed to shed light on the anticipated maximum differential settlement and angle of distortion that are likely to develop in the tailings dam foundation as a result of the mining activities. Predicted differential settlement results could serve as another criterion for crown pillar sizing from the perspective of overlying infrastructure stability. The reactivation of two nearby faults due to mining activities is explored. It appears that larger shear displacements occur on the fault plane that is parallel to the orebody strike compared to the cross fault. Finally, the effect of hanging wall overbreak on surface subsidence is examined. A new methodology for the estimation of hanging wall overbreak is developed by removing and backfilling predicted stope overbreak in a bottomup mining and backfilling sequence. The method is believed to be more realistic compared to conventional modelling methods as it considers the effect of stress shadow created by preceding 
stoping activities. The new method leads to higher hanging wall overbreak volumes, which are found to further aggravate ground surface subsidence. To mitigate this situation, a horizontal sill pillar is left in place to divide the orebody into two ore zones. The results show reduced hanging wall overbreak volume. The sill pillar is mined at the end of the mining sequence. The location of the sill pillar is further optimized to obtain the least amount of hanging wall overbreak. These measures could help minimize ore dilution and boost mining profitability. 


\section{Résumé}

L'extraction de gisements de minerai peu profonds en utilisant des méthodes d'extraction souterraine plutôt que l'exploitation à ciel ouvert est commun aujourd'hui, en particulier avec les contraintes environnementales accrues telles que le maintien de l'écologie de surface et / ou la protection des infrastructures sus-jacentes. Le rôle du pilier de la couronne de surface - la couverture rocheuse constituée de roches minéralisées qui restent au-dessus des chantiers supérieurs - est de séparer la surface sus-jacente de l'exploitation minière souterraine. Bien que le problème de la conception des piliers de couronne de surface a été étudié pendant que plus de 30 ans, les mécanismes de stabilité et les directives de conception sont encore limités. Ces limitations sont dû de la grande variété et la complexité des conditions spécifiques au site. Ainsi, les méthodes empiriques et analytiques ne sont utilisées que pour la conception préliminaire et des méthodes plus complètes telles que la modélisation numérique doit être adoptées pour la conception finale.

Cette thèse étudie les stratégies de conception d'un pilier de couronne de surface dans une exploitation minière aurifère ayant un nouveau gisement de filons aurifères peu profond et à forte inclinaison qui s'étend sous une installation de stockage de résidus existante. Le gisement se trouve à proximité de deux failles régionales. Dans cette étude, des approches de modélisation numérique sont développées en utilisant le code aux différences finies FLAC3D 7.0. Les facteurs critiques tels que le régime de contraintes in situ, les principales structures géologiques, les séquences minières, la topographie de surface inclinée et la surcharge due à l'installation de stockage des résidus sont pris en compte à l'aide d'une analyse élastoplastique tridimensionnelle en utilisant le critère de rupture Hoek-Brown. Une étude paramétrique modèle est réalisée pour étudier l'effet des propriétés des failles et du rapport des contraintes horizontales à verticales in situ sur la stabilité de la surface du pilier de la couronne. L'affaissement de surface induite par l'exploitation minière est ensuite analysé pour faire la lumière sur le tassement différentiel maximal prévu et l'angle de distorsion qui sont susceptibles de se développer dans la fondation du barrage de résidus à la suite des activités minières. Les résultats de tassements différentiels prévus pourraient servir de critère supplémentaire pour le dimensionnement des piliers de la couronne du point de vue de la stabilité des infrastructures sus-jacentes. La réactivation de deux failles proches en raison des activités minières est explorée. Il semble que les déplacements de cisaillement plus substantielle se produisent sur le plan de faille qui est parallèle à la direction du gisement par rapport à la faille 
croisée. Enfin, la thèse examine l'effet de la rupture excessive du mur suspendu sur l'affaissement de la surface. Une nouvelle méthodologie pour l'estimation du sur-bris des murs suspendus est mise au point en supprimant et en remblayant le sur-bris de chantier prévu dans une séquence d'extraction et de remblayage ascendante. On pense que la méthode est plus réaliste que les méthodes de modélisation conventionnelles car elle prend en compte l'effet de l'ombre de contrainte créée par les activités d'arrêt précédentes. La nouvelle méthode mène à des volumes de franchissement de murs suspendus plus élevés, qui aggravent encore l'affaissement de la surface du sol. Pour atténuer cette situation, un pilier de seuil horizontal est laissé en place pour diviser le gisement en deux zones minéralisées. Les résultats montrent une réduction du volume de surbrillance du mur suspendu. Le pilier de seuil est exploité à la fin de la séquence d'extraction. L'emplacement du pilier de seuil est en outre optimisé pour obtenir le moins de surbranchage du mur suspendu. Ces mesures pourraient aider à minimiser la dilution de minerai et à accroître la rentabilité minière. 


\section{Acknowledgment}

I wish to express my sincere appreciation to my supervisor Prof. Hani S. Mitri, who gave me the golden opportunity to do this fascinating project. His dedicated guidance and deep knowledge supported me in exploring and thinking in the mining field during my master's studies. The numerous discussions have helped me put forward practical methodologies towards engineering problems and finalize this project.

My thesis was financially supported by my supervisor's grant from the Natural Science and Engineering Research Council (NSERC). Their support is gratefully acknowledged.

I wish to express my gratitude to Kinross Gold Corporation for providing the data of the mine case study and giving permission to publish my work. I am extremely thankful to Dr. Jerry Ran from Kinross for his valuable comments that have greatly enhanced this thesis.

I wish to thank my colleagues in the Mine Design Lab: Isaac, Kelly, Yizhuo, Jorge, and Christian

for the time we worked together and the fun we had. I would like to thank Shahé Shnorhokian for his technical support during the project.

Last but not least, I am grateful for the love, understanding, and dedication of my parents, who have always encouraged me and supported me throughout my life. 


\section{Table of Contents}

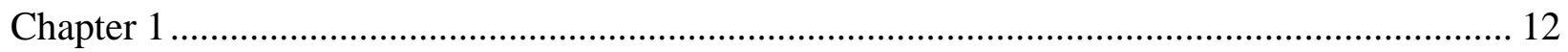

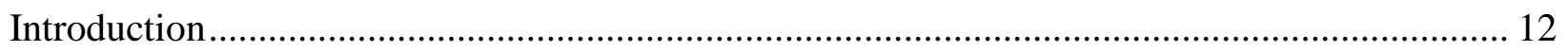

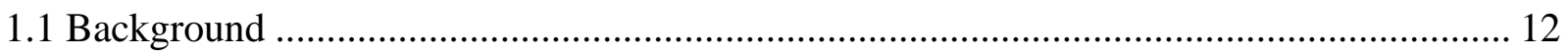

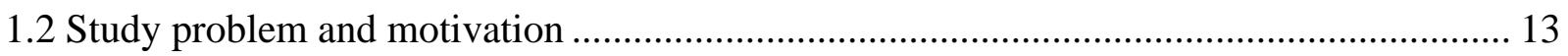

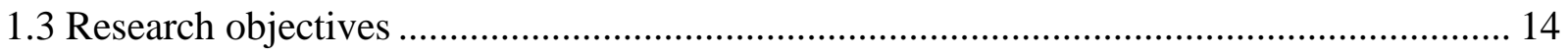

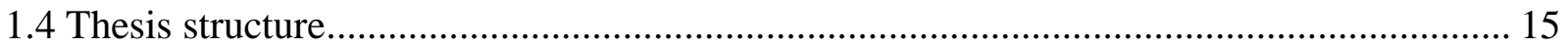

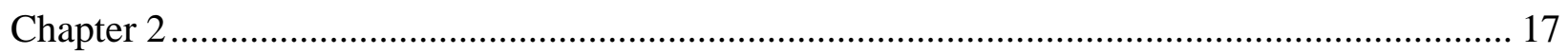

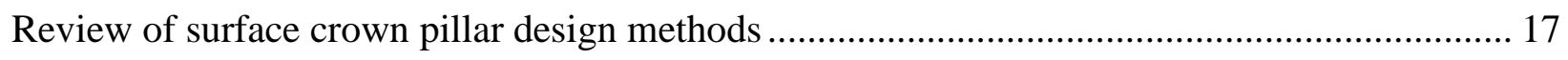

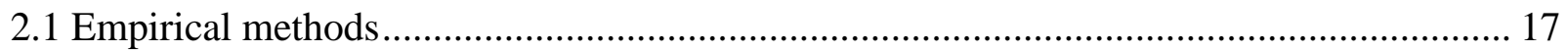

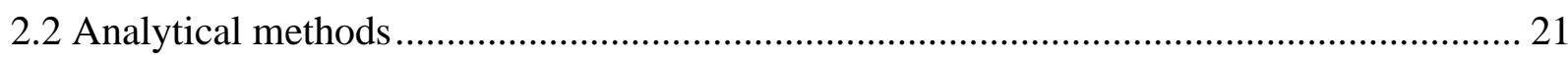

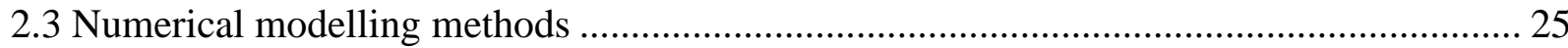

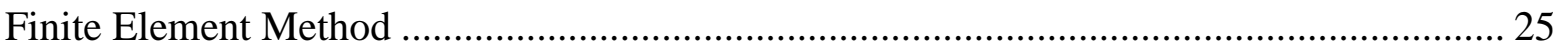

Finite Difference Method ............................................................................................. 26

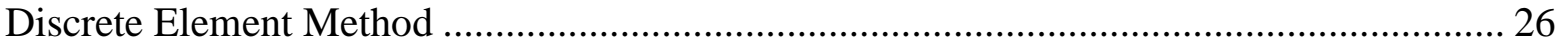

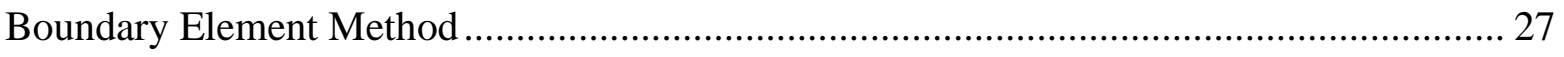

Numerical modelling applications for crown pillar design........................................... 28

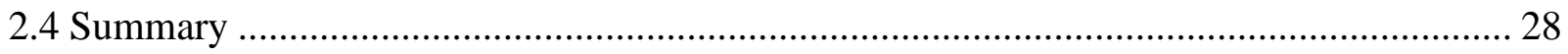

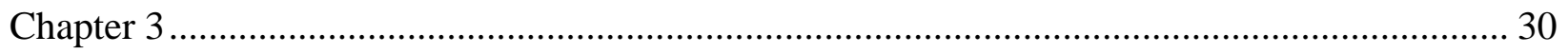

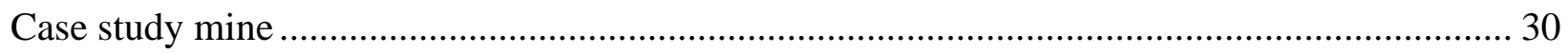

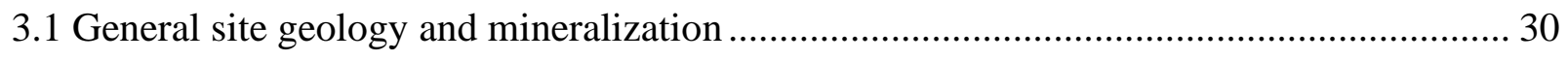

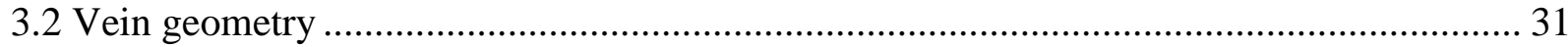




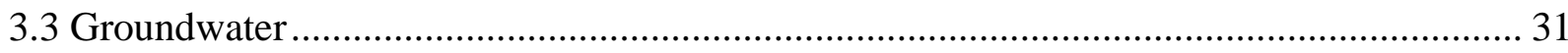

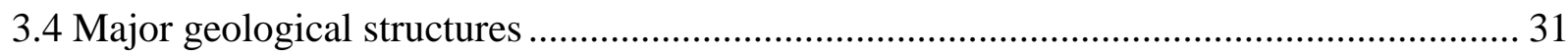

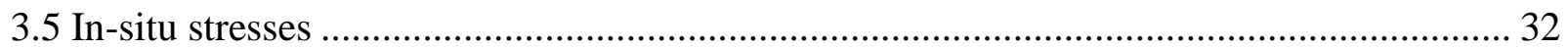

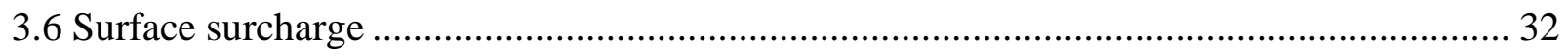

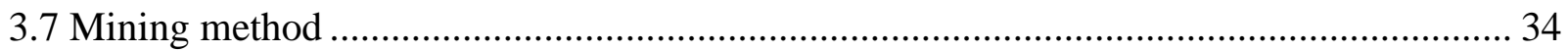

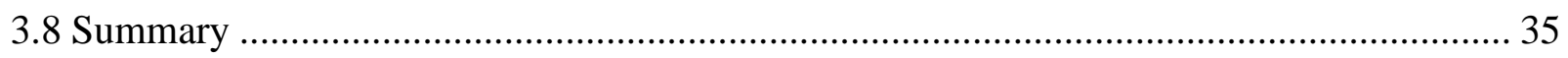

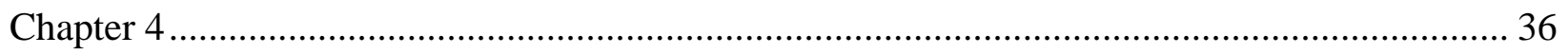

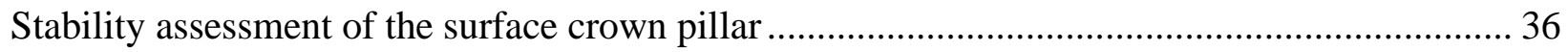

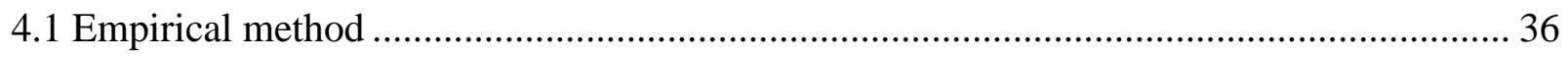

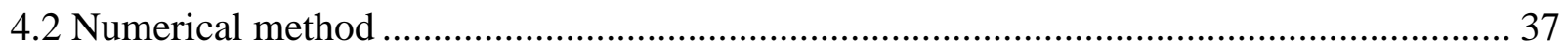

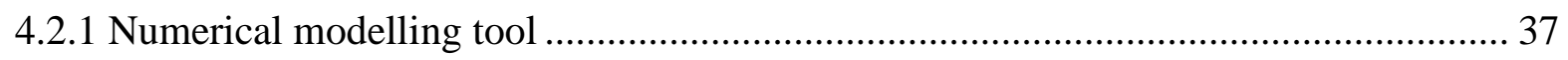

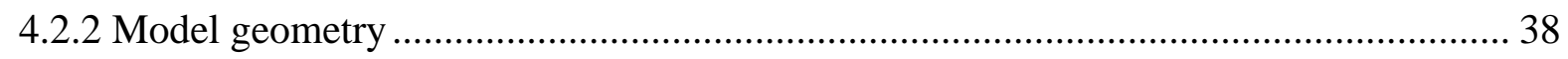

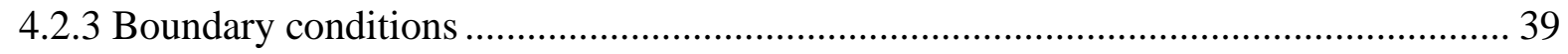

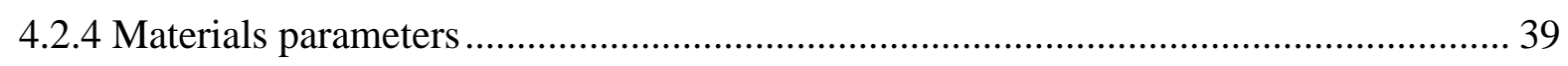

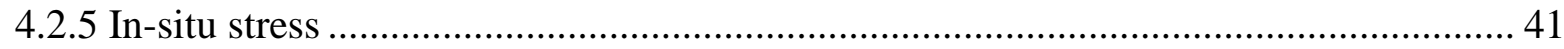

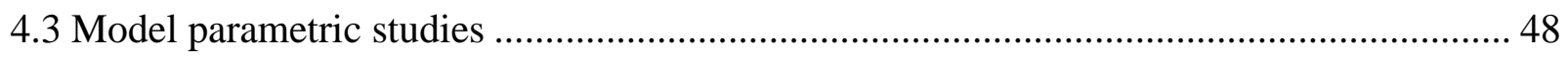

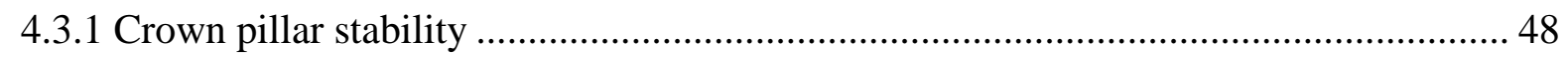

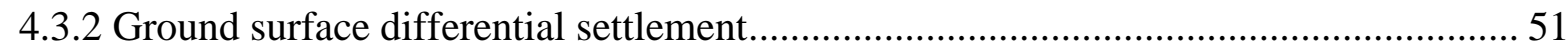

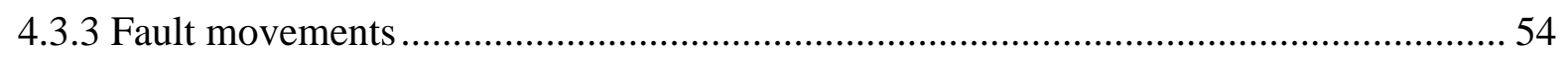

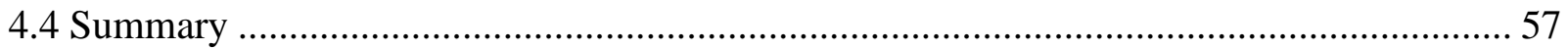

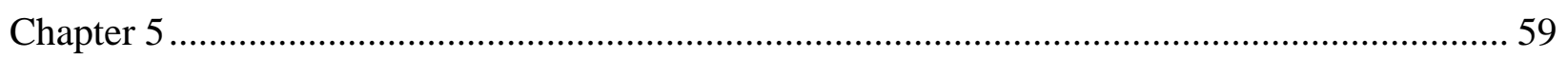

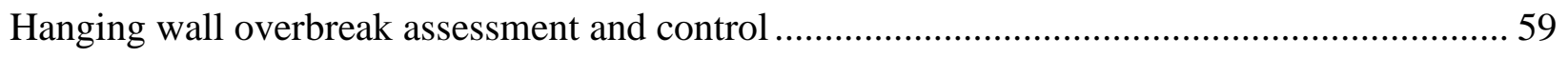

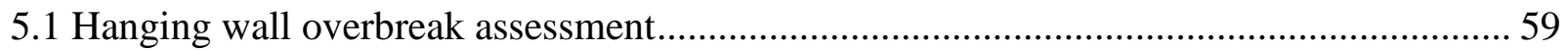




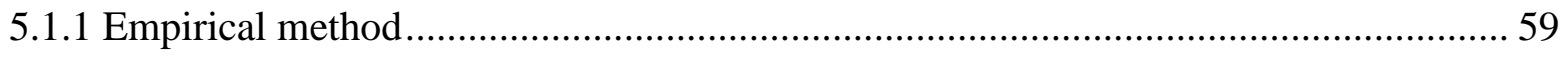

5.1.2 Proposed numerical modelling methodology ................................................. 66

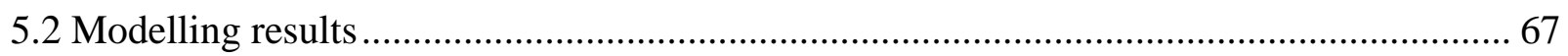

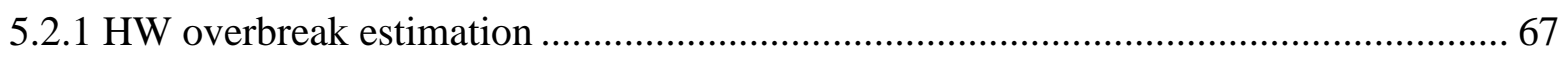

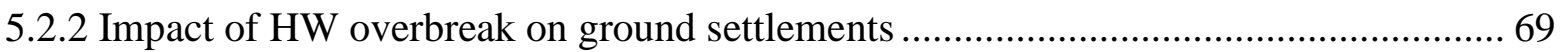

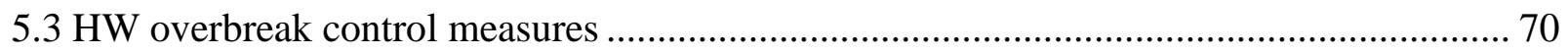

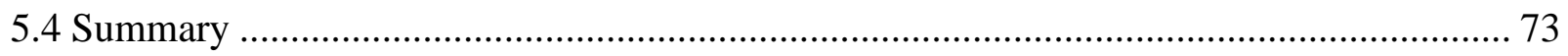

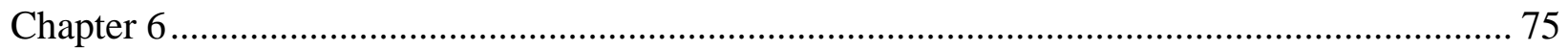

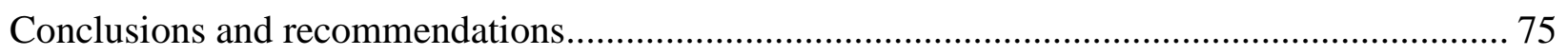

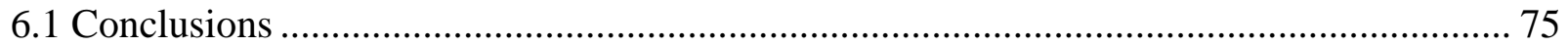

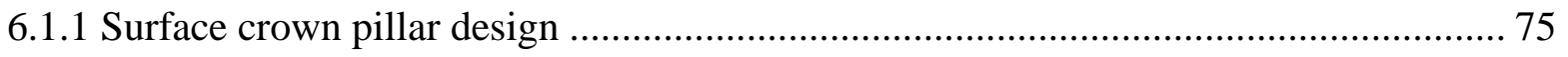

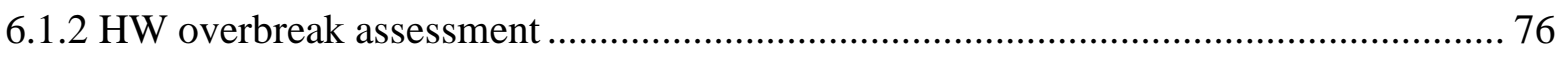

6.2 Recommendations for future work .................................................................. 78 


\section{List of Figures}

Figure 1.1: Schematic of cut and fill underground mining method..... 13

Figure 2.1: Thickness-to-span plot with respect to rock quality Q and RMR (from Carter, 2014)

Figure 2.2: Calculated FoS values for stopes investigated (from Henning, 2007). 19

Figure 2.3: Scaled span chart with probability of failure contour intervals (from Carter, 2014) . 20

Figure 2.4 Schematic of a rectangular pillar geometry 23

Figure 3.1: Geological property mapping of the case study mine ....................................... 30

Figure 3.2: Longitudinal section of the studied vein ....................................................... 31

Figure 3.3: Leapfrog model of the case study mine ...................................................... 32

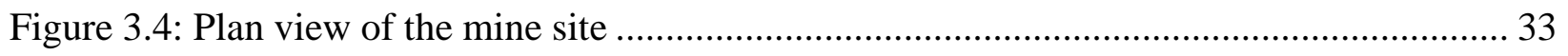

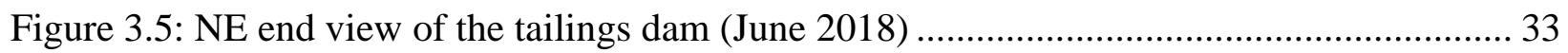

Figure 3.6: Plan view of the expected TSF in the year 2024 ........................................... 34

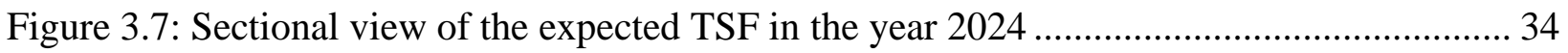

Figure 3.8: Schematic showing Avoca mining method .................................................. 35

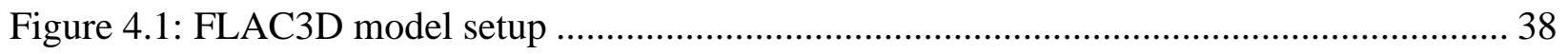

Figure 4.2: Model plan view showing stress orientations with respect to the vein ................... 41

Figure 4.3: In-situ stress initialization scheme ......................................................... 43

Figure 4.4: In-situ stress initialization results (unit: Pascal).............................................. 44

Figure 4.5: Apply surcharge to the FLAC3D model. ......................................................... 45

Figure 4.6: Stress and displacement results after applying surface surcharge......................... 46

Figure 4.7: Planned mining levels of the case study vein ................................................... 47

Figure 4.8: Location of the critical section R-R ............................................................ 49 
Figure 4.9: Minimum principal stress and pillar yielding conditions of the three states of Model 1 (unit: Pascal). Note: Negative principal stress values represent compression. 50

Figure 4.10: Plan view of vertical displacements on the ground surface at different mining stages of Model 1 (unit: meter) 52

Figure 4.11: Dam foundation uneven deforamation 53

Figure 4.12: Sectional view of vertical displacements under the tailings dam at different mining stages of Model 1 (unit: meter). Note: The black line denoted the location of the parallel fault. 54 Figure 4.13: Fault shear displacements at mining stage 10 of different models (unit: meter) ..... 56

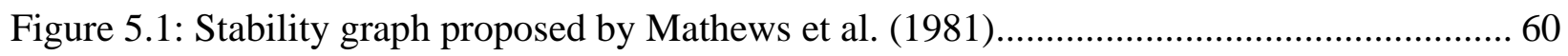

Figure 5.2: Equivalent linear overbreak/sloughage (ELOS) ......................................... 61

Figure 5.3: Empirical dilution design graph (from Clark \& Pakalnis, 1997) ............................. 62

Figure 5.4: Empirical charts for determining A, B and C............................................... 65

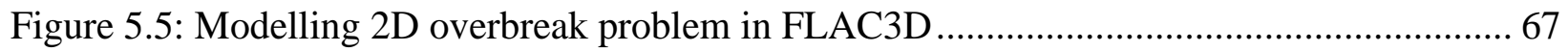

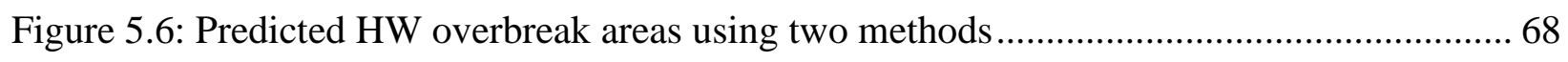

Figure 5.7: Stress shadow zones caused by stoping activities (unit: Pascal) ........................... 68

Figure 5.8. Comparison of the predicted HW ELOS between conventional and new methods ... 69

Figure 5.9: HW overbreak results with different sill pillar placement schemes....................... 71

Figure 5.10: HW ELOS versus mining levels in different models ........................................ 72

Figure 5.11: Sill pillar separates stoping levels to reduce stress shadow due to lower zone mining (unit: Pascal). Note: Positive principal stress values represent tension. 72 


\section{List of Tables}

Table 2.1: Acceptable risk exposure guidelines - comparative significance of crown pillar failure

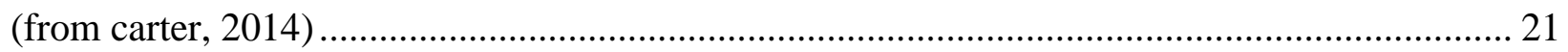

Table 4.1: Rock mass strength and stiffness parameters used for simulating bedrock and ore in the

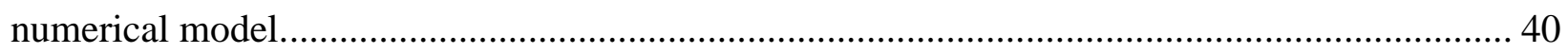

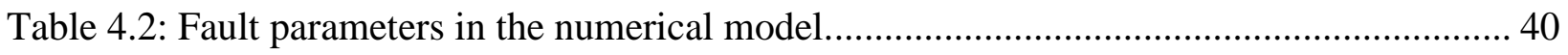

Table 4.3: Simulated mining stages in FLAC3D model........................................................... 47

Table 4.4: Model parametric study on in-situ stress and fault parameters .................................. 48

Table 4.5: Crown pillar thickness at different yielding states .................................................. 50

Table 4.6: Summary of dam foundation deformations at different mining stages ........................ 53

Table 4.7: Maximum fault shear displacements at mining stage 10.......................................... 57

Table 5.1: Predicted HW ELOS values obtained from two methods ............................................. 69

Table 5.2: Predicted differential settlements obtained using two methods .................................. 70

Table 5.3: HW ELOS values when implementing sill pillars at different levels.......................... 73 


\section{Chapter 1}

\section{Introduction}

\subsection{Background}

Nowadays, the preferred method of extraction of shallow deposits is by underground mining, and this is primarily due to environmental constraints that aim to limit the footprint of mining activities. Although surface mining may offer economic benefits and cause fewer safety issues, underground mining has greater potential benefits as the orebody extends to deeper horizons. The environmental problems could be reduced to a minimum level as the mining operations are conducted underground. Furthermore, existing surface infrastructures such as roads, channels, electrical substations, or dams can be maintained.

Controlling the risk of shallow underground mining operations to ensure ground stability is, however, still challenging. There are many considerations when it comes to the long-term stability of surface crown pillars, such as chemical ground erosion, surface water, or the physical stability of the crown pillar above the shallow excavation. In this study, the assessment of surface crown pillar stability will be assessed concerning the influence of shallow underground mining.

Surface crown pillars are formed above all underground mining operations situated near the ground surface, as shown in Fig.1.1. As mining proceeds towards the ground surface, the thickness of the rock cover decreases. At one point, a portion of the orebody must be left behind to separate the underground working from the ground surface, thus preventing stope cave-ins and maintaining the stability of any ground infrastructure. A surface crown pillar is made up of any rock strata that remain between underground openings and the ground surface. In order to ensure the safety of both surface and underground operations, it is vital to determine the appropriate thickness of the crown pillar. Several approaches - analytical and empirical - have been developed and report in the literature. The safe thickness of a surface crown pillar is determined based on considerations of (1) strength of the rock mass, (2) geological structures, (3) in-situ stresses, and 4) hydrogeology. Although this problem in a mining context has been researched for more than 30 years, little is reported in the literature on the influence of undulating surface topography on in-situ stress variation and how it could affect crown pillar stability. Thus, the underlining mechanisms and design guidelines of the crown pillar are still limited. 


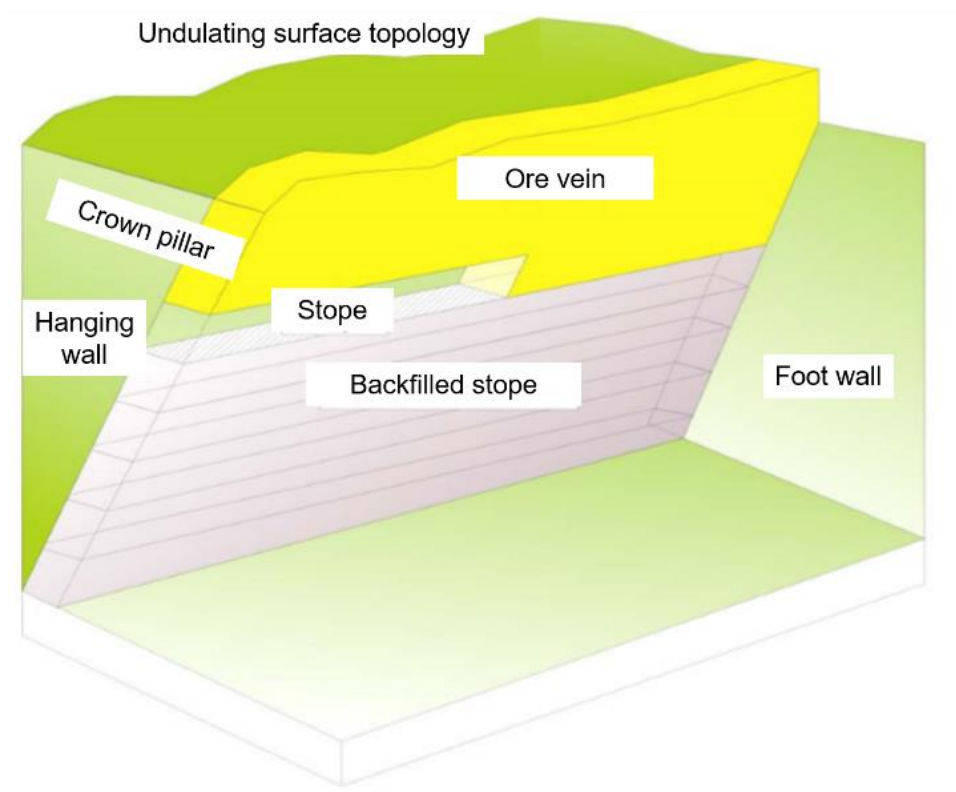

\section{Figure 1.1: Schematic of cut and fill underground mining method}

\subsection{Study problem and motivation}

Problems from collapses of near-surface workings and unfavorable ground surface settlements have plagued mining operations for years. Establishing the competence and adequacy of the rock cover that will remain in place above a near-surface excavation is key to preventing cave-ins and ensuring the stability of any infrastructure above underground workings. At most currently operating mines, engineering assessment of the minimum stable crown pillar dimensions for current conditions is required during mine planning.

If the crown pillar thickness is inadequately designed, potentially unstable zones may extend to a substantial depth below the ground surface, resulting in ground surface settlement or excavation cave-ins. The factors which contribute to surface crown pillar stability include:

- Rock mass structure and condition

- Mechanical properties of the rock mass

- In-situ stress regime

- Geological structures such as faults

- Ground surface topography

- Ground water condition and rock mass permeability

- Span and depth of mine openings 
- Nearby mining activities.

Before the 1980s, the "Rules of Thumb" were the principal, and in many cases, the only approach used for sizing of the crowns. The concept of the scaled span was introduced by Carter et al. (1992). It has established a more systematic approach for the empirical design of the crown pillar dimension. However, none of these empirical or semi-empirical approaches could take into consideration all the abovementioned factors that affect crown pillar stability thoroughly into account. The accuracy of the empirical approaches for assessing crown pillar stability, such as the scaled span chart, is mainly controlled by the database of crown pillar records. Thus, using empirical approaches for the appropriate design of the crown pillar dimension cannot be achieved without some judgment by the rock mechanics engineer as the mine site conditions vary from case to case. Another issue causing more recent failures is the lack of insight into the underlying mechanisms controlling crown pillar stability. Generally, the reason that these more recent collapses have occurred can be traced to the same primary cause: - lack of knowledge regarding critical factors pertinent to adequate design (Carter, 2014)

Nowadays, advanced numerical modelling tools provide a means for understanding the underlying mechanisms of crown pillar stability. This, together with site-specific geotechnical investigations and laboratory testing for rock characterization form a sound approach for crown pillar design. Therefore, to assess crown pillar stability comprehensively in undulating surface topography, 3-D non-linear numerical modelling is adopted in this study.

\subsection{Research objectives}

This research is part of a feasibility study of a shallow deposit extending underneath overlying infrastructure. The fundamental problem studied in this thesis is a mine case study involving the design of safe surface crown pillar thickness. Besides, the influence of stope hanging wall overbreak on surface subsidence will be assessed. The main objectives are the following:

1. To propose a methodology for surface crown pillar stability assessment using numerical modelling;

2. To investigate the influence of regional faults and in-situ stresses on the crown pillar stability and ground surface settlements; 
3. To suggest a minimum safe crown pillar thickness considering the stability of both surface crown pillar and overlying infrastructure;

4. To propose a modelling methodology for estimating overall stope dilution/overbreak volume and explore its influence on surface subsidence;

5. To propose and examine measures for the reduction of stope overbreak.

In this study, a shallow underground mining case of a hard rock narrow vein is simulated from the bottom up using advanced FLAC3D numerical modelling software to assess crown pillar stability during underground mining. For the modelling technique, a more site-specific geotechnical information from this case study is considered in the numerical model, such as crown pillar rock properties, existing in-situ stress regime, nearby geological structures, ground topography, ground overburden, mining methods, and sequence. Meanwhile, a parametric study will be carried out to analyze the influence of horizontal-to-vertical in-situ stress ratio and nearby geological fault on the crown pillar stability. The influence of major geological structures, i.e., faults that exist near the vein will be simulated in the study. Hence, the underlying mechanisms and factors affecting crown pillar stability can be analyzed in the study, and the suggested minimum crown pillar thickness can be obtained from the modelling results. Moreover, surface overburden such as surcharge of a tailings dam will be simulated to model the actual effects of ground loading. The predicted ground reaction will be obtained from the modelling results to examine the influence of shallow excavation on the stability of ground infrastructure, and this ground settlement results can be used as a criterion for designing crown pillar thickness.

\subsection{Thesis structure}

This thesis consists of 6 chapters as follows. Following the introduction in Chapter 1, a state-ofthe-art literature review is reported in Chapter 2. Empirical, analytical and numerical methods of analysis are reviewed. The case study mine is described in Chapter 3. The proposed mining method of the two orebodies comprising the case study is presented in detail. Surface topography and nearby infrastructure are presented. The modelling technique adopted in this study is presented in Chapter 4. This is followed by a detailed model parametric study to examine the effect of parameter variation on the stresses and deformations in the crown pillar. The crown pillar stability is examined based on the numerical modelling results. Chapter 5 proposes a new method to estimate stope hanging wall overbreak and explores its influence on the ground subsidence. Stope 
overbreak control measures are also examined with the introduction of a sill pillar dividing the orebody into two ore zones. Chapter 6 presents the conclusions. It summarizes the underlying mechanism of crown pillar stability under shallow underground mining activities and suggests the minimum crown pillar thickness for the case study mine. It also provides recommendations for future work. 


\section{Chapter 2}

\section{Review of surface crown pillar design methods}

Even though a thick surface crown pillar provides support for underground stopes and help surface stability, the overestimation of surface crown pillar thickness is uneconomical from the mineral recovery point of view. Thus, the optimization of surface crown pillar dimension is vital for shallow underground mining. The estimation of optimum crown pillar thickness is a complex task; surface crown pillars at many mines were designed based on practical past engineering experience and rule of thumb. At present, empirical, analytical, and numerical modelling are widely used for assessing the stability of crown pillars. In this chapter, the most commonly used methods are reviewed, and the pros and cons of each method are discussed.

\subsection{Empirical methods}

Before the 1980s, "rule of thumb" was almost the only principal method for crown pillar design. In most mines, surface crown pillar design is only considered by selecting an adequate crown pillar thickness to span ratio. The most essential evaluation using this method is past engineering experience. Some rules of thumb could be considered in some mines where the rock rover properties are similar. However, many rules are site-specific and could only be used locally.

By the end of the 1990s, it was recognized that the dimension of most surface crown pillars was not formally "designed" but was merely decided according to the traditional rules of thumb. Although most survived, some failure cases have occurred, which proved that using rules of thumb only is inappropriate. Fig. 2.1 is an empirical graph for the selection of thickness-to-span (T/S) ratio of the crown pillar based on the Rock Mass Rating (RMR) or the Rock Quality Index. Black circles represent failure cases, and open circles represent stable cases. A regression line defining the $\mathrm{T} / \mathrm{S}$ ratio is given by

$$
T / S=1.55 Q^{-0.62}
$$

where $T$ is the crown pillar thickness, $S$ is the crown pillar span, and $Q$ is the rock mass quality index from the Norwegian Geotechnical Institute (NGI) (Barton et al, 1974). 


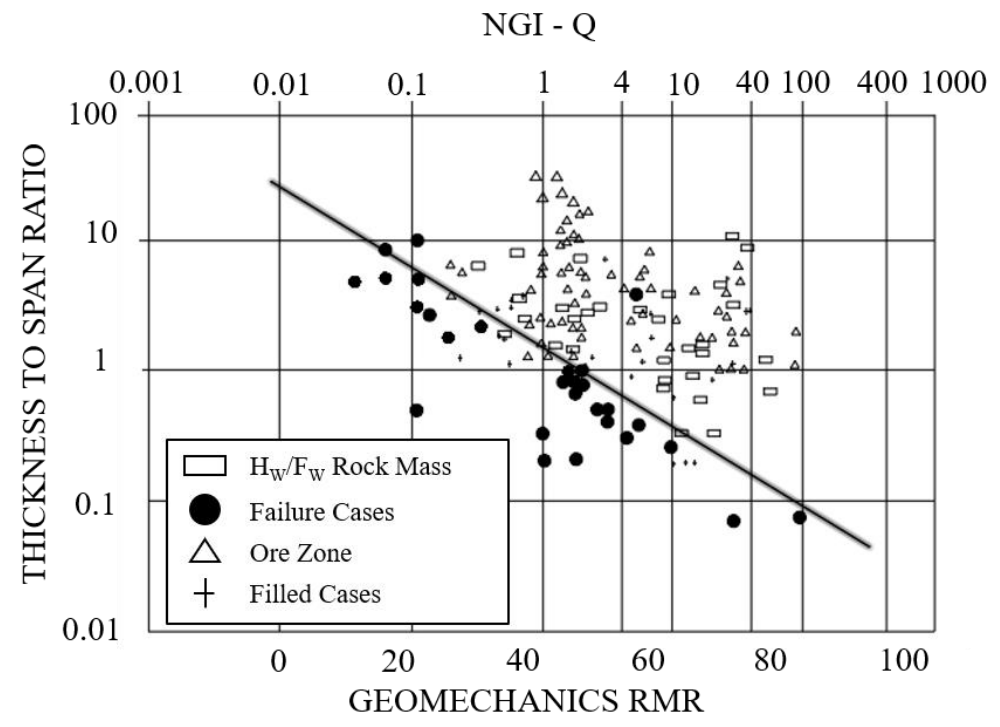

Figure 2.1: Thickness-to-span plot with respect to rock quality $Q$ and $R M R$ (from Carter, 2014)

Although it is difficult to justify these methods theoretically, the empirical scaled span method was developed and later improved by Carter $(1992,2014)$, to provide better guidelines to the safe design of the T/S ratio. With Carter's method, the crown pillar geometry is first used to calculate a "scaled span" as follows.

$$
C_{S}=S\left(\frac{\gamma}{T\left(1+S_{R}\right)(1-0.4 \cos \theta)}\right)^{0.5}
$$

where:

$C_{S}=$ scaled crown span $(\mathrm{m})$

$S=$ the stope $\operatorname{span}(\mathrm{m})$

$\gamma=$ specific gravity of the rock cover

$T=$ surface crown pillar thickness (m)

$S_{R}=$ span ratio (stope span /stope length)

$\theta=$ stope dip angle

The obtained scaled span $C_{S}$ is compared to the critical scaled span to assess the stability of the surface crown pillar for a given rock quality. Empirically, the cases where scaled span has exceeded critical scaled span have been failed in the database. The original formula for the critical scaled span is calculated according to the equation (Carter, 1992): 


$$
S_{C}=3.3 \times Q^{0.43} \times \sinh ^{0.0016}(Q)
$$

where: $S_{C}=$ critical scaled span $(\mathrm{m})$; and $Q=$ rock mass quality index.

In its most basic form, the scaled span method can be applied deterministically to assess failure risk by simply comparing the scaled span $\left(C_{S}\right)$ reflecting the crown pillar geometry, to the critical span $\left(S_{C}\right)$, reflecting the rock mass quality. The approximate Factor of Safety (FoS) can be calculated by the following equation:

$$
\mathrm{FoS} \approx S_{C} / C_{S}
$$

For any crown pillar with an FoS less than 1.0, the likelihood of failure would be predicted to be very high, unless the stope had been sufficiently supported, or appropriate backfill had been used in mining. The appropriate FoS ranges can be identified from the database of crown pillar stability or surface subsidence inventory. Henning (2007) summarized from local experiences that some crown pillars have failed at FoS values around 2 (see Figure 2.2).

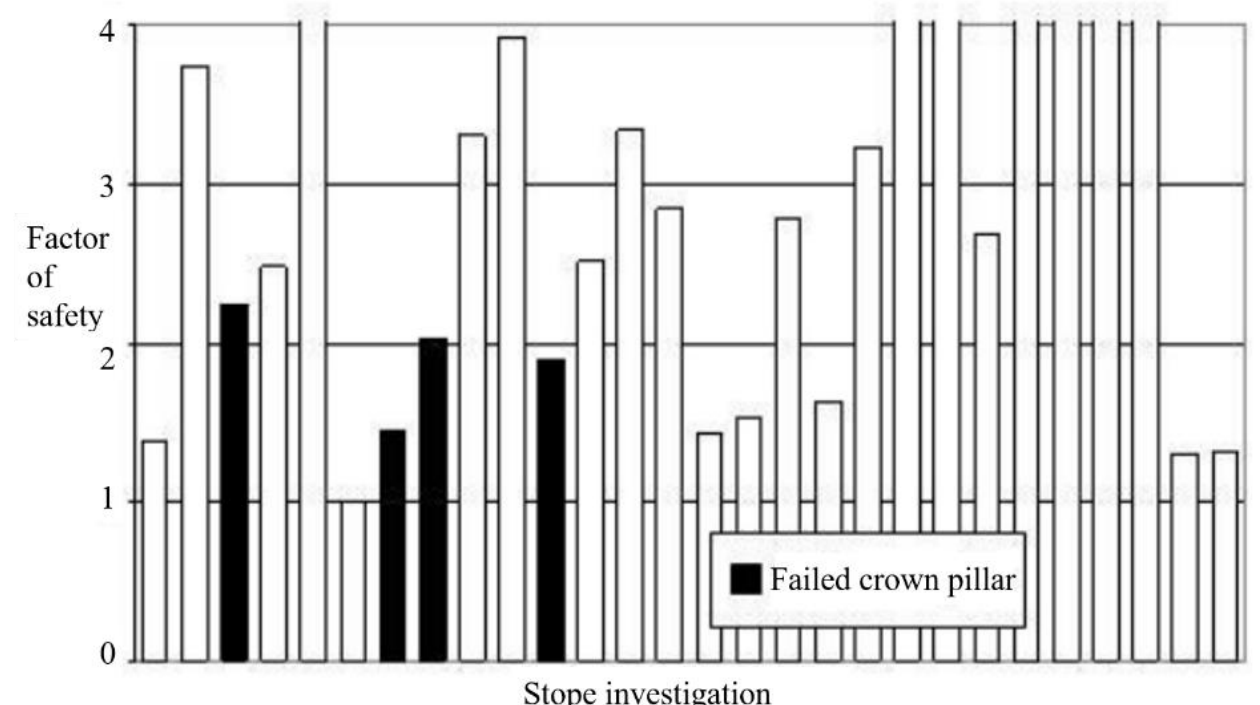

Figure 2.2: Calculated FoS values for stopes investigated (from Henning, 2007)

The scaled span method was later improved by addressing various levels of allowable risk from the perspective of different stakeholders, as shown in Figure 2.3 (Carter, 2014). Along with this chart, a more systematic classification for assessing the acceptable risk of crown pillar failure was also proposed, as illustrated in Table 2.1. Each crown pillar class comes up with estimated 
pillar acceptability and serviceable life span. For instance, when FoS is around 2, the pillar life span is 50 to 100 years and incidental superficial monitoring is recommended. Table 2.1 provides guidelines for crown pillar closure and remediation and can also be used for checking if the designed crown pillar thickness is adequate through estimating the FoS and probability of failure.

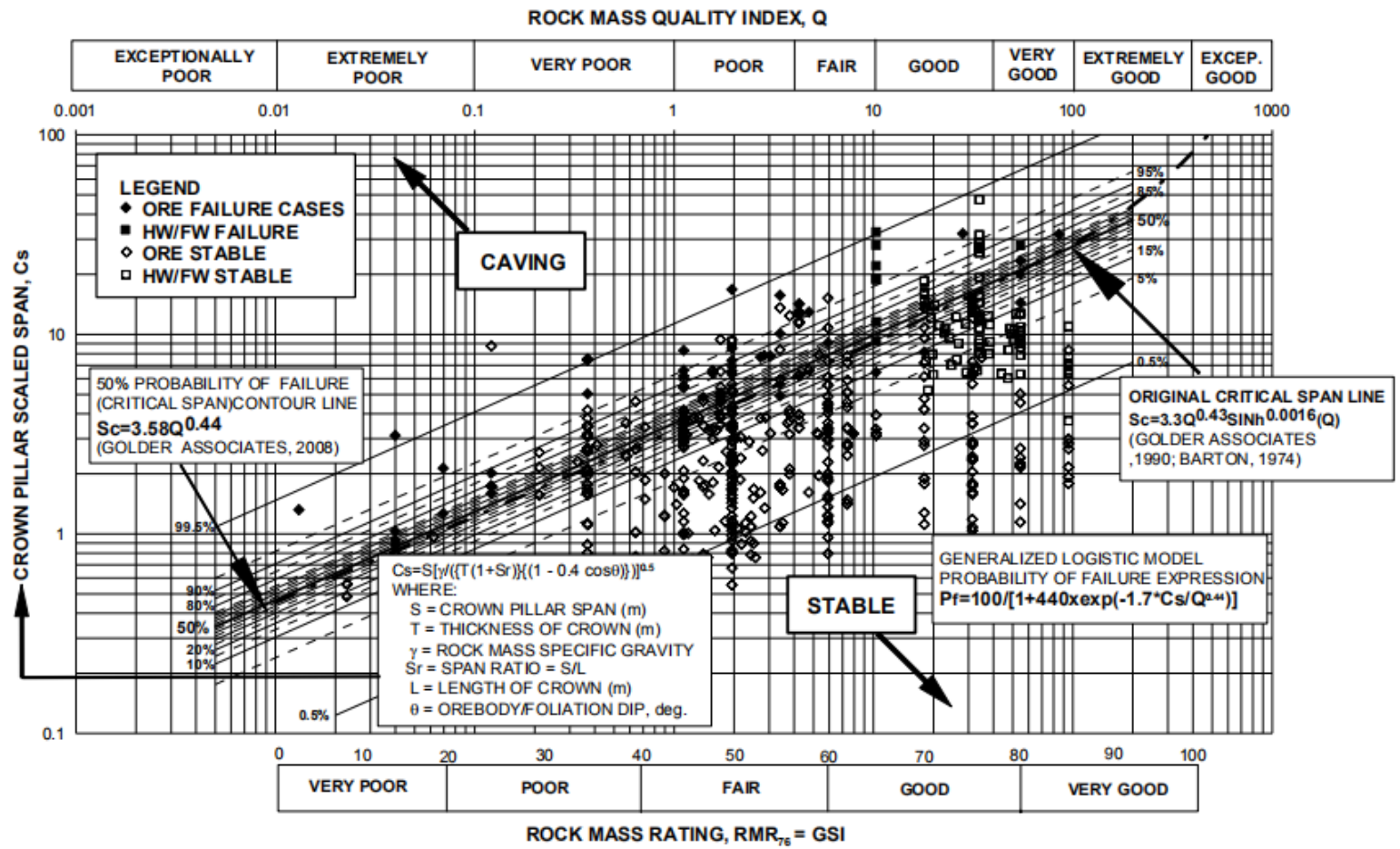

Figure 2.3: Scaled span chart with probability of failure contour intervals (from Carter, 2014) 
Table 2.1: Acceptable risk exposure guidelines - comparative significance of crown pillar failure (from Carter, 2014)

\begin{tabular}{|c|c|c|c|c|c|c|c|c|c|}
\hline \multirow[b]{2}{*}{ Class } & \multirow{2}{*}{$\begin{array}{c}\text { Probability } \\
\text { of Failure } \\
\%\end{array}$} & \multirow{2}{*}{$\begin{array}{l}\text { Minimum } \\
\text { Factor of } \\
\text { Safety }\end{array}$} & \multirow{2}{*}{$\begin{array}{l}\text { Maximum } \\
\text { Scaled } \\
\text { Span, } \\
\text { Cs }(=\mathrm{Sc})\end{array}$} & \multirow{2}{*}{$\begin{array}{l}\text { ESR } \\
\text { (Barton } \\
\text { et al. } \\
\text { 1974) }\end{array}$} & \multicolumn{5}{|c|}{ Design Guidelines for Pillar Acceptability/Serviceable Life of Crown Pillar } \\
\hline & & & & & Expectancy & Years & $\begin{array}{l}\text { Public } \\
\text { Access }\end{array}$ & $\begin{array}{l}\text { Regulatory } \\
\text { position on } \\
\text { closure }\end{array}$ & $\begin{array}{c}\text { Operating } \\
\text { Surveillance } \\
\text { Required }\end{array}$ \\
\hline A & $50-100$ & $<1$ & $11.31 Q^{0.44}$ & $>5$ & Effectively zero & $<0.5$ & Forbidden & $\begin{array}{l}\text { Totally } \\
\text { unacceptable }\end{array}$ & Ineffective \\
\hline B & $20-50$ & 1.0 & $3.58 Q^{0.44}$ & 3 & $\begin{array}{l}\text { Very, very short-term } \\
\text { (temporary mining purposes } \\
\text { only; unacceptable risk of } \\
\text { failure for temporary civil } \\
\text { tunnel portals }\end{array}$ & 1.0 & $\begin{array}{l}\text { Forcibly } \\
\text { Prevented }\end{array}$ & $\begin{array}{l}\text { Not } \\
\text { acceptable }\end{array}$ & $\begin{array}{l}\text { Continuous } \\
\text { sophisticated } \\
\text { monitoring }\end{array}$ \\
\hline C & $10-20$ & 1.2 & $2.74 Q^{0.44}$ & 1.6 & $\begin{array}{l}\text { Very short-term (quasi- } \\
\text { temporary stope crowns ; } \\
\text { undesirable risk of failure for } \\
\text { temporary civil works) }\end{array}$ & $2-5$ & $\begin{array}{l}\text { Actively } \\
\text { prevented }\end{array}$ & $\begin{array}{l}\text { High level of } \\
\text { concern }\end{array}$ & $\begin{array}{l}\text { Continuous } \\
\text { monitoring } \\
\text { with } \\
\text { instruments }\end{array}$ \\
\hline D & $5-10$ & 1.5 & $2.33 Q^{0.44}$ & 1.4 & $\begin{array}{l}\text { Short-term (semi-temporary } \\
\text { crowns, e.g.under non- } \\
\text { sensitive mine infrastructure) }\end{array}$ & $5-10$ & Prevented & $\begin{array}{l}\text { Moderate } \\
\text { level of } \\
\text { concem }\end{array}$ & $\begin{array}{l}\text { Continuous } \\
\text { simple } \\
\text { monitoring }\end{array}$ \\
\hline E & $1.5-5$ & 1.8 & $1.84 Q^{0.44}$ & 1.3 & $\begin{array}{l}\text { Medium-term (semi- } \\
\text { permanent crowns, possibly } \\
\text { under structures) }\end{array}$ & $15-20$ & Discouraged & $\begin{array}{l}\text { Low to } \\
\text { moderate } \\
\text { level of } \\
\text { concern }\end{array}$ & $\begin{array}{l}\text { Conscious } \\
\text { superficial } \\
\text { monitoring }\end{array}$ \\
\hline $\mathrm{F}$ & $0.5-1.5$ & 2 & $1.12 Q^{0.44}$ & 1 & $\begin{array}{l}\text { Long-term (quasi-permanent } \\
\text { crowns, civil portals, near- } \\
\text { surface sewer tunnels) }\end{array}$ & $50-100$ & Allowed & $\begin{array}{l}\text { Of limited } \\
\text { concern }\end{array}$ & $\begin{array}{l}\text { Incidental } \\
\text { superficial } \\
\text { monitoring }\end{array}$ \\
\hline G & $<0.5$ & $\gg 2$ & $0.69 Q^{0.44}$ & 0.8 & $\begin{array}{l}\text { Very long-term (permanent } \\
\text { crowns over civil tunnels) }\end{array}$ & $>100$ & Free & Of no concern & $\begin{array}{l}\text { None } \\
\text { required }\end{array}$ \\
\hline
\end{tabular}

The empirical scaled span method, however, should be implemented with caution. This is because the accuracy of empirical methods largely relies on the quality of the database. When designing the surface crown pillar for a new case, the geometry and geology could be very different from that of recorded case histories used for developing these charts. Besides, other conditions, including geological structures, surface surcharging, and horizontal stresses, are site-specific and difficult to be incorporated into the empirical equations.

\subsection{Analytical methods}

A number of roof beam and plate analysis methods have long been used to explore surface rock cover stability, typically crown pillar will be simplified as a beam either cantilevered or supported at both ends, and equivalent beam thickness and most critical failure mode of the beam will be assumed. The total force applied to the beam structure is equal to its self-weight plus any overlying load.

The CPillar program (Hoek, 1989; RocScience, 2000) can be used to assess crown pillar stability using limit equilibrium techniques and probabilistic approach. In a deterministic analysis, it is assumed that all input parameters are "exactly" known (e.g., pillar geometry, in-situ stresses, shear strength, groundwater conditions, etc.), and CPillar computes the FoS for a single pillar. In a 
probabilistic analysis, statistical information can be entered to account for uncertainty in pillar dimensions, shear strength, and other parameters. This results in a safety factor distribution from which a probability of failure is calculated.

The program offers three different limit equilibrium analysis methods, including rigid plate analysis, elastic plate analysis, and Voussoir (no tension) plate analysis.

For a rigid plate analysis, the only failure mode considered is shear. The crown pillar is idealized as a rigid block that fails by plug-sliding along the abutments. This type of failure most likely occurs in areas of low horizontal stress constrain acting on the pillar. A rectangular pillar is shown in Figure 2.4. A thickness of overburden $\left(t_{0}\right)$ can be added above the pillar. The height of water $\left(h_{\mathrm{w}}\right)$ can also be specified to any height above the base of the pillar. The FoS of the pillar against vertical downward sliding is given by the ratio of the sum of the shear forces acting on the four sides of the pillar, to the total weight of the pillar, including overburden and free water, if any, as shown below:

$$
F_{\mathrm{O}} S_{\text {shear }}=\frac{\text { Shear resistance }}{\text { Dead load }}=\frac{2\left(\frac{\tau_{x z} z}{x}+\frac{\tau_{y z} z}{y}\right)}{q}
$$

where $F o S_{\text {shear }}$ is the FoS for shear failure, $\tau_{x z}$ and $\tau_{y z}$ are the shear strengths on the vertical sides of the pillar, $z$ is the pillar height, $x$ is the pillar length, $y$ is the pillar width, $q$ is the total dead load due to rock, overburden, and water. 


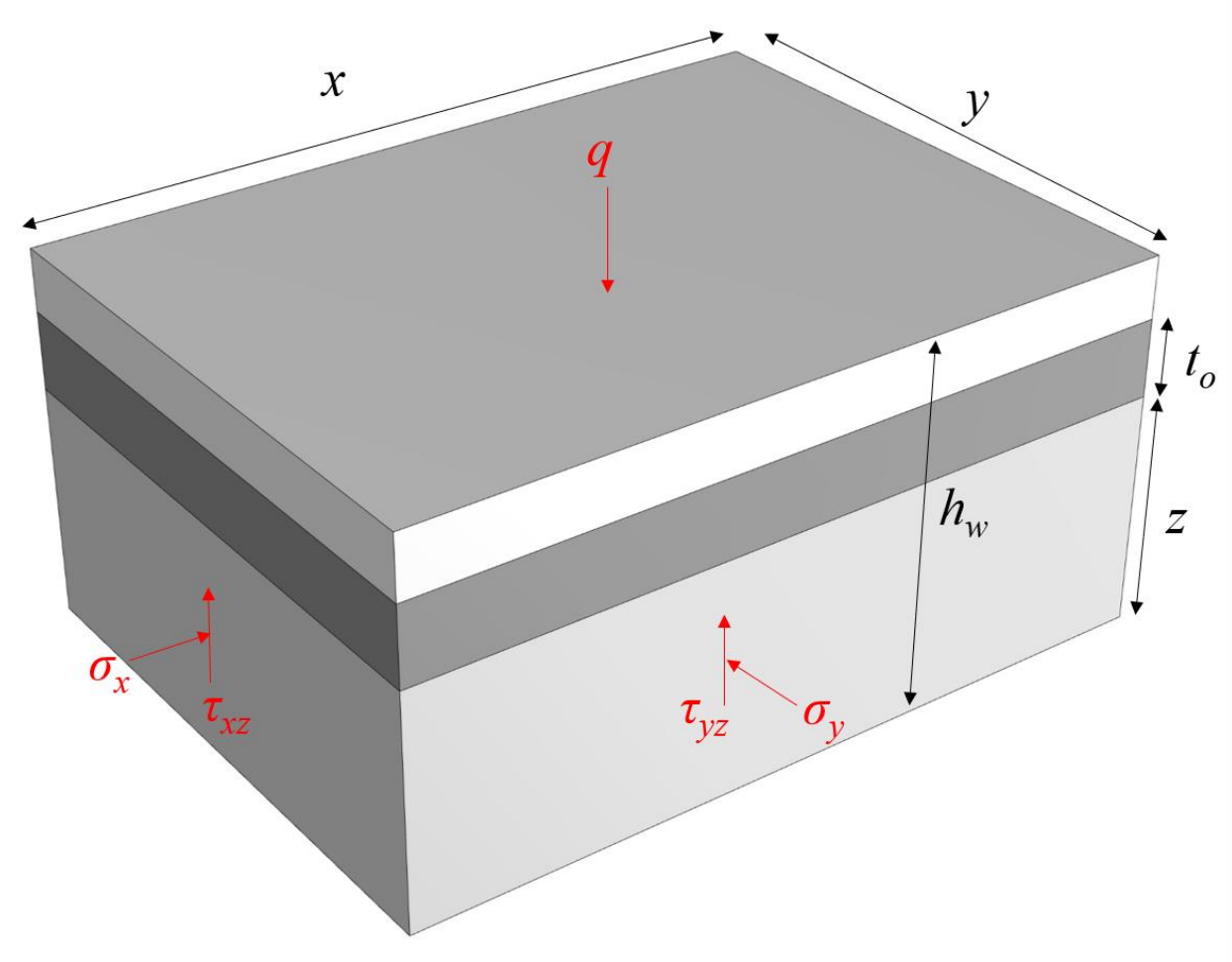

Figure 2.4: Schematic of a rectangular pillar geometry

For elastic plate analysis, two types of failure modes are considered: shear and elastic buckling. The shear failure analysis is similar to the one in rigid plate analysis, but the area on which the shear stress act is smaller if bending stresses are high. Similar to rigid plate analysis, a rectangular pillar geometry (see Figure 2.4) is defined first in CPillar. The crown pillar heights in the $\mathrm{x}$ and $\mathrm{y}$ directions are corrected when abutments are under tension. Thus,

$$
\begin{gathered}
z_{1}=\frac{\left(\sigma_{b x}-\sigma_{x}\right)}{2 \sigma_{t x}} \times z, \text { if } \sigma_{x}+\sigma_{t x}<0 \\
z_{2}=\frac{\left(\sigma_{b y}-\sigma_{y}\right)}{2 \sigma_{t y}} \times z, \text { if } \sigma_{y}+\sigma_{t y}<0
\end{gathered}
$$

where $\sigma_{b x}$ and $\sigma_{b y}$ are the tensile axial stresses due to bending, $\sigma_{x}$ and $\sigma_{y}$ are the axial stresses due to lateral pressure, $z_{1}$ and $z_{2}$ are the corrected pillar heights.

After correction, the shear area will be effectively reduced in the FoS calculation: 


$$
F_{0} S_{\text {shear }}=\frac{\text { Shear resistance }}{\text { Dead load }}=\frac{2\left(\frac{\tau_{x z} z_{1}}{x}+\frac{\tau_{y z} z_{2}}{y}\right)}{q}
$$

In the elastic buckling analysis, the horizontal confining stress is set equal to the stress along the longer dimension of the beam. Buckling or bending is assumed to occur in the longer dimension. If the lateral stresses are very low, the elastic buckling safety factor will be very high:

$$
F o S_{\text {buckling }}=\frac{\text { Euler buckling stress }}{\text { Horizontal confining stress }}=\frac{\left(\frac{\pi^{2} E_{r m} z^{2}}{3 L_{\text {span }}{ }^{2}}\right)}{\sigma_{c}}
$$

where $F o S_{\text {buckling }}$ is FoS for buckling failure, $E_{r m}$ is the rock modulus, $z$ is the pillar height, $L_{s p a n}$ is the pillar span, and $\sigma_{c}$ is the horizontal confining stress.

For the Voussoir analysis, three failure modes are considered: shear (vertical slippage at abutments), buckling due to gravity, and localized crushing failure. The FoS for shear failure is calculated as follows (Curran et al., 1996).

$$
\begin{aligned}
F O S_{\text {shear }} & =\frac{\text { Shear resistance }}{\text { Dead load }}=\frac{2 \tau_{\max } n b}{\gamma_{\text {eff }} a(b-k)} \\
k & =\frac{L_{\text {span }}}{2}\left[\sqrt{\left(\frac{a}{b}\right)^{2}+3}-\frac{a}{b}\right]
\end{aligned}
$$

where $F o S_{\text {shear }}$ is the FoS for shear failure, $\tau_{\max }$ is the maximum shear strength which is computed based on the maximum arch compressive strength from the Voussoir iteration procedure, $a$ is the breadth of the pillar, $b$ is the span of the pillar, $n$ is the thickness of the compressive arch, and $\gamma_{e f f}$ is the effective unit weight of the pillar.

Similar to elastic buckling analysis, the buckling failure due to gravity is highly pertinent to pillar geometry and rock mass modulus. However, the driving force for gravity buckling is the selfweight of the rock, whereas the driving force for elastic buckling is the externally applied lateral stress. The buckling parameter calculated in a Voussoir analysis represents the percentage of unstable arch configurations for a given geometry and rock mass modulus, as determined by the 
Voussoir analysis iteration procedure. A buckling parameter $=35 \%$ has been determined by Hutchinson et al. (1996) as a limit above which a roof should be considered unstable.

If induced lateral compressive stress exceeds the UCS of the rock, localized crushing failure is considered to have occurred, and gravity bucking may follow, even though the primary buckling analysis may indicate a stable arch. The factor of safety is calculated as follows:

$$
F O S_{\text {crushing }}=\frac{\sigma_{c i}}{\sigma_{c \max }}
$$

Where $\sigma_{c \max }$ is the maximum induced lateral compressive stress, and $\sigma_{c i}$ is the UCS of the intact rock.

\subsection{Numerical modelling methods}

Many numerical modelling codes were developed for civil and mining engineering applications in rock mechanics. Currently, commercial numerical software is available for both two-dimensional (2D) or three-dimensional (3D).

2D modelling is typically used for problems such as linear excavation of tunnels or stopes, based on the assumption that stresses and displacements which are perpendicular to the modelled plane are not affected by the excavations, and geometry and loading do not vary significantly in the longitudinal direction. When complicated geometry and geological structures are encountered, the implementation of 3D models is required for better accuracy. Several commonly used numerical modelling methods are introduced in the following paragraphs.

\section{Finite Element Method}

The finite element method (FEM) is one of the most common methods for civil and mining engineering problems. It is based on dividing a model domain into a finite number of elements. FEM is very popular due to its versatility and applicability to solve complicated engineering problems. The numerical model domain can be set as heterogeneous or anisotropic, and the nonlinear problems can also be addressed using this method. Meshing is then performed by discretizing the model domain into small finite elements. The reason for this discretization is that the solution of the original system is too complex to obtain. If the domain is divided into small size elements, the solution for each element can be approximated using simple polynomial 
functions. Eventually, the solution for all small elements is obtained by the solution of the whole structure or domain. Obviously, as the number of elements increases, the solution will be more accurate. However, the increase of number of elements will lead to longer computation time.

Currently, some robust commercial codes are built from the FEM theory, such as COSMOS, ABAQUS, etc. All loading, support installation, and construction sequencing simulations can be achieved in these FEM codes. A system can be composed of one or more material types by assigning different material properties or constitutive models in different groups.

\section{Finite Difference Method}

The implementation of finite difference method (FDM) in numerical modelling began in the early 1950s, and the emergence of computers stimulated its development. Computers provided a useful framework for dealing with complex scientific and technical problems. The FDM is a numerical modelling technique that assumes the rock mass to be a continuum, then addresses the problem as a differential equation. The domain is partitioned in space and in time, and the disturbance at nodes within the rock mass affects only its adjacent points. Node displacements will propagate through the domain over certain time steps until reaching convergence. The error between the numerical solution and the exact solution is determined by the error that is committed by going from one differential operator to another. This error is called the discretization error, which reflects the fact that a finite part of a Taylor series is used in the approximation.

FLAC2D/3D is one of the well-known commercial code using this numerical technique and is appropriate to model large material deformations. Because time-dependent analysis is allowed by the FDM codes, a dynamic module is also incorporated for dynamic disturbance or seismic simulation.

\section{Discrete Element Method}

The discrete element method (DEM), called initially the distinct element method, is used to simulate the behavior of a particulate interaction of independent particles (Cundall \& Strack, 1979). In the DEM, each particle is represented numerically and is identified with its specific properties (e.g., shape, size, material properties, initial velocity). Thus, this method will regard the rock mass domain as an assembly of blocks, which is well suited for modelling structurally controlled types

of rock failure that occur in blocky rock mass. In the simulation process, subdivided blocks are 
subjected to a small motion (based on Newton's laws) over iterations. This small motion will cause some blocks to contact each other or boundaries, producing discrete reaction forces on each block. The magnitude of the contacting forces is determined by a contact model, and the total force on each particle is then computed. The particle motion, such as acceleration, velocity, or displacement, is determined by Newton's laws of motion over the small-time interval. Steady-state solutions will be derived through dynamic relaxation (local or global damping, viscous, or kinetic).

Nowadays, many more sophisticated models for both the solid material and contacts have been formulated in the context of DEM, and this technique is widely accepted as an effective method of addressing engineering problems in granular and discontinuous materials, especially in granular flows, powder mechanics, and rock mechanics. However, the estimation of proper input parameters remains challenging for users, and engineering expertise is highly required for solving complex problems. The use of DEM in solving large scale problems such as a crown pillar would require significant computational power due to the large number of degrees of freedom in the system.

\section{Boundary Element Method}

The boundary element method (BEM) is a numerical modelling technique to solve linear partial differential equations if these can be formulated as integral boundary equations. In this technique, only the excavation boundary needs to be defined, while external boundaries are not defined, and rock mass is regarded as an infinite continuum. The BEM is based upon an integral statement of the governing equations of elasticity, which contains unknowns only over the boundaries. This integral boundary equation may then be solved by using concepts from the FEM; the boundary may be discretized into elements and solved by the interpolation approximation.

The BEM system is generally much smaller than that generated by FEM. By avoiding interior discretization, fewer elements will be generated and computed during the numerical process. Thus, the boundary element scheme has significant advantages over other numerical techniques, including finite elements, for infinite domains, and for cases in which only boundary information is required (Brebbia \& Dominguez, 1994). The method is however limited in its applications to rock mechanics problems, especially when the model domain involves more than one rock material or when the analysis is to be carried out beyond the linear elastic range. 


\section{Numerical modelling applications for crown pillar design}

Many efforts have been deployed so far to achieve crown pillar stability assessment and dimension design using numerical modelling techniques. Li et al. (2013) conducted a numerical modelling study of the crown pillar in a subsea gold mine to determine the minimum crown pillar thickness using FLAC3D code, which is based on FDM. The distribution of principal stresses, displacements, and plastic zone development associated with the excavation steps are analyzed. The required minimum crown pillar thickness is found to be at least $50 \mathrm{~m}$ in the study area. Georgieva et al. (2016) performed a 3D numerical study for assessing the stability of the crown pillar in Chelopech underground mine. They modelled the crown pillar using Map3D software based on BEM. The stress-strain state of the crown pillar is analyzed in each mining step to detect potential overstressed failure zones, and the obtained modelling results confirmed the field observations. Kuma et al. (2016) carried out a 2D numerical analysis of sill and crown pillar stability using FEM. Parametric studies were conducted by varying uniaxial compressive strength, elasticity modulus, and pillar thickness to analyze stresses, displacements, and yield zones development around stopes. It eventually suggested the optimum thickness of the crown and sill pillar in different mining conditions. Yardimci (2016) ascertained the stable crown pillar thickness for the transition region from the surface to underground operations in a case study using the 2D finite element method. Rocscience RS2 software was used in the study to calculate the crown pillar factor of safety in an elastic model, and the results showed that the crown pillar is safe enough regarding global stability. Kalenchuk et al. (2019) evaluated the risk of crown pillar extraction in an underground - open pit

mine transition area using FLAC3D. Open-pit and long-hole mining methods were simulated and compared in the study. The predicted ground reactions, both underground and in the open pit, were measured. The results showed that the long-hole mining option was more favorable as it reduced exposure to higher ground risk in the pit and allowed for higher recovery of reserves from an economic view.

\subsection{Summary}

In summary, the scaled span method, one of the empirical analysis methods suggested by Carter (2014), has been used to determine the stability of surface crown pillars in both active and abandoned mines. The accuracy of empirical methods relies on the quality of the global database. Thus, empirical methods should be applied with the judgment of on-site experts, as site-specific 
conditions such as geological structures, surface surcharging and horizontal stresses may dictate the crown pillar stability.

Many analytical methods were proposed to assess crown pillar stability by simplifying the crown pillar as a beam either cantilevered or supported at both ends and predefining a specific failure mode. For example, in the CPillar program of RocScience, the factor of safety in different possible failure modes, including shear failure, buckling failure, and localized crush failure, can be estimated using either deterministic or probabilistic approaches. However, analytical methods ideally simplify a complex crown pillar into several predefined failure modes, and it is difficult to incorporate other influential factors such as nearby faults. In conclusion, for a more rigorous failure mode analysis of crown pillars, the numerical modelling approach is a better choice, as the aforementioned influential factors can be considered and modelled using robust numerical tools. 


\section{Chapter 3}

\section{Case study mine}

A case study is carried out to gain a better understanding of the controlling factors on crown pillar stability using numerical modelling techniques. Data is provided by Kinross Gold Corporation, Canada. This study is part of a feasibility study of a shallow, narrow vein deposit, with the primary purpose of selecting adequate surface crown pillar thickness through design with numerical modelling. For confidentiality reasons, the location of the mine site will not be disclosed in the thesis. Other relevant information about this gold mining operation is discussed in the following sections.

\subsection{General site geology and mineralization}

The geological properties of the mine site are shown as Fig. 3.1. The site is underlain by a bimodal suite of andesite fragmentals, feldspar-hornblende porphyry, andesite (trachytic andesite) flows that include minor basalt that dips shallowly eastward. Gold and silver mineralization of the vein is hosted by colloform to crustiform-banded quartz-adularia and polyphase breccias.

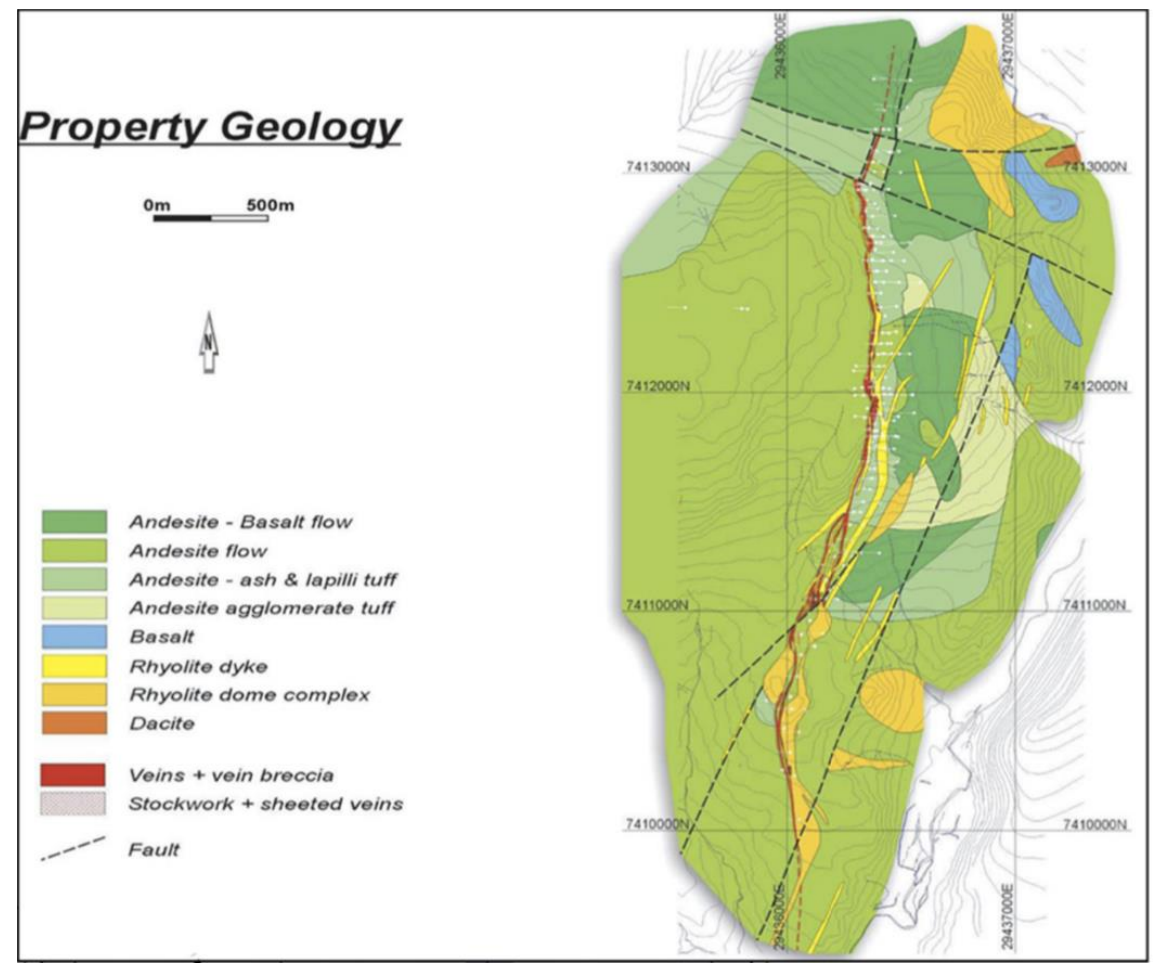

Figure 3.1: Geological property mapping of the case study mine 


\subsection{Vein geometry}

Specific to the vein geometry, the strike length is approximately $550 \mathrm{~m}$ in NW-SE direction, and vertical extent is about $230 \mathrm{~m}$ as shown in Fig. 3.2. The vein thickness ranges from $0.1 \mathrm{~m}$ to 4.4 $\mathrm{m}$, with an average thickness of around $1 \mathrm{~m}$. The vein is dipping towards $\mathrm{SW}$ direction with a dip angle of 75 degrees. The area in the red dash box is the projected mining area.

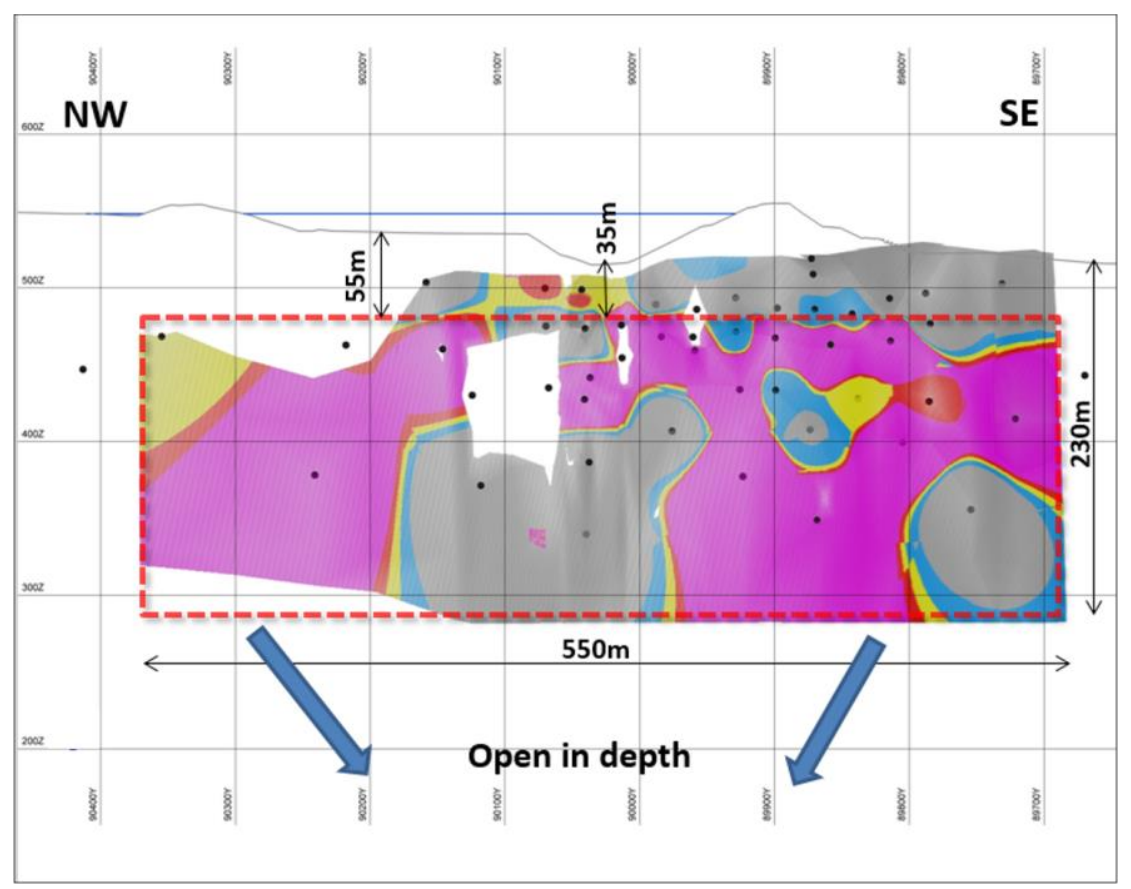

Figure 3.2: Longitudinal section of the studied vein

\subsection{Groundwater}

The mine site is located just north of the Arctic Circle. The temperature records indicate that the ground temperature is below $0^{\circ} \mathrm{C}$ all year round. Thus, frozen ground conditions are assumed in the numerical study; rock permeability and hydro-mechanical coupling are not accounted for in the numerical analysis.

\subsection{Major geological structures}

In the mining area, geological structures have been delineated in Leapfrog model - a 3D geological modelling tool - as shown in Fig. 3.3. There are two major faults near the vein - one approximately parallel to the vein while the other crosses through the vein at mid-strike. No detailed measurements and descriptions of fault formation are available for this study. Besides, the case 
study vein is approximately $300 \mathrm{~m}$ west of another unmined zone called SEN deposits (See Figure 3.3), which will be included in the numerical model.

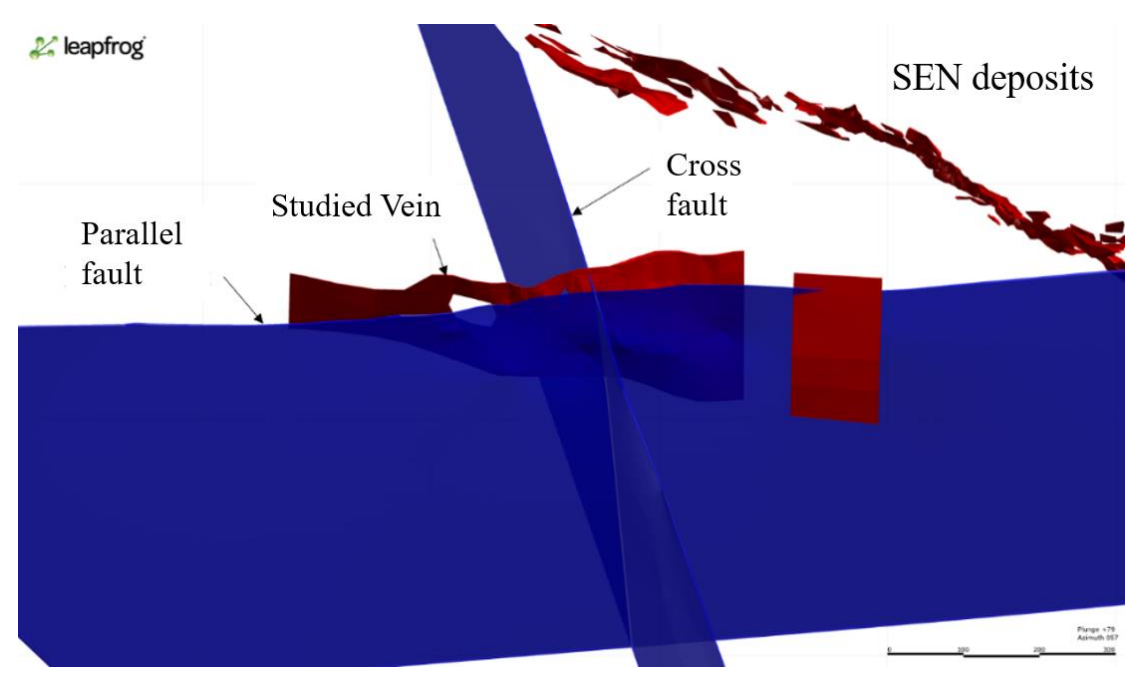

Figure 3.3: Leapfrog model of the case study mine

\subsection{In-situ stresses}

For the in-situ stress, no direct measurements are available for this study. The in-situ stresses are estimated based on the world stress map data available for this area, and previous feasibility study results. The estimated horizontal-to-vertical stress ratio or k-ratio is around 2 . The vertical stress gradient is $0.027 \mathrm{MPa} / \mathrm{m}$. This high horizontal stress regime is considered reasonable for the shallow mining depth according to the general convention that the value of k-ratio tends to be high at shallow depths at civil and mining sites around the world (Hoek et al. 1995). Moreover, the studied area experienced recent glaciation events, resulting in typical high horizontal stresses near the surface.

\subsection{Surface surcharge}

Surface surcharge refers to the vertical pressure that acts over the ground surface due to buildings, structures, embankments, etc. In the case study area, a tailings storage facility (TSF) was built on the top of the unmined vein, as illustrated in Figure 3.4. The red area represents the studied vein, directly situated under tailings and a tailings dam. Figure 3.5 presents a field photo of the tailings dam. Also, as shown in Fig.3.6 and 3.7, the dimensions of the projected tailings site are approximately $600 \mathrm{~m} \times 1000 \mathrm{~m} \times 60 \mathrm{~m}$. The unit weight of the tailings is $11.5 \mathrm{kN} / \mathrm{m}^{3}$ and that of 
the dam structure is $20 \mathrm{kN} / \mathrm{m}^{3}$. Based on this information, the surcharge of the equivalent stresses of the tailings and dam will be considered in the numerical modelling study.

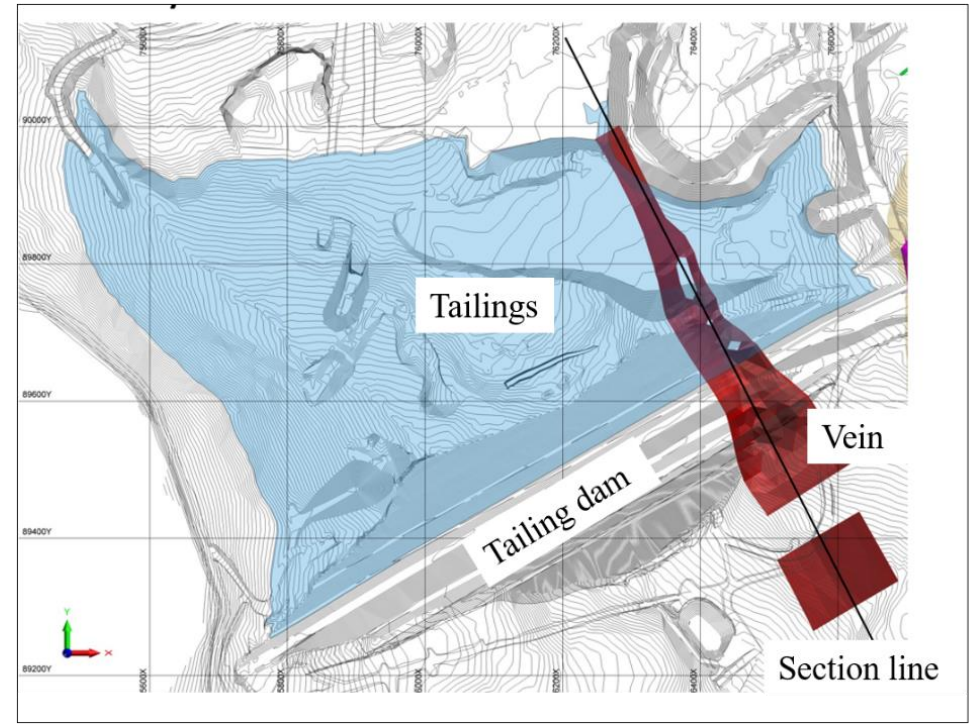

Figure 3.4: Plan view of the mine site

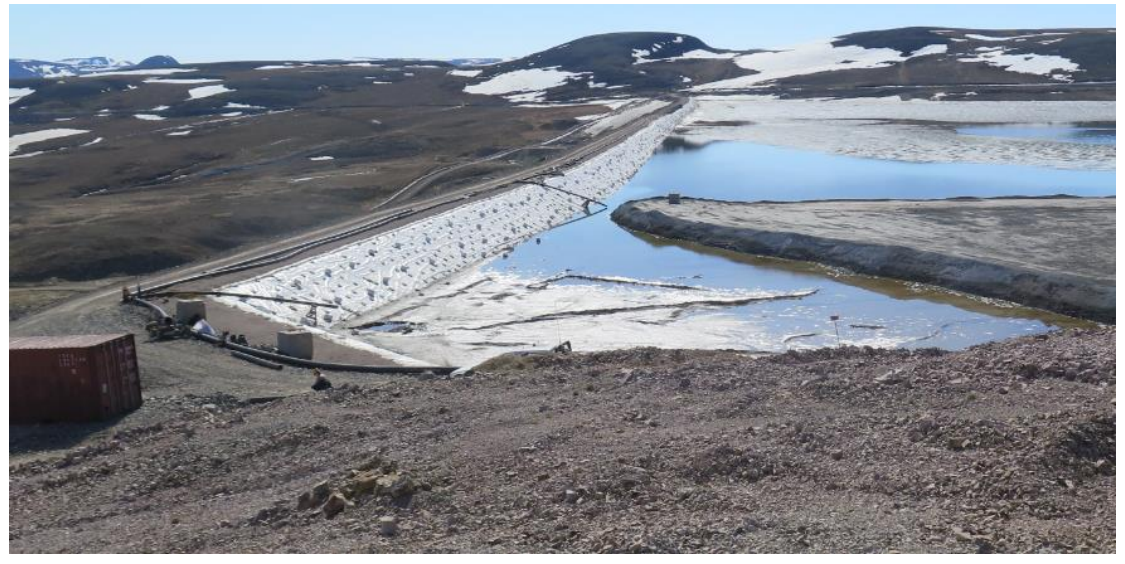

Figure 3.5: NE end view of the tailings dam (June 2018) 


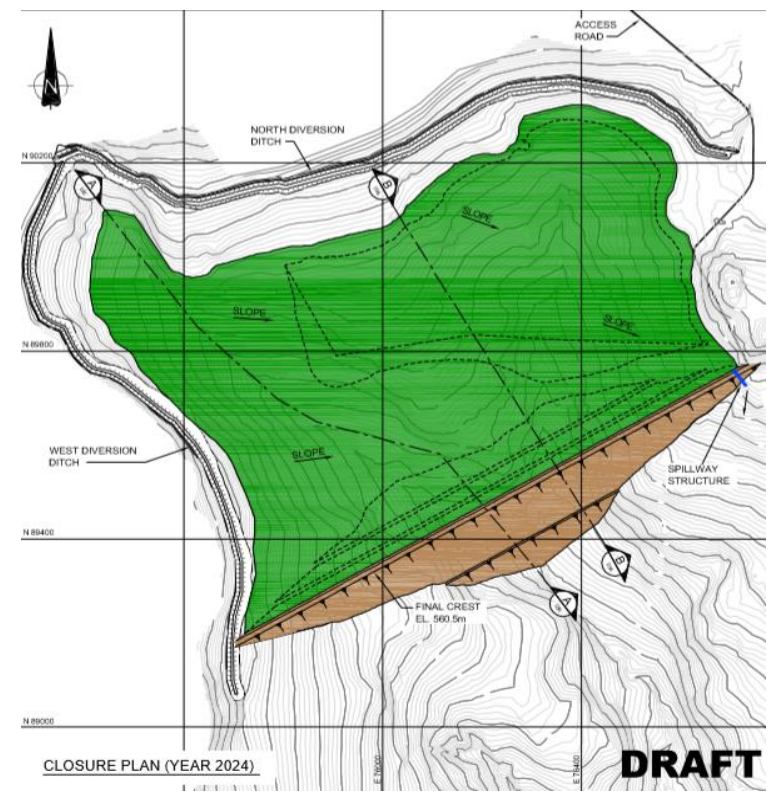

Figure 3.6: Plan view of the expected TSF in the year 2024

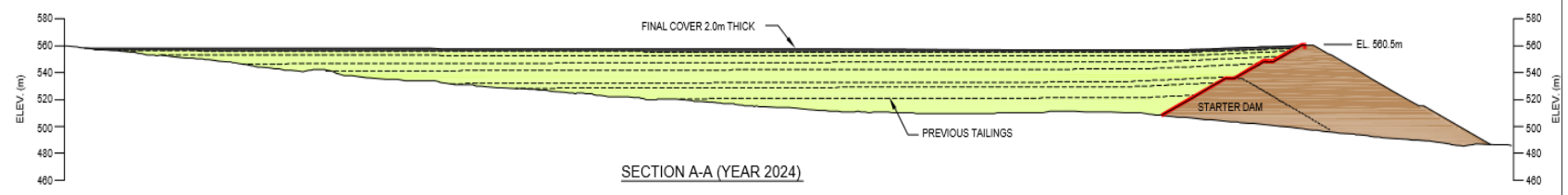

Figure 3.7: Sectional view of the expected TSF in the year 2024

\subsection{Mining method}

The orebody is planned to be mined bottom-up by long hole longitudinal retreat sublevel open stoping, also known as the Avoca method; see Fig. 3.8. Sills are driven on $15 \mathrm{~m}$ (sublevel) intervals, approximately $4.5 \mathrm{~m}$ high. Long hole stopes (panels) are drilled using parallel or fanned drill holes between sublevels (approximately $11 \mathrm{~m}$ ). A slot is drilled and blasted first to create a void to shoot to if one does not exist and multiple rings are blasted into the void until planned hydraulic radius is reached. Stopes are later filled with waste rock as production advances, typically leaving only $20 \mathrm{~m}$ of voids to reduce dilution. The production cycle is repeated until the level is completed. Unconsolidated backfill is an integral part of the production cycle of the mining method, and no cemented backfill is used on-site due to economic considerations. 


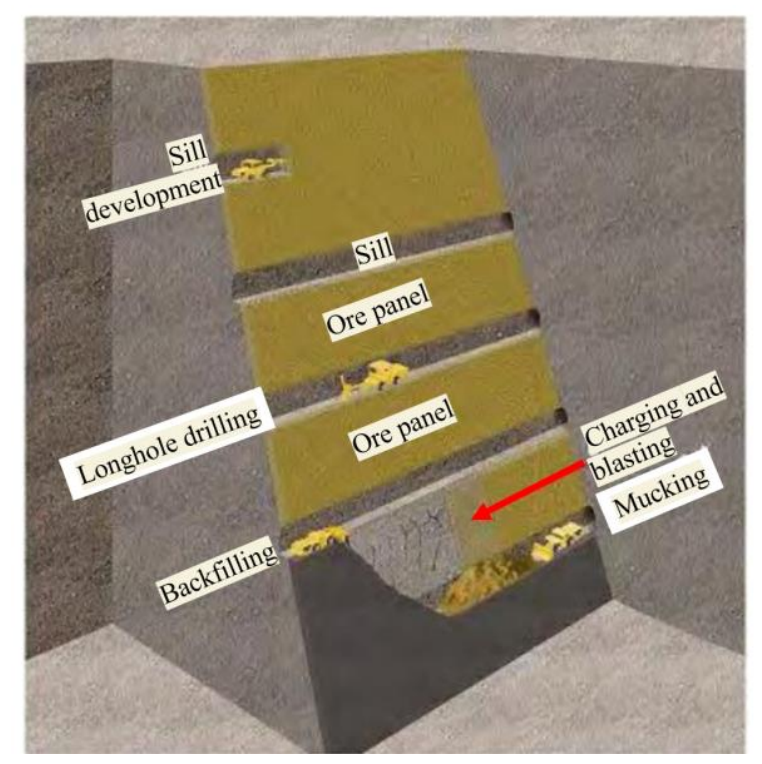

Figure 3.8: Schematic showing Avoca mining method

\subsection{Summary}

This study is part of a feasibility study of the surface crown pillar design. The studied narrow vein is planned to be mined bottom-up with $15 \mathrm{~m}$ stoping intervals using long hole mining method with unconsolidated backfill. The deposit is located directly underneath a tailings storage facility in operation. Two major faults exist near the vein body. Hence, when assessing the crown pillar stability, the following factors should be incorporated.

- Mechanical properties of the rock mass and backfill;

- In-situ stress regime;

- Influence of nearby faults;

- Ground topography;

- Span and depth of mine openings;

- Mining method and sequence.

Besides, a tailings dam is situated above the vein orebody, and its foundation stability is a critical consideration when crown pillar thickness is selected. As underground mining advances towards the ground surface, the mining-induced subsidence and potential damage to the tailings dam foundation must also be examined. Portion of the orebody needs to be left behind not only to prevent stopes from caving in but also to maintain the stability of the overlying tailings dam. 


\section{Chapter 4}

\section{Stability assessment of the surface crown pillar}

\subsection{Empirical method}

The empirical scaled span method developed by Carter (1992) is widely accepted and has been implemented at mine sites worldwide to provide practical guidelines for the crown pillar design. It will first be employed for the initial assessment of crown pillar stability, and the results will be compared with numerical modelling results afterward. The "scaled span," a parameter that describes crown pillar conditions, is calculated by the following equation:

$$
C_{S}=S\left(\frac{\gamma}{T\left(1+S_{R}\right)(1-0.4 \cos \theta)}\right)^{0.5}
$$

Where:

$C_{S}$ is the crown pillar scaled span;

$S$ is the crown pillar span (m);

$\gamma$ is the specific gravity of the rock cover;

$T$ is the thickness of overlying rock cover (m);

$S_{R}$ is the span ratio (crown pillar span /crown pillar strike length);

$\theta$ is the orebody dip angle.

Carter (2014) reported a summary of crown pillar design scenarios in Table 2.1. The table divides the risk of crown pillar failure into seven classes with a minimum FoS and an estimated serviceable life span in each class. Henning (2007) summarized from local experiences that some crown pillars have failed at FoS values around 2 (see Figure 2.2). Hence, if the crown pillar falls within Class G (FoS >>2) in Table 2.1, it is considered stable, without monitoring requirements and safety concerns.

For the studied surface crown pillar, the rock quality index $Q$ is 1.5 . The maximum scaled span $C_{S}$ $\max$ can be calculated for the Class G.

$$
C_{S \max }=0.69 \times Q^{0.44}=0.69 \times 1.5^{0.44}=0.82
$$


The smaller surface crown pillar thickness $T$, the higher the scaled span $C_{S}$. The following equation can be derived from Equation 4.1 to calculate minimum allowable crown pillar thickness in Class $\mathrm{G}:$

$$
T_{\min }=\frac{\gamma S^{2}}{C_{S}^{2}\left(1+S_{R}\right)(1-0.4 \cos \theta)}=\frac{2.42 \times 4^{2}}{0.82^{2}\left(1+\frac{4}{550}\right)\left(1-0.4 \cos 75^{\circ}\right)} \approx 63.8 m
$$

The result shows if the crown pillar thickness is above $63.8 \mathrm{~m}$, it falls into the class $\mathrm{G}$ with the factor of safety $>>2$, and no surveillance is required.

Then, the maximum scaled span is calculated for crown pillars in class $\mathrm{F}$, of which the minimum FoS is 2:

$$
C_{s \max }=1.12 \times Q^{0.44}=0.69 \times 1.5^{0.44}=1.34
$$

Similarly, the minimum allowable surface crown pillar thickness in class $\mathrm{F}$ is derived to be 23.9 $\mathrm{m}$ from Equation 4.5.

$$
T_{\min }=\frac{\gamma S^{2}}{C_{S}^{2}\left(1+S_{R}\right)(1-0.4 \cos \theta)}=\frac{2.42 \times 4^{2}}{1.34^{2}\left(1+\frac{4}{550}\right)\left(1-0.4 \cos 75^{\circ}\right)} \approx 23.9 m
$$

According to the empirical guidelines of Table 2.1, if the crown pillar thickness exceeds $63.8 \mathrm{~m}$, it will not require surveillance and there will be no concern about mine closure. If the crown pillar thickness is less than $63.8 \mathrm{~m}$, incidental superficial monitoring is required, and the estimated serviceable life is more than 50 years. However, if the thickness of the surface crown pillar is below $23.9 \mathrm{~m}$, public access is discouraged; continuous monitoring will be required on-site, and the estimated serviceable life is less than 20 years.

\subsection{Numerical method}

\subsubsection{Numerical modelling tool}

The FDM code FLAC3D 7.0, developed by the Itasca Ltd, will be used to conduct numerical modelling study on surface crown pillar stability. FLAC3D utilizes an explicit FDM formulation that can analyze non-linear material behavior and capture failure/yielding zone development in a model consisting of several operation stages. In literature, a few attempts have been reported to 
evaluate the crown pillar stability using FLAC3D. Li et al. (2013) conducted a numerical modelling study of the crown pillar in a subsea gold mine to determine the minimum crown pillar thickness using FLAC3D. Kalenchuk et al. (2019) evaluated the risk of crown pillar extraction in an underground - open pit mine transition area using FLAC3D 5.0. In this study, a large-scale three-dimensional model that incorporates the vein, nearby major faults, and the surface surcharge will be examined in robust FLAC3D 7.0 code to provide recommendations for crown pillar dimension design.

\subsubsection{Model geometry}

The modelling software Rhino 6 developed by Robert McNeel Associates is utilized to build the numerical model, as shown in Figure 4.1. The model dimensions are $1800 \mathrm{~m} \times 1200 \mathrm{~m} \times 600 \mathrm{~m}$. It comprises the case study vein, nearby unmined SEN deposits (yellow areas), and two major faults. The undulating surface topography is simulated according to the actual ground surface geometry. A unified $4 \mathrm{~m}$ span is employed for the studied vein as the possible drift dimension is 4 $\mathrm{m} \times 4 \mathrm{~m}$.

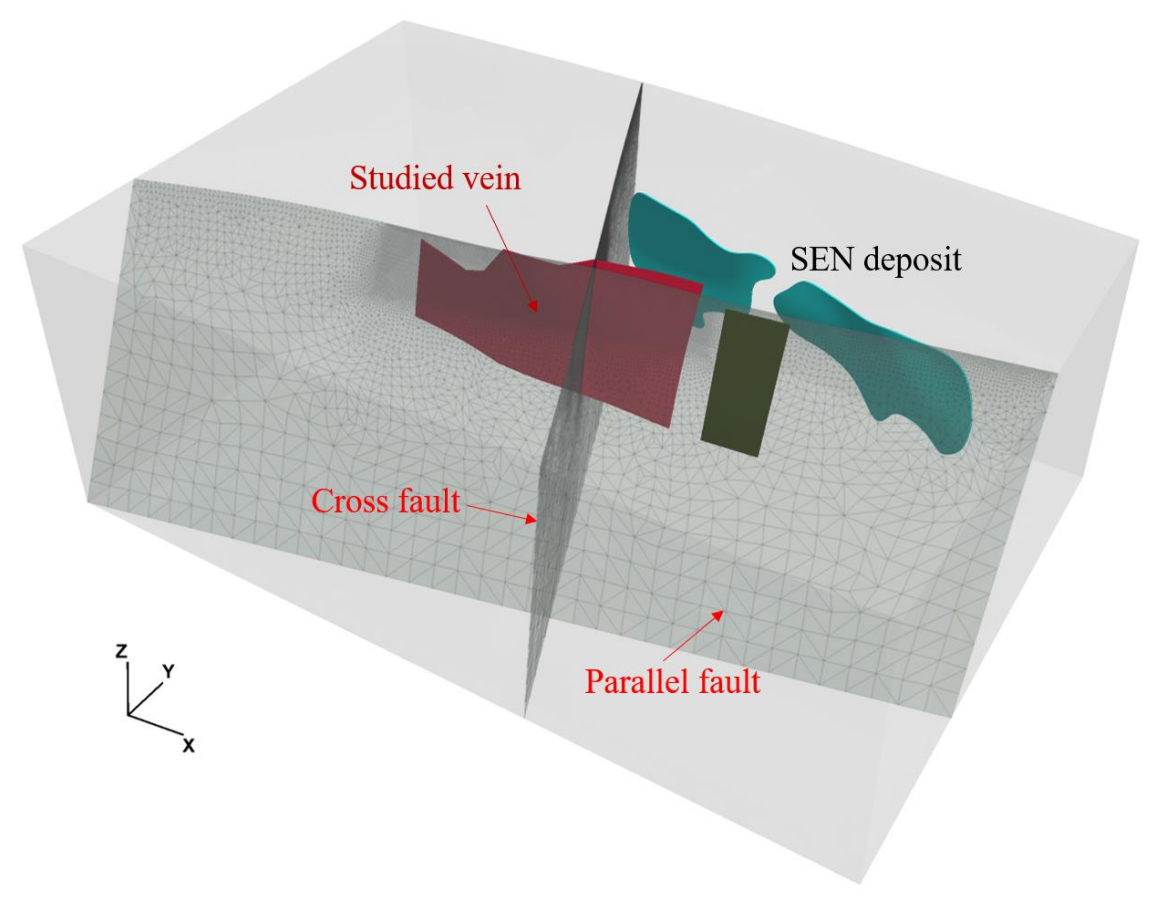

Figure 4.1: FLAC3D model setup 


\subsubsection{Boundary conditions}

For boundary conditions, roller boundaries are applied to the bottom and four vertical sides of the model. The model outer boundaries are constrained to a minimum to avoid undesired development of local stress concentrations near the boundaries. Gravity is applied as a body force, and in-situ stresses are initialized by applying horizontal-to-vertical stress ratios in the domain.

\subsubsection{Materials parameters}

Rock mass parameters of different geological units are estimated using empirical relationships with rock classification systems. Rock mass quality Q' estimated from drill hole logs is used to calculate rock mass parameters based on the following equations (Hoek \& Diederichs, 2006):

$$
\begin{gathered}
G S I=9 \ln Q^{\prime}+44 \\
s=\exp \left(\frac{G S I-100}{9-3 D}\right) \\
m_{b}=m_{i} \exp \left(\frac{G S I-100}{28-14 D}\right) \\
\sigma_{1}=\sigma_{3}+\sigma_{c i}\left(m_{b} \frac{\sigma_{3}}{\sigma_{c i}}+s\right)^{0.5} \\
E_{r m}=100000\left(\frac{1-D / 2}{1+e^{\frac{75+25 D-G S I}{11}}}\right)
\end{gathered}
$$

Where:

GSI is the Geological Strength Index.

$Q$ is the rock mass quality index from the Norwegian Geotechnical Institute (NGI).

$D$ is the disturbance factor.

$s, m_{i}$, and $m_{b}$ are rock mass material constants.

$E_{r m}$ is the rock mass modulus of elasticity.

The estimated input parameters for different materials in the FLAC3D model are shown in Table 4.1. The elasto-plastic Hoek-Brown rock mass strength criterion is selected for modelling the case 
study mine, and the elastic model is used for modelling the backfill material. The parameters used are justifiable according to the previous feasibility report of the mine site.

\section{Table 4.1: Rock mass strength and stiffness parameters used for simulating bedrock and ore in the numerical model.}

\begin{tabular}{ccccccccccc}
\hline & & \multicolumn{3}{c}{ Rock Mass Parameter } & \multicolumn{5}{c}{ Rock Mass Strength Parameters } \\
\cline { 3 - 8 } $\begin{array}{c}\text { Rock } \\
\text { Type }\end{array}$ & Criterion & $\begin{array}{c}\mathrm{E}_{\mathrm{rm}} \\
(\mathrm{GPa})\end{array}$ & $\begin{array}{c}\text { Poisson's } \\
\text { Ratio }\end{array}$ & $\begin{array}{c}\text { Density } \\
\left(\mathrm{g} / \mathrm{cm}^{3}\right)\end{array}$ & $\mathrm{m}_{\mathrm{i}}$ & $\mathrm{m}_{\mathrm{b}}$ & $\mathrm{s}$ & UCS (MPa) & $\begin{array}{c}\text { Tensile } \\
\text { Strength } \\
(\mathrm{MPa})\end{array}$ \\
\hline $\begin{array}{l}\text { Host } \\
\text { rock }\end{array}$ & $\begin{array}{c}\text { Hoek- } \\
\text { Brown }\end{array}$ & 18 & 0.25 & 2.42 & 19 & 4.2 & 0.009 & 50 & 0.23 \\
Ore & $\begin{array}{c}\text { Hoek- } \\
\text { Brown }\end{array}$ & 8 & 0.25 & 2.48 & 20 & 3.1 & 0.003 & 90 & 0.22 \\
Backfill & Elastic & 0.2 & 0.25 & 1.8 & & & & & \\
\hline
\end{tabular}

The Mohr-Coulomb criterion is used for the stress-strain relations of the faults. Due to the absence of fault property data on site, two sets of possible parametric fault parameters will be applied in the parametric study to examine the influence of fault properties on the crown pillar stability. As listed in Table 4.2, the fault parameters for parametric models 1 and 3 are obtained from relevant fault-slip research by Sainoki \& Mitri (2014), based on the reasonable assumption of hard rock formation without infilling. The friction and residual friction angles of the other parametric models 2 and 4 are lowered from $30^{\circ}$ and $25^{\circ}$ to $15^{\circ}$ and $10^{\circ}$, respectively, for comparison.

\section{Table 4.2: Fault parameters in the numerical model.}

\begin{tabular}{ccccccccc}
\hline $\begin{array}{c}\text { Parametric } \\
\text { model }\end{array}$ & Criterion & $\begin{array}{c}\text { Stiffness- } \\
\text { normal } \\
(\mathrm{MPa} / \mathrm{m})\end{array}$ & $\begin{array}{c}\text { Stiffness- } \\
\text { shear } \\
(\mathrm{MPa} / \mathrm{m})\end{array}$ & $\begin{array}{c}\text { Friction } \\
\text { angle }\left(^{\circ}\right)\end{array}$ & $\begin{array}{c}\text { Residual } \\
\text { friction } \\
\text { angle }\left(^{\circ}\right)\end{array}$ & $\begin{array}{c}\text { Cohesion } \\
(\mathrm{MPa})\end{array}$ & $\begin{array}{c}\text { Dilation } \\
\text { angle }\left(^{\circ}\right)\end{array}$ & $\begin{array}{c}\text { Tensile } \\
\text { strength }\end{array}$ \\
\hline 1 and 3 & $\begin{array}{c}\text { Mohr- } \\
\text { Coulomb }\end{array}$ & 3100 & 3100 & 30 & 25 & 0 & 0 & 0 \\
2 and 4 & $\begin{array}{c}\text { Mohr- } \\
\text { Coulomb }\end{array}$ & 3100 & 3100 & 15 & 10 & 0 & 0 & 0 \\
\hline
\end{tabular}




\subsubsection{In-situ stress}

\subsubsection{Horizontal-to-vertical stress ratios}

For in-situ stresses, there are no direct measurements available on site. The world stress map data and previous feasibility report indicate that the horizontal-to-vertical stress ratio of the studied area is around two. Therefore, two sets of horizontal-to-vertical stress ratios are assumed and applied in the study: $K_{x}=1.5 \& \mathrm{~K}_{\mathrm{y}}=1.8 ; K_{x}=1.8 \& K_{y}=2.2$. The $K_{x}$ and $K_{y}$ are horizontal-to-vertical stress ratios in $\mathrm{x}$ - and $\mathrm{y}$-directions, respectively. The horizontal stress directions with respect to the vein body in FLAC3D model are illustrated in Fig. 4.2. The vertical stress gradient is $0.027 \mathrm{MPa} / \mathrm{m}$. The relations between horizontal stresses and vertical stress in numerical modelling are defined as follows:

$$
\begin{gathered}
\sigma_{z z}^{0}=\rho g H \\
\sigma_{x x}^{0}=K_{x} \sigma_{z z}^{0} \\
\sigma_{y y}^{0}=K_{y} \sigma_{z z}^{0}
\end{gathered}
$$

where $H$ is the depth below ground surface, $\rho$ is the rock density, $g$ is the gravitational constant, and $\sigma_{x x}^{0}, \sigma_{y y}^{0}$ and $\sigma_{z z}^{0}$ are in-situ stresses in $\mathrm{x}-, \mathrm{y}-$, and $\mathrm{z}$-directions, respectively.

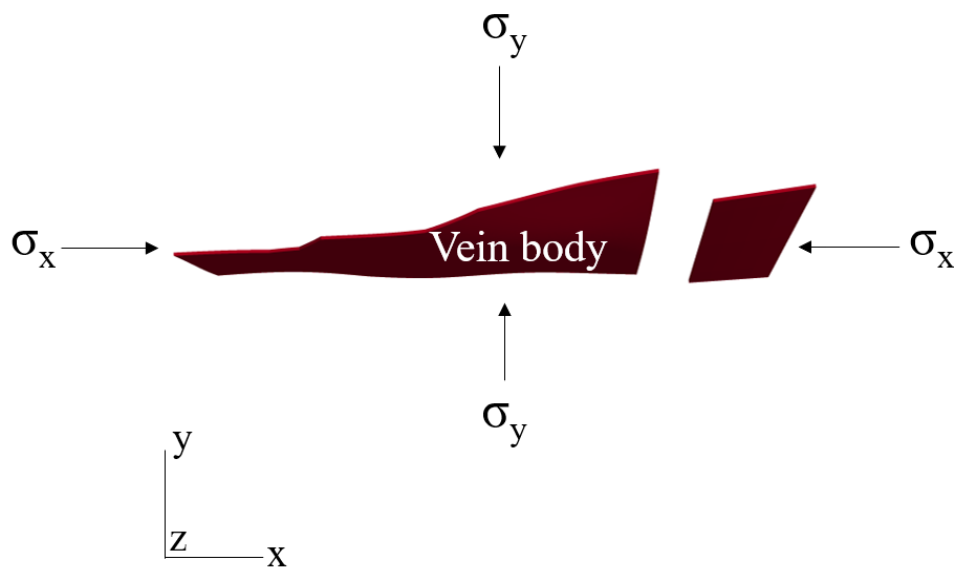

Figure 4.2: Model plan view showing stress orientations with respect to the vein 


\subsubsection{Stress initializing scheme for undulating surface}

Numerical modeling of in situ stresses under undulating/slanting ground surface is first considered. Many researchers have shown that mining-induced subsidence, tilt and horizontal displacement are affected by surface topography (Franks \& Geddes, 1986; Peng et al., 1987; Holla, 1997; Cai et al., 2014). They found that surface movement for a steep terrain is considerably different from that for a flat/relatively gentle slope surface. Horizontal displacements on the slope are increased in the region of the slope crest (Franks \& Geddes, 1986). As the surface inclination increases, the maximum vertical subsidence value increases, and the subsidence pattern becomes asymmetrical (Cai et al., 2014). Thus, the model surface is crafted according to the actual ground topography to improve modelling accuracy.

Mining under sloping ground surface, however, involves varying depths of overburden. Because in-situ stresses are defined as functions of only the depth below surface, $\mathrm{H}$, in numerical codes, this would cause unrealistic displacement and yielding failure on slopes of the surface (Itasca, 2017). In this study, a scheme to initialize in-situ stress for numerical model under undulating surface is put forward here. The procedures are as follows.

1. Add an artificial overburden layer to flatten the ground surface, as illustrated in Fig. 4.3a.

2. In-situ stresses can now be initialized uniformly based on horizontal-to-vertical stress ratios being functions of depth, $\mathrm{H}$. The vertical stress is calculated based on rock density and depth below the flat topography surface.

3. Once stress initialization is complete, the artificial overburden is removed to reveal the actual topography, as shown in Fig. 4.3b. In effect, this represents the simulation of surface erosion that led to the formation of the undulating surface.

4. Set model displacement to zero and keep the resulting initial stresses due to the erosion simulation.

By implementing the proposed scheme, the in-situ stresses are initialized, and consistent stress fields are shown in Figure 4.4. As can be seen, no tension areas are found on model surface, proving the proposed stress initialization scheme is effective. It is note worthy that the vertical 
initial vertical stress is nearly zero at the ground surface as shown in Fig. 4.4c (approximately $0.002 \mathrm{MPa})$.

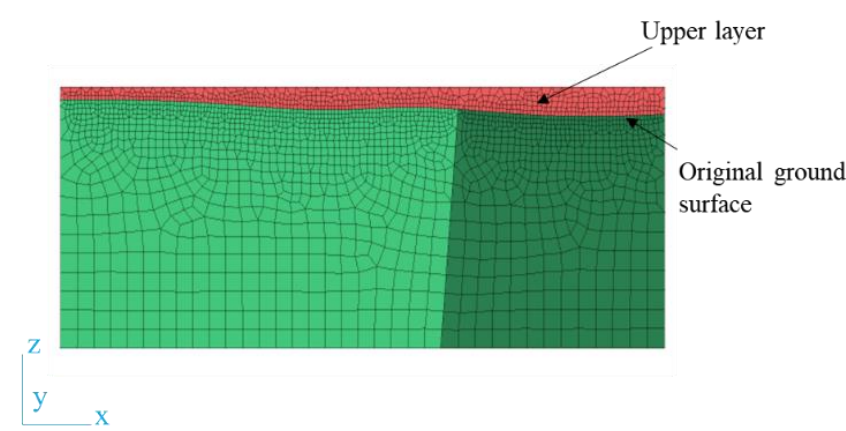

(a)

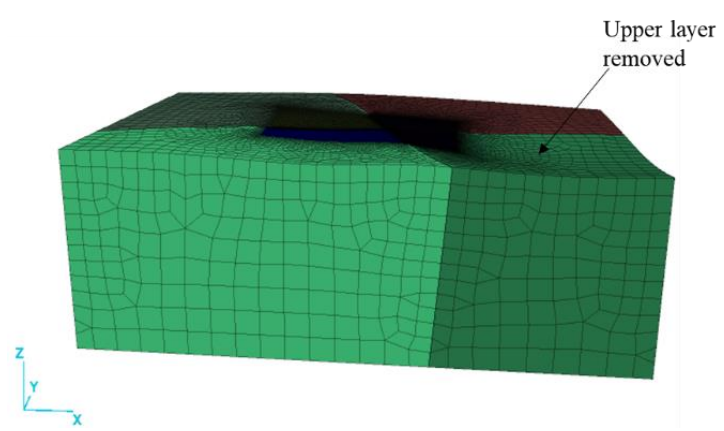

(b)

Figure 4.3: In-situ stress initialization scheme

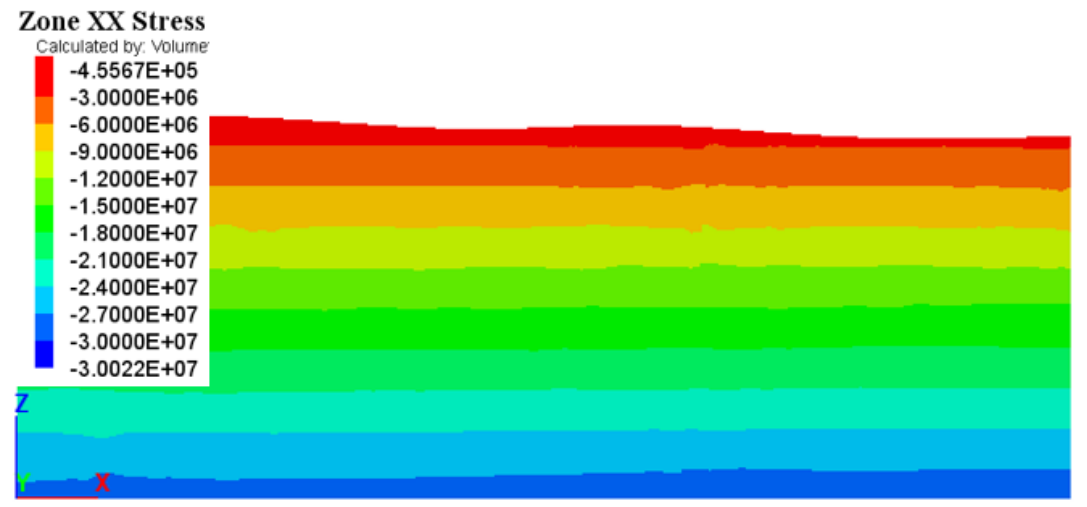

(a) Horizontal stress in $\mathrm{x}$-direction

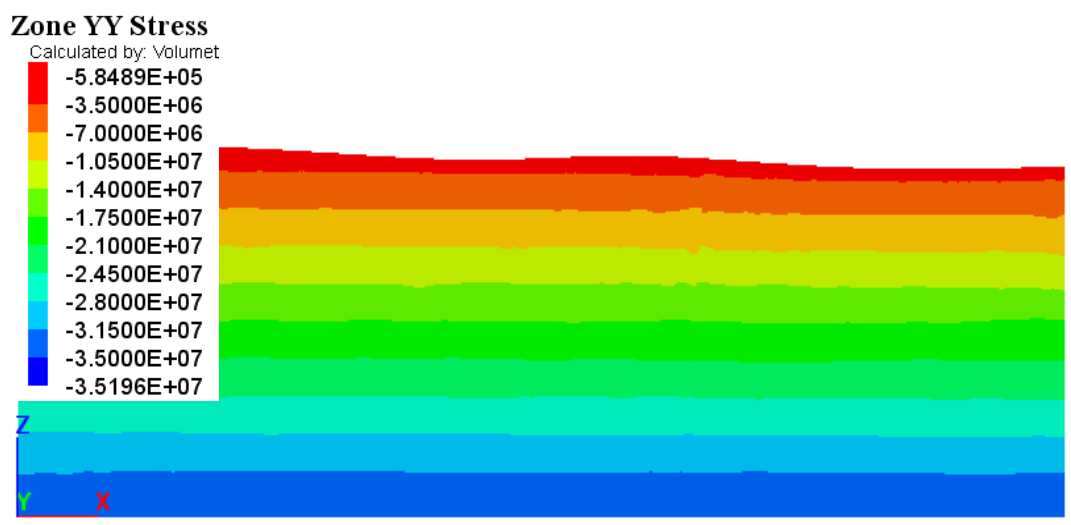

(b) Horizontal stress in y-direction 


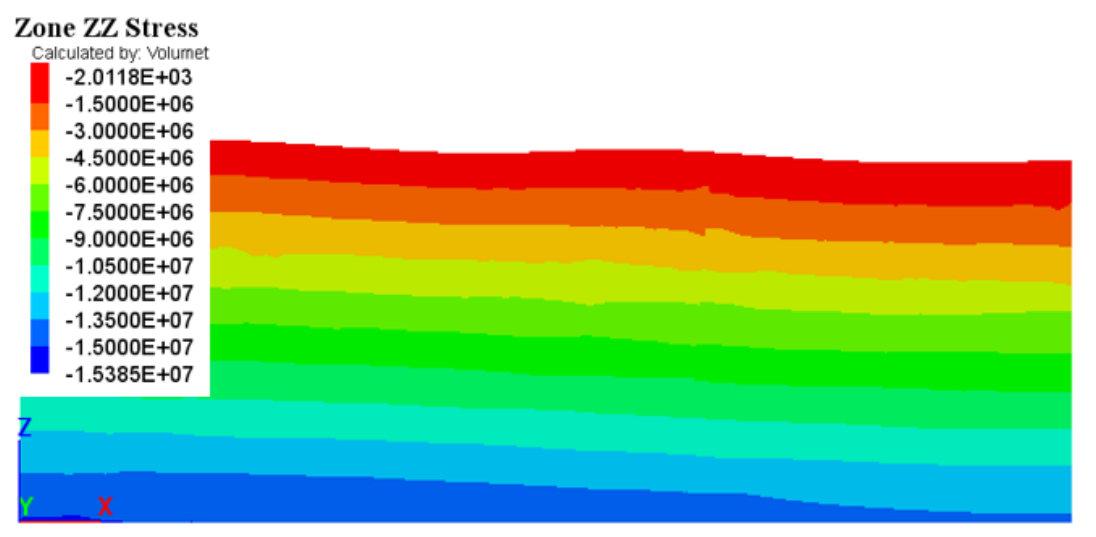

(c) Vertical stress

Figure 4.4: In-situ stress initialization results (unit: Pascal)

\subsubsection{Surface surcharge}

After stress initialization, the surcharge of the TSF on the ground surface is applied. The unit weights of the tailings and dam reported in Chapter 3 are applied. Thus, the equivalent stresses can be calculated and applied based on the planed tailings dam geometry, as shown in Fig. 4.5. The area of the projected tailings site is about $600 \mathrm{~m} \times 1000 \mathrm{~m}$. The maximum height of the tailings dam is about $70 \mathrm{~m}$. The equivalent surcharge of $1.4 \mathrm{MPa}$ is applied at the location of the tailings dam, and it gradually decreases to $0 \mathrm{MPa}$ when reaching the boundary of the TSF. The vertical stress and displacement contours after applying surcharge due to the TSF are shown in Figure 4.6.

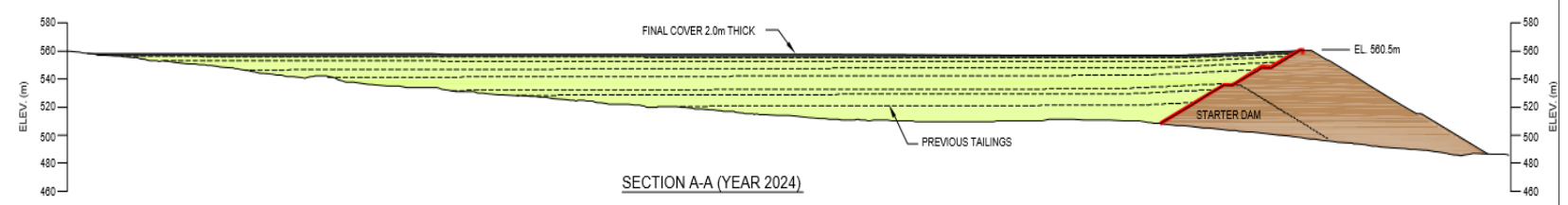

(a) Planned tailings volume in the year 2024 


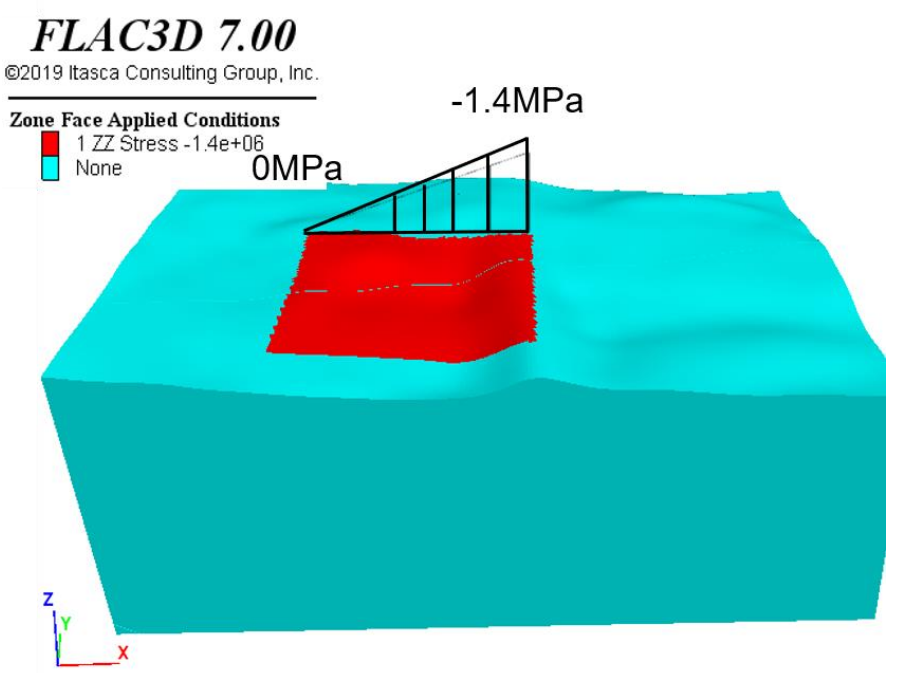

(b) Equivalent stresses of the TSF

Figure 4.5: Apply surcharge to the FLAC3D model

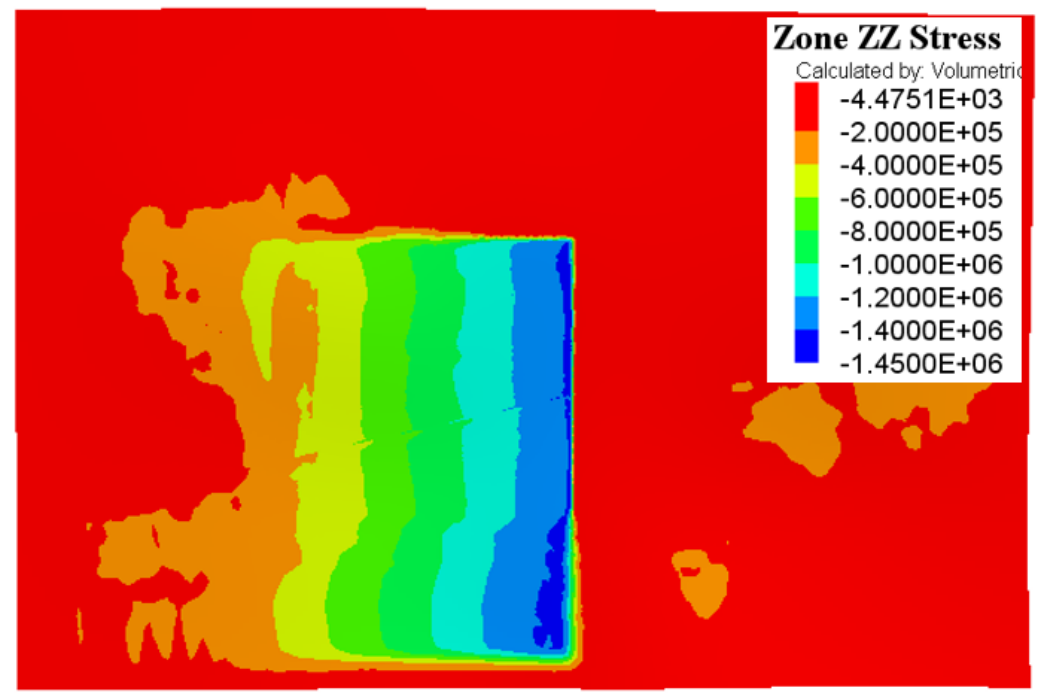

(a) Vertical stress (Pascal) 


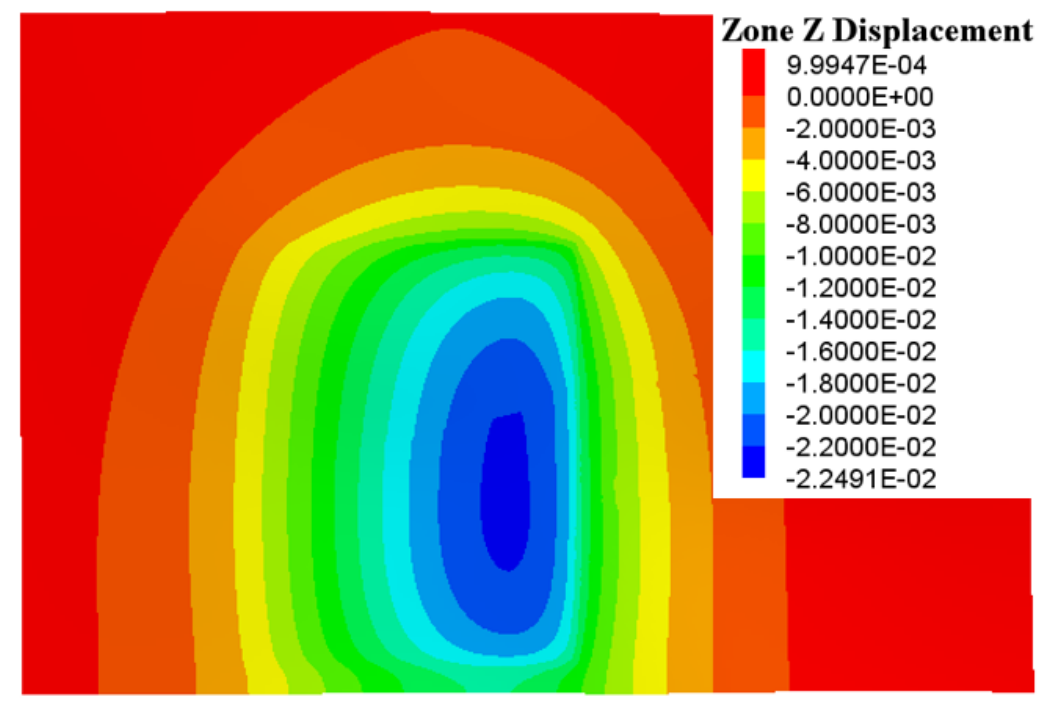

(b) Vertical displacement (m)

\section{Figure 4.6: Stress and displacement results after applying surface surcharge}

The orebody is mined bottom-up by the Avoca method with $15 \mathrm{~m}$ sublevel intervals. The unconsolidated backfill is an integral part of the production circle of the mining method. Based on the proposed mining method, the case study vein is divided into 17 levels with $15 \mathrm{~m}$ intervals, as illustrated in Figure 4.7. Ten mining stages are simulated in FLAC3D. After applying the surcharge from the TSF, two levels of the ore body are excavated and backfilled in each stage for the first six stages. As mining approaches the ground surface, the ore body is mined and backfilled level by level to examine the influence of shallow underground mining on the crown pillar stability. In the final stage, two mining levels of orebody are left above as surface crown pillar to separate ground surface and underground workings. Different modelling stages are shown in Table 4.4. 


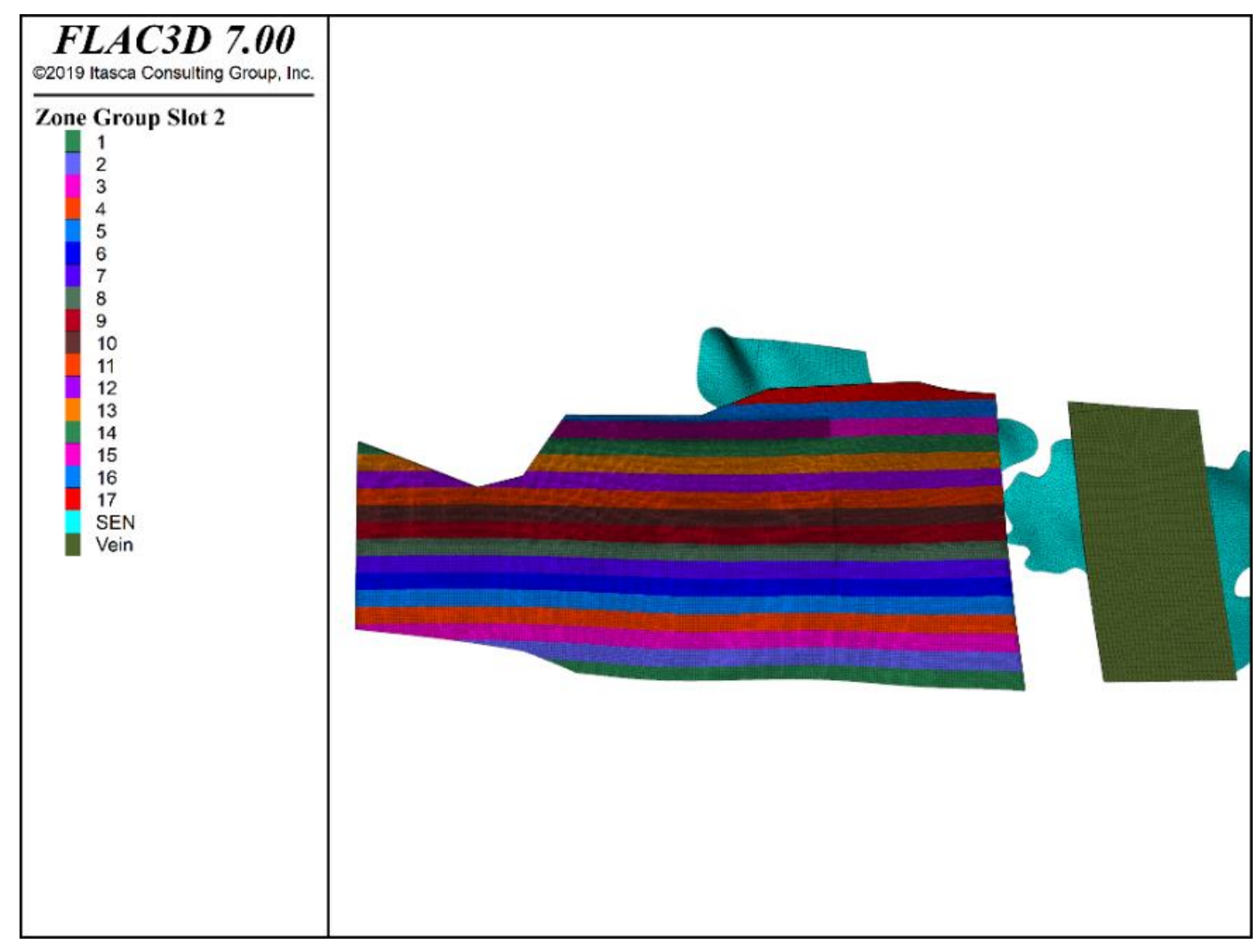

Figure 4.7: Planned mining levels of the case study vein

Table 4.3: Simulated modelling stages in FLAC3D model

\begin{tabular}{cc}
$\begin{array}{c}\text { Modelling } \\
\text { stage }\end{array}$ & Procedure description \\
\hline $\begin{array}{c}\text { Initial } \\
\text { Surcharge }\end{array}$ & Initialize in-situ stresses \\
1 & Apply the loads due to the TSF \\
2 & Excavate levels 1-2 \\
3 & Backfill levels 1-2 and excavate levels 3-4 levels 3-4 and excavate levels 5-6 \\
4 & Backfill levels 5-6 and excavate levels 7-8 \\
5 & Backfill levels 7-8 and excavate levels 9-10 \\
6 & Backfill levels 9-10 and excavate level 11 \\
7 & Backfill level 11 and excavate level 12 \\
8 & Backfill level 12 and excavate level 13 \\
9 & Backfill level 13 and excavate level 14 \\
10 & Backfill level 14 and excavate level 15 \\
\hline
\end{tabular}




\subsection{Model parametric studies}

Four models of possible parameters are examined to investigate the stability of the surface crown pillar, due to the uncertainties in the in-situ stresses and faults properties. Table 4.4 summarizes four sets of parameters that are tested while other parameters remine the same during parametric study.

Table 4.4: Model parametric study on in-situ stress and fault parameters

\begin{tabular}{ccccc}
\hline $\begin{array}{c}\text { Parametric } \\
\text { model }\end{array}$ & $K_{x}$ & $K_{y}$ & $\begin{array}{c}\text { Fault friction } \\
\text { angle }\left(^{\circ}\right)\end{array}$ & $\begin{array}{c}\text { Fault residual friction } \\
\text { angle }\left(^{\circ}\right)\end{array}$ \\
\hline 1 & 1.8 & 2.2 & 30 & 25 \\
2 & 1.8 & 2.2 & 15 & 10 \\
3 & 1.5 & 1.8 & 30 & 25 \\
4 & 1.5 & 1.8 & 15 & 10 \\
\hline
\end{tabular}

\subsubsection{Crown pillar stability}

Crown pillar stability analysis is presented for the most critical section R-R (as illustrated in Fig. 4.8), because the crown pillar in this section has the smallest thickness and would show yielding failure first compared with other sections. The yielding zone development above the uppermost stope will be used as a criterion to evaluate the crown pillar stability. To determine the stable crown pillar thickness, the crown pillar yielding conditions are characterized into three states below:

(1) Yielding zone initiates - the rock mass above the uppermost stope starts to show yielding failure but will not affect the overall stability;

(2) Yielding zone coalesces - the yielding zones start to join each other, and some parts propagate to the ground surface;

(3) Completely failed - the rock cover above the stope has completely yielded. 


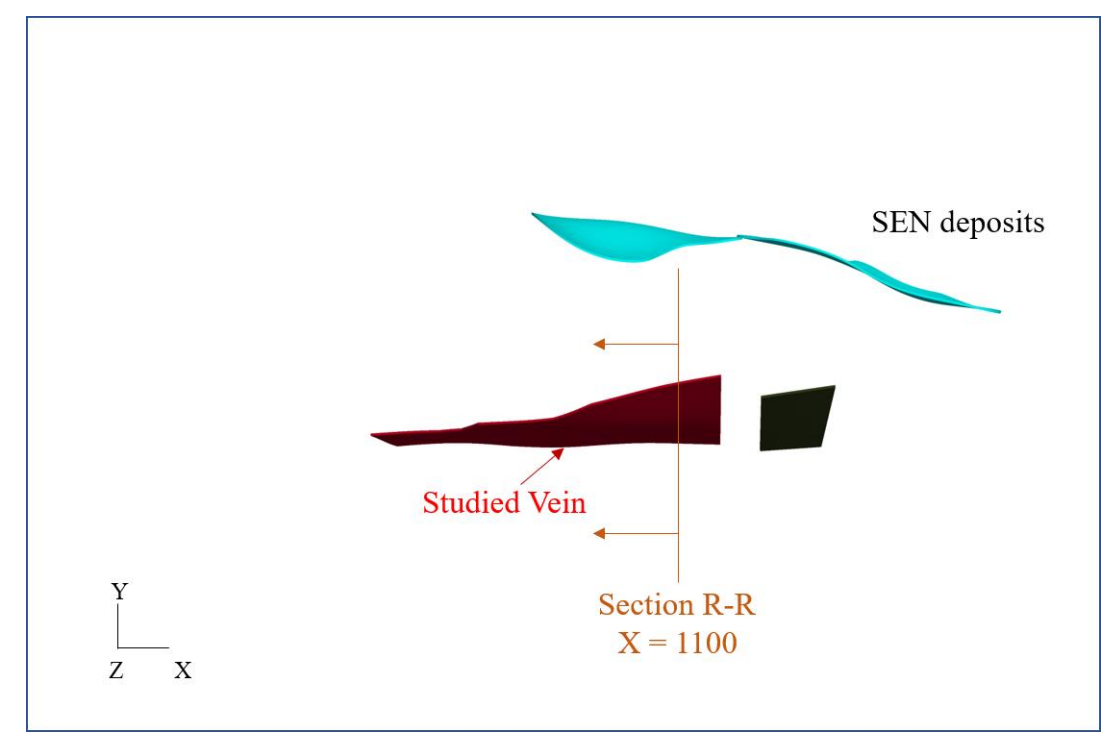

Figure 4.8: Location of the critical section $R-R$

The results of minimum principal stress and pillar yielding failure of the three states of Model 1 are shown in Figure 4.9. Table 4.5 summarizes crown pillar thickness in the three yielding states for each model. The results indicate that the model 2 had the worst crown pillar stability during the mining operations, which has a higher horizontal stress ratio and a low fault frictional angle. The crown pillar thickness in model 2 is $72 \mathrm{~m}$ in the critical section when the yielding zone starts to develop, and it is $43 \mathrm{~m}$ when completely yielded. This implies that the crown pillar is more likely to yield under higher deviatoric stress $\left(\sigma_{1^{-}} \sigma_{3}\right)$ and a lower fault friction angle.

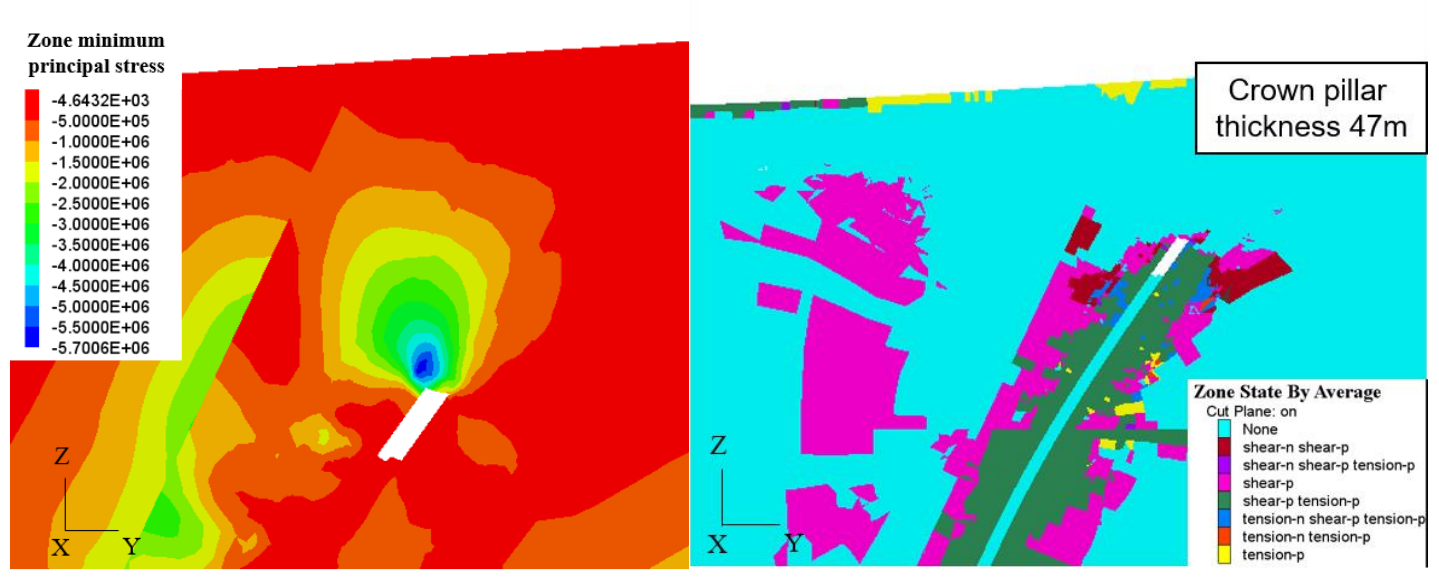

(a) Yielding zone initiation state 


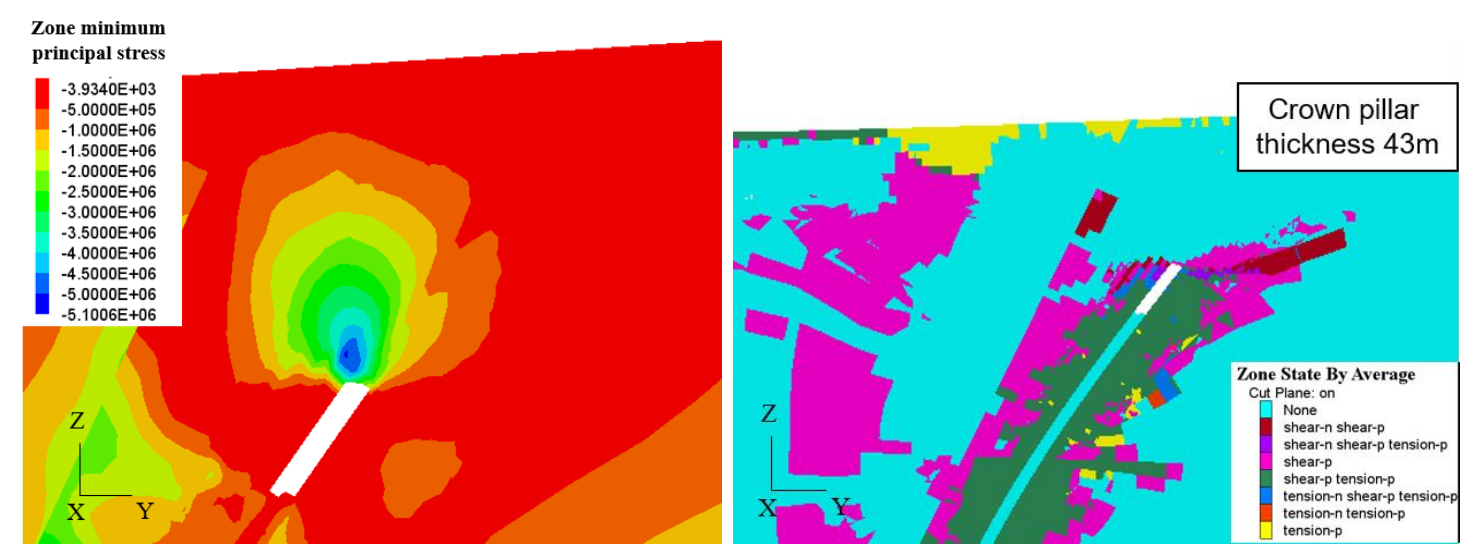

(b) Yielding zone coalescence state

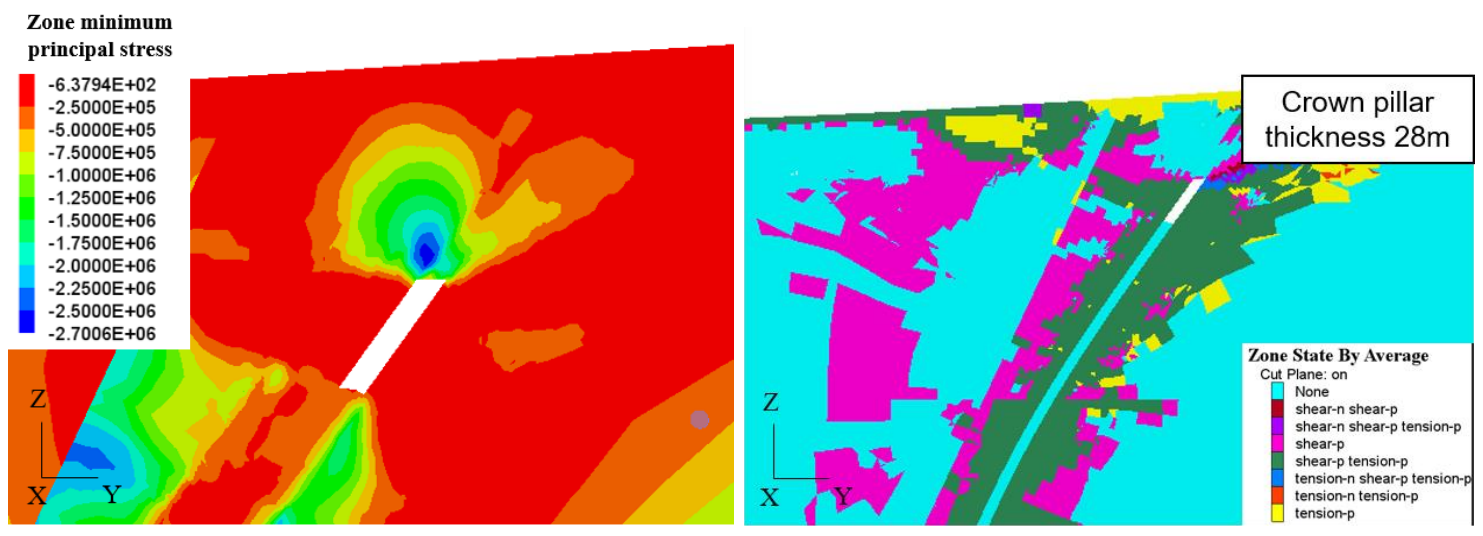

(c) Complete yielding state

Figure 4.9: Minimum principal stress and pillar yielding conditions on section $R-R$ of the three states of Model 1 (unit: Pascal). Note: Negative principal stress values represent compression.

Table 4.5: Crown pillar thickness at different yielding states

\begin{tabular}{ccccccc}
\hline $\begin{array}{c}\text { Parametric } \\
\text { Model }\end{array}$ & $K_{x}$ & $K_{y}$ & $\begin{array}{c}\text { Fault } \\
\text { Friction } \\
\text { angle }\left({ }^{\circ}\right)\end{array}$ & $\begin{array}{c}\text { Crown pillar } \\
\text { thickness } \\
\text { when } \\
\text { yielding } \\
\text { zones initiate } \\
(\mathrm{m})\end{array}$ & $\begin{array}{c}\text { Crown pillar } \\
\text { thickness } \\
\text { when } \\
\text { yielding } \\
\text { zones } \\
\text { coalesce (m) }\end{array}$ & $\begin{array}{c}\text { Crown pillar } \\
\text { thickness } \\
\text { when pillar } \\
\text { completely } \\
\text { yields (m) }\end{array}$ \\
\hline 1 & 1.8 & 2.2 & 30 & 47 & 43 & 28 \\
2 & 1.8 & 2.2 & 15 & 72 & 56 & 43 \\
3 & 1.5 & 1.8 & 30 & 43 & 37 & 28 \\
4 & 1.5 & 1.8 & 15 & 57 & 45 & 28 \\
\hline
\end{tabular}




\subsubsection{Ground surface differential settlement}

Underground mining activities cause creep in geological strata and lead to subsidence on the ground surface. Mining-induced subsidence effects usually appear as surface ground settlement and deformation, resulting in damage to overlying civil engineering structures such as retaining walls, roadways, buildings, and dams. As reported by Bétournay (2002), unstable shallow stopes are usually close the surface within $30 \mathrm{~m}$, situated at or very near overburdened bodies of water or infrastructure. The natural tectonic ground stresses may not be sufficient to prevent stope cavesin, or in the case of intense regional mining activity, the rock mass may be destressed, resulting in sudden, piecewise, or gradual surface subsidence.

Mining subsidence cases are common in coal, metal, and other types of mining, and have been reported by many authors. For example, Beauchamp et al. (2006) studied a highway section damaged by the mining subsidence of steeply dipping narrow veins. The stopes were mined and backfilled with unconsolidated sand. Potentially unstable crown pillars over the mined-out areas compromise surface infrastructures, particularly the main highway. Also, as reported by Can et al. (2012), underground coal mining in the Zonguldak region caused serious subsidence of the masonry building's foundation. Vertical settlements were measured to be from 25 to $75 \mathrm{~mm}$ using precise leveling network approach, and the resultant major cracks forced people to evacuate these masonry buildings.

In this study, a tailings dam is situated directly above the orebody, and thereby the stability of the surface tailings dam is a critical consideration when determining surface crown pillar thickness. Therefore, the dam foundation settlements accompanied by underground mining are analyzed in the following sections.

Figure 4.10 shows surface vertical displacement contours at different mining stages of Model 1. The grey area symbolizes the location of the tailings dam foundation. As shown in Fig. 4.10a, dam foundation settlements already showed up after applying surcharge. The maximum settlements are $1.6 \mathrm{~cm}$ in the middle, while the minimum settlements are around $0.8 \mathrm{~cm}$ at two sides of the foundation. As underground mining proceeds, it can be observed that the ground surface undergoes differential settlements; one side of the dam foundation is uplifting while another side is settling. In the final mining stage, the differential settlements along the dam foundation reaches $3.6 \mathrm{~cm}$, 
with the maximum settlements and uplifts of $3.2 \mathrm{~cm}$ and $0.4 \mathrm{~cm}$, respectively, as shown in Figure 4.10f.

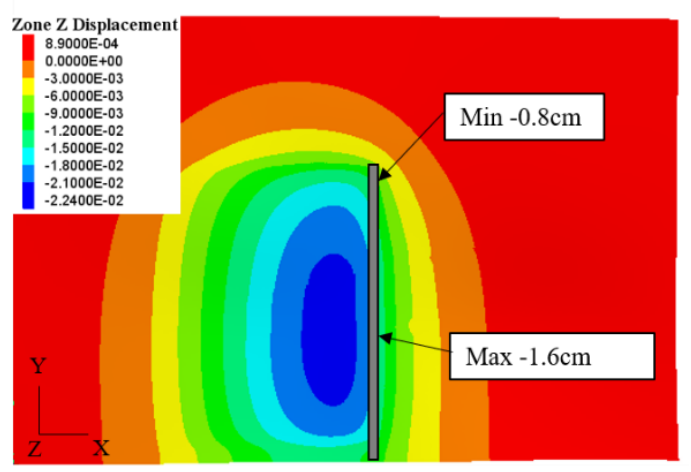

(a) Surcharge

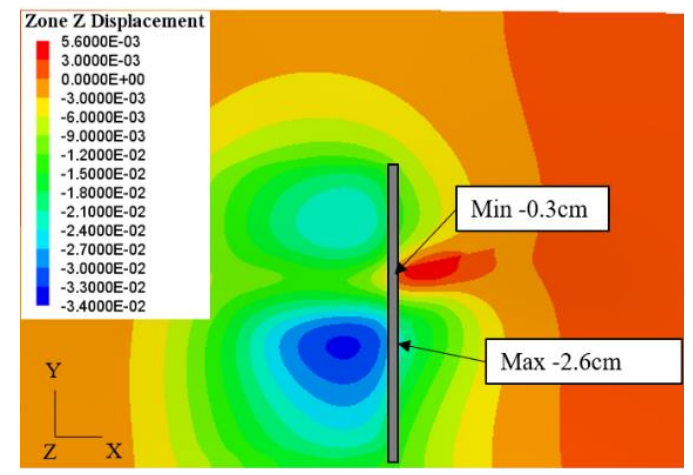

(c) Stage 7

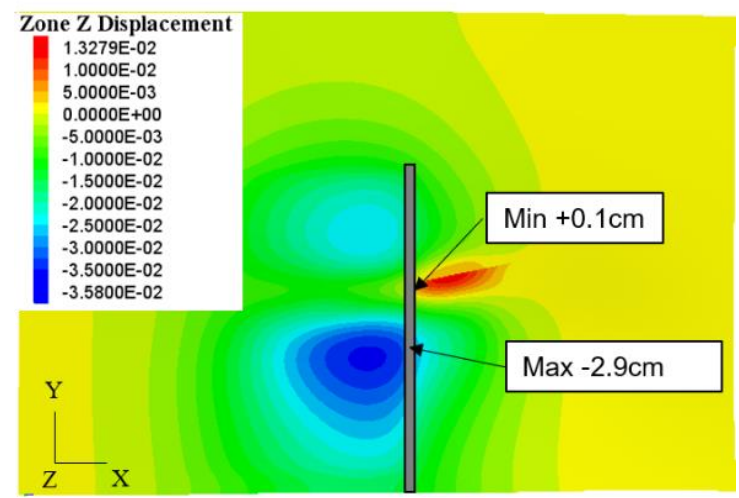

(e) Stage 9

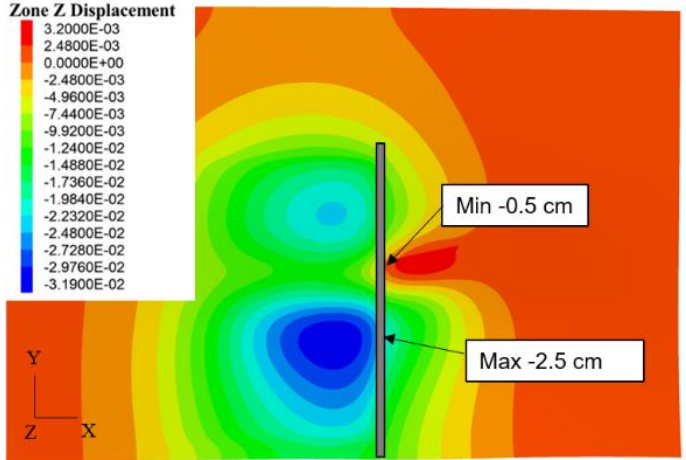

(b) Stage 6

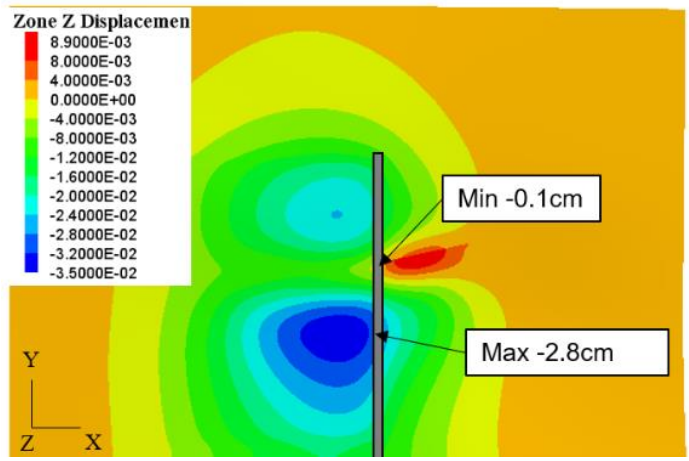

(d) Stage 8

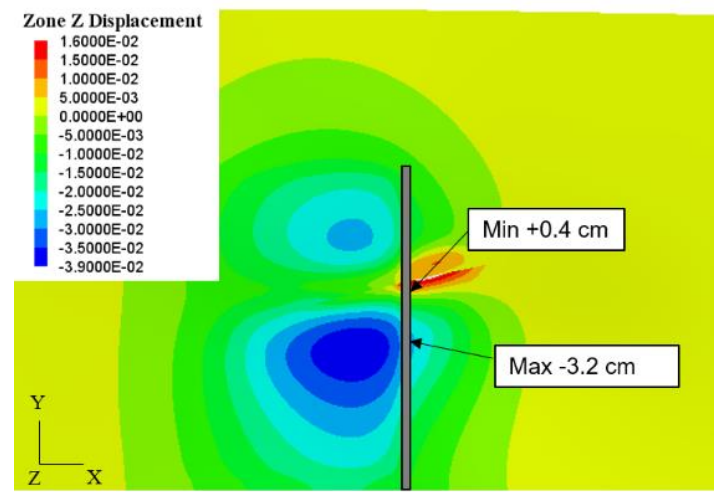

(f) Stage 10

Figure 4.10: Plan view of vertical displacements on the ground surface at different mining stages of Model 1 (unit: meter) 
The predicted dam foundation differential subsidence induced by underground mining for four parametric models is summarized in Table 4.6. Two parameters are used here to quantify uneven deformation of the dam foundation. The differential settlement $\delta$ is the difference between the maximum $\rho_{\max }$ and minimum settlements $\rho_{\min }$ along the dam foundation, and the angular distortion $\beta$ is the ratio of the differential settlement $\delta$ and the distance L between two points (Skempton \& MacDonald, 1956), as illustrated in Figure 4.11. From Table 4.6, we can find that the more intensive horizontal stresses and lower fault frictional angles were applied, the greater differential settlements experienced along the dam foundation. Model 2 is the worst-case scenario with the highest horizontal stresses and lowest fault's frictional angles, experiencing a differential settlement of $4.4 \mathrm{~cm}$ and an angular distortion of $0.025 \%$ at stage 10.

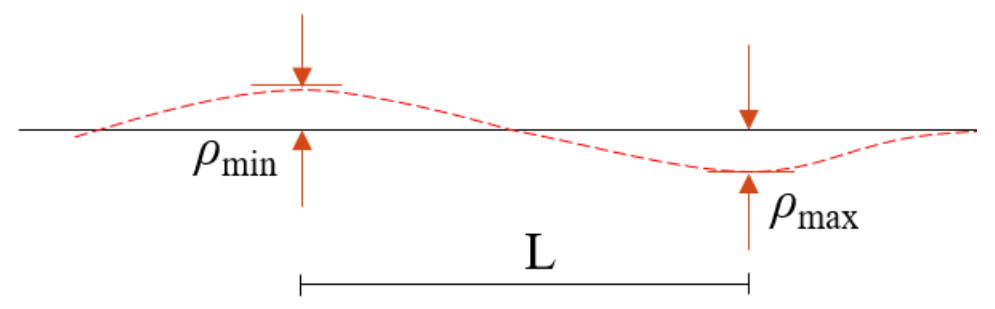

Figure 4.11: Dam foundation uneven deformation

Table 4.6: Summary of dam foundation deformations at different mining stages

\begin{tabular}{|c|c|c|c|c|c|c|c|c|c|c|}
\hline \multirow{2}{*}{$\begin{array}{l}\text { Parametric } \\
\text { Model }\end{array}$} & \multicolumn{5}{|c|}{$\begin{array}{l}\text { Maximum differential settlement } \\
\qquad \delta=\rho_{\max }-\rho_{\min }(\mathrm{cm})\end{array}$} & \multicolumn{5}{|c|}{$\begin{array}{l}\text { Angular distortion } \\
\quad \beta=\delta / \mathrm{L}(\%)\end{array}$} \\
\hline & Surcharge & 7 & 8 & 9 & 10 & Surcharge & 7 & 8 & 9 & 10 \\
\hline 1 & 0.8 & 2.3 & 2.7 & 3 & 3.6 & 0.002 & 0.013 & 0.016 & 0.017 & 0.021 \\
\hline 2 & 0.8 & 3.1 & 3.5 & 3.9 & 4.4 & 0.002 & 0.018 & 0.020 & 0.022 & 0.025 \\
\hline 3 & 0.8 & 1.8 & 2.1 & 2.4 & 2.7 & 0.002 & 0.010 & 0.012 & 0.014 & 0.016 \\
\hline 4 & 0.8 & 2.7 & 3.1 & 3.4 & 4 & 0.002 & 0.016 & 0.018 & 0.020 & 0.023 \\
\hline
\end{tabular}

Figure 4.12 shows a sectional view of vertical displacements under the tailings dam at different mining stages of Model 1. The black line denotes the location of the parallel fault. It can be observed that the maximum uplifting displacement occurred along the parallel fault. This could be due to the reactivation of the reverse fault; under the influence of nearby stoping activities, the intensive horizontal stresses cause the hanging wall side of the fault moving upwards over the footwall. 


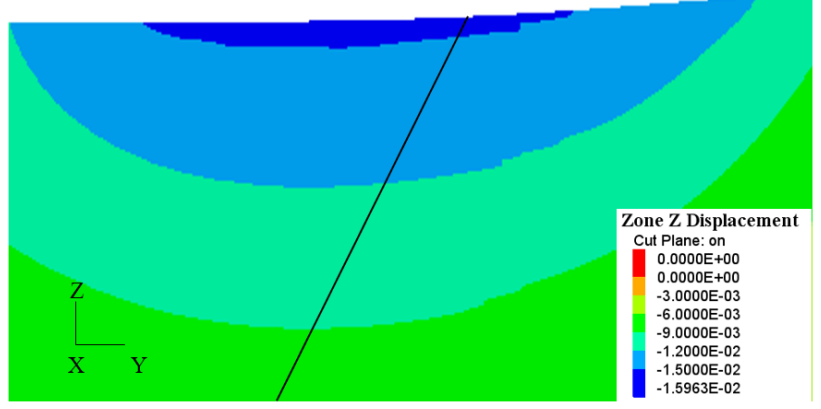

(a) Surcharge

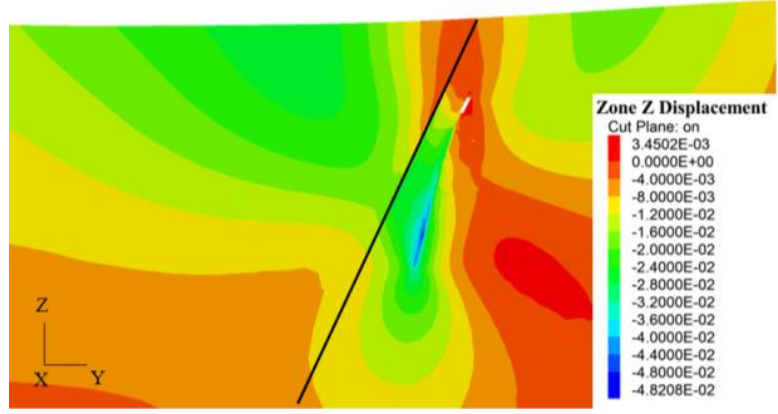

(c) Stage 7

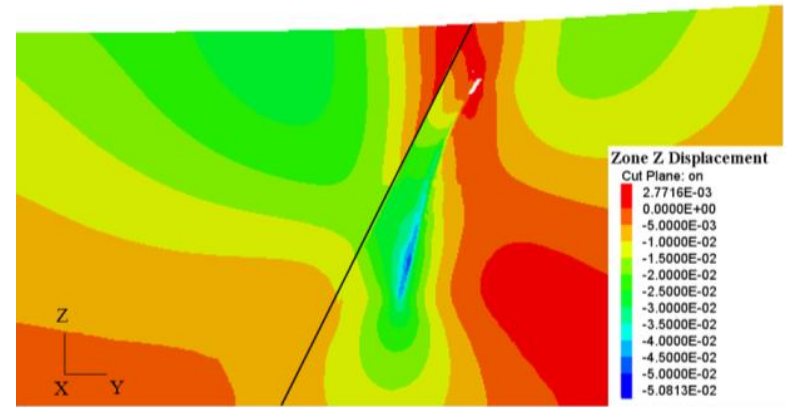

(e) Stage 9

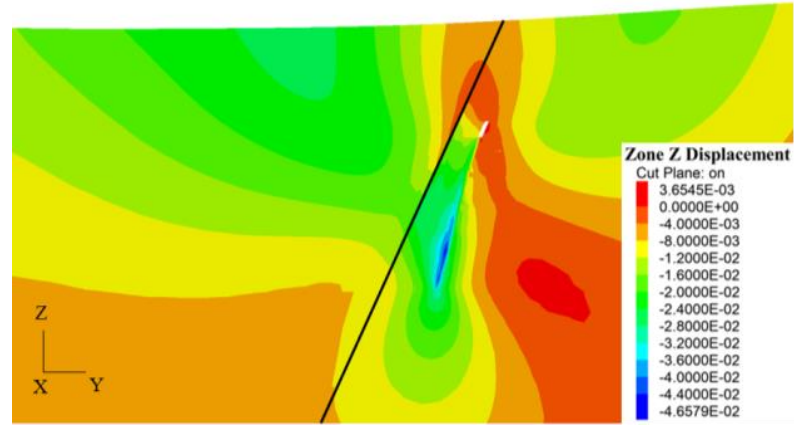

(b) Stage 6

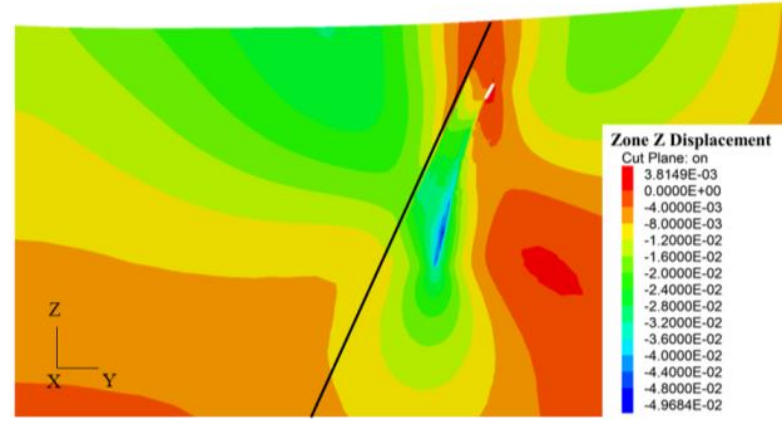

(d) Stage 8

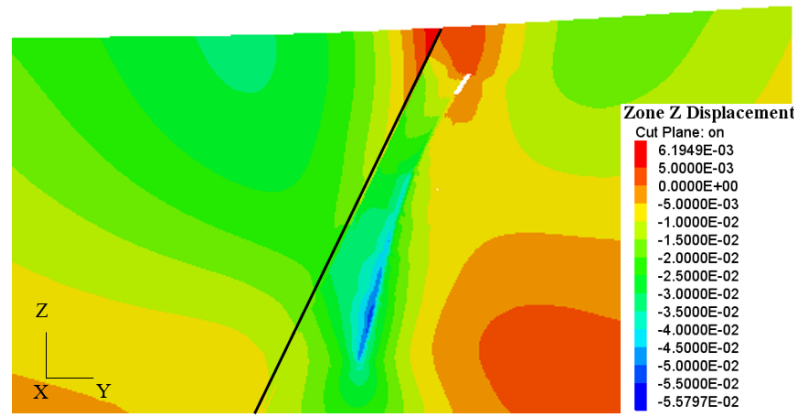

(f) Stage 10

Figure 4.12: Sectional view of vertical displacements under the tailings dam at different mining stages of Model 1 (unit: meter). Note: The black line denoted the location of the parallel fault

\subsubsection{Fault movements}

As a weak structural plane, the fault is an important factor for the stability of overburden strata associated with nearby underground mining activities. The strength of fault is much lower than that of the rock mass around it, so the existing faults are susceptible to experience shear slip along the fault plane induced by nearby mining activities, that is fault reactivation (Donnelly, 2000). Ma 
et al. (2011) found that the overburden strata movements are induced by the nearby fault movement when mining a steep-inclined coal seam. The existence of faults impacts the normal arrangement of the mining area and disrupts the regular displacements pattern around the stope.

The modelling results show that the crown pillar stability is influenced by nearby fault properties, and the maximum uplifting deformation of the tailings dam foundation occurred near the parallel fault. Thus, fault reactivation induced by mining activities is analyzed. The shear displacement contours of two nearby faults at the final mining stage are plotted in Fig. 4.13.
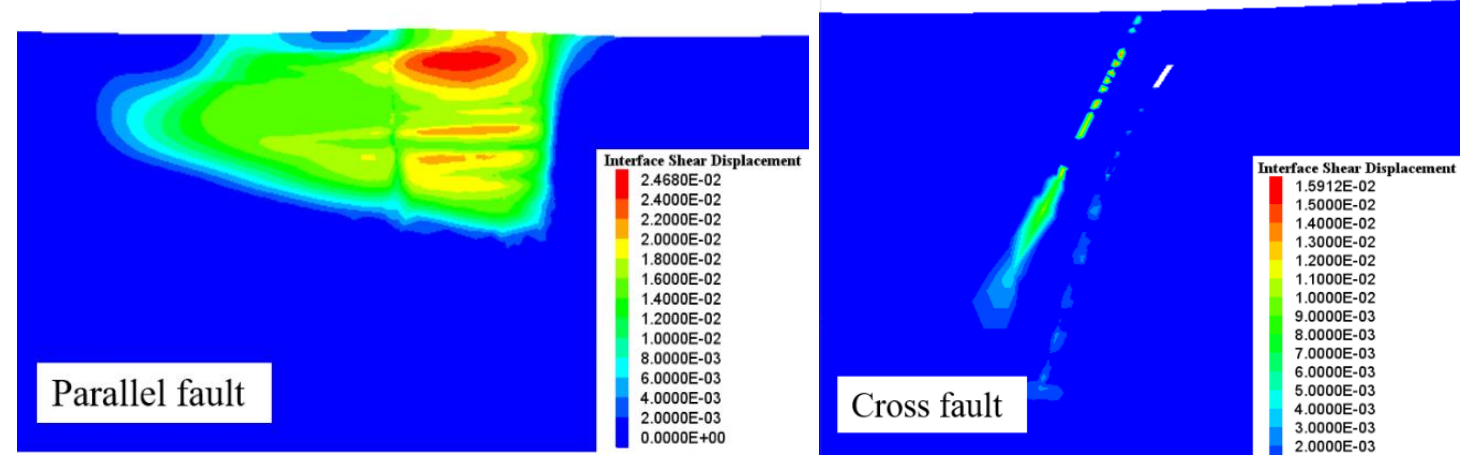

(1) Model 1
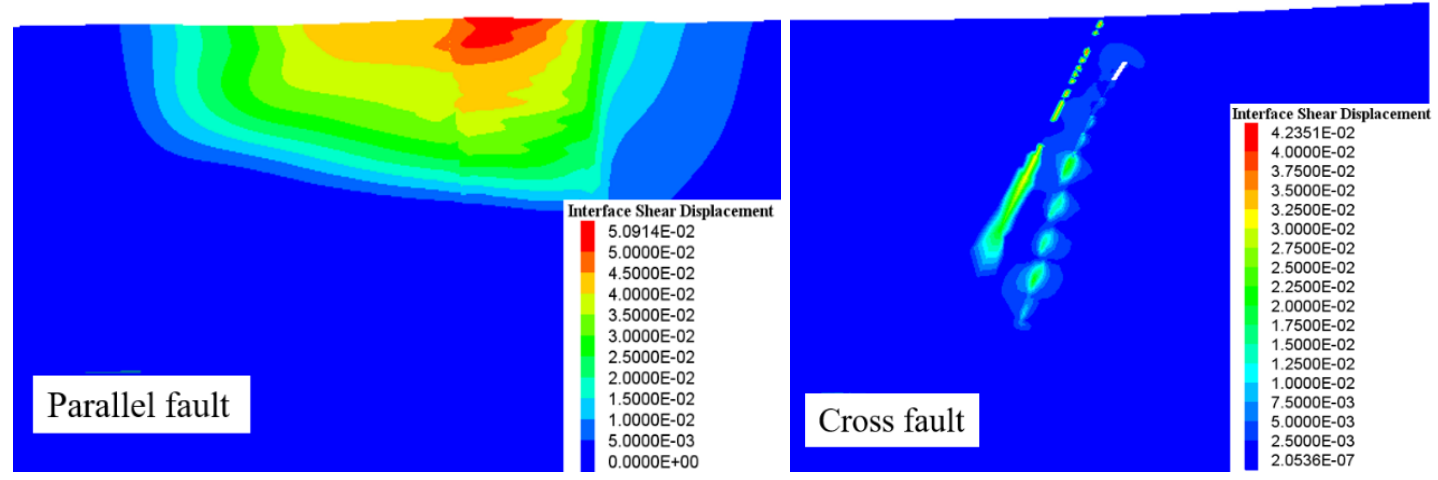

(2) Model 2 


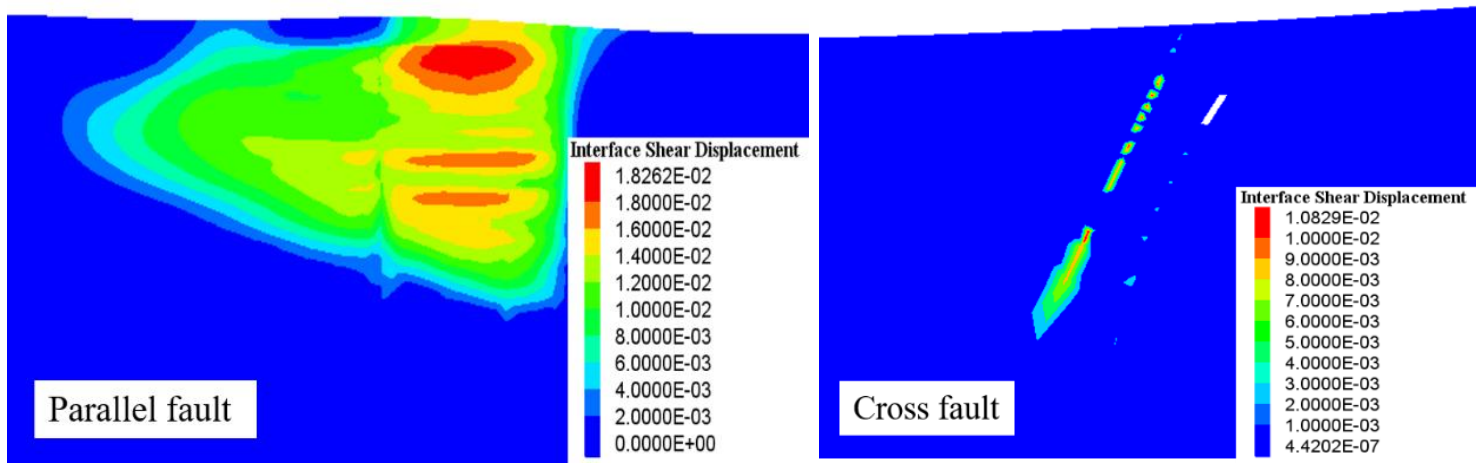

(3) Model 3
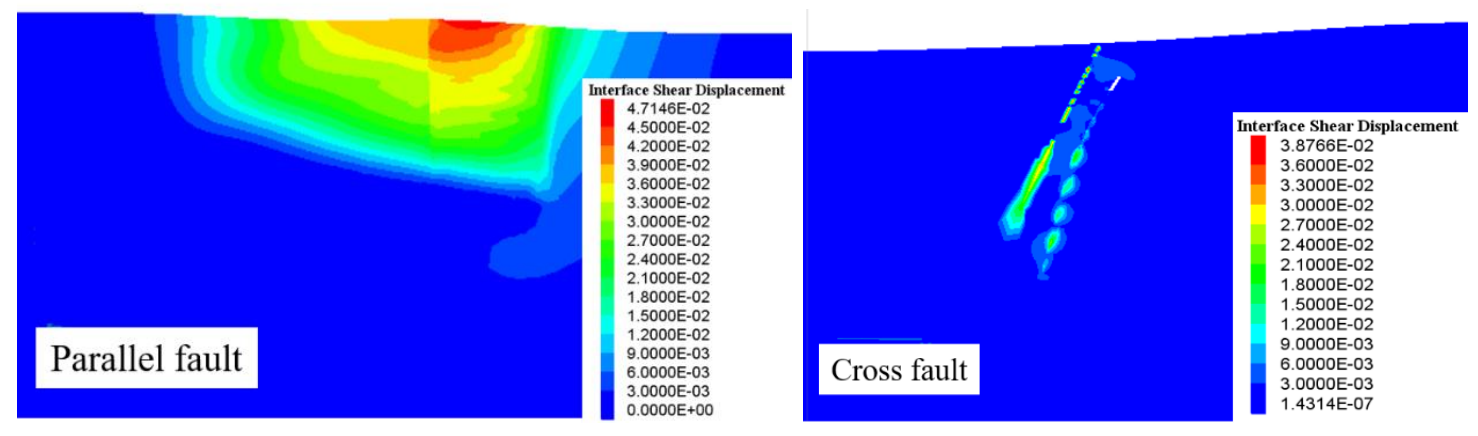

(4) Model 4

Figure 4.13: Fault shear displacements at mining stage 10 of different models (unit: meter)

It is observed that mining-induced fault reactivation is experienced on both regional faults, but the stoping activities have a more significant impact on the fault parallel to the vein than the one crossing the vein, as the parallel fault has much greater reactivation range and maximum shear displacement. These results coincide with the previous findings of Ji et al. (2012) that the case of the working face perpendicular to the fault experienced much less stress disturbance than that of the working face parallel to the fault.

The maximum shear displacements of two faults are summarized in Table 4.7. The maximum shear displacements of both faults increase sharply when the fault friction angle is lower. The shear displacements are approximately doubled when fault frictional angle drops from $30^{\circ}$ to $15^{\circ}$. Besides, by comparing the results from Models 1 and 3, it appears that the maximum shear displacements on both faults increases by around $0.5 \mathrm{~cm}$ when in-situ stress ratios increase. It can 
be concluded that the fault friction angle is a more dominant factor controlling fault shear displacements compared with in-situ stress.

Table 4.7: Maximum fault shear displacements at mining stage 10

\begin{tabular}{cccccc}
\hline Model & $K_{x}$ & $K_{y}$ & $\begin{array}{c}\text { Fault friction } \\
\text { angle }\left({ }^{\circ}\right)\end{array}$ & $\begin{array}{c}\text { Maximum shear } \\
\text { displacements on the } \\
\text { parallel fault }(\mathrm{cm})\end{array}$ & $\begin{array}{c}\text { Maximum shear } \\
\text { displacements on the } \\
\text { cross fault (cm) }\end{array}$ \\
\hline 1 & 1.8 & 2.2 & 30 & 2.46 & 1.59 \\
2 & 1.8 & 2.2 & 15 & 5.09 & 4.23 \\
3 & 1.5 & 1.8 & 30 & 1.82 & 1.08 \\
4 & 1.5 & 1.8 & 15 & 4.71 & 3.87 \\
\hline
\end{tabular}

\subsection{Summary}

In order to determine the adequate surface crown pillar dimensions for the case study vein, both empirical and numerical methods are carried out to assess crown pillar stabilities. The scaled span method developed by Carter (1992) is first utilized to provide empirical guidelines for surface crown pillar design. FDM-based numerical modelling software FLAC3D 7.0 is utilized to conduct a model parametric study on the crown pillar stability. Four numerical models are built to examine the effect of in-situ stresses and faults properties. To evaluate surface crown pillar stability, three crown pillar yielding states were characterized: yield zone initiation, yield zone coalescence, and complete yielding. The results of dam foundation differential settlement are also analyzed, which can be used to determine the adequate crown pillar thickness from the perspective of surface infrastructure stability. The key observations from the crown pillar assessment are:

- The empirical scaled span method suggests that the safe thickness for the studied crown pillar is larger than $63.8 \mathrm{~m}$ when the estimated serviceable life span is more 100 years without any surveillance needs. If the crown pillar thickness is less than $63.8 \mathrm{~m}$, incidental superficial monitoring is required; while if it is less than $23.9 \mathrm{~m}$, conscious and continuous monitoring would be required on-site, and the predicted serviceable life is less than 20 years.

- The numerical modelling results indicate that the crown pillar is more likely to yield with higher deviatoric stresses and lower fault friction angle. The estimated safe minimum 
crown pillar thickness varies from $43 \mathrm{~m}$ to $72 \mathrm{~m}$ based on pillar initial yielding state of four parametric models.

- If uneven deformation or subsidence on top of the mined-out area cannot be effectively controlled, it could cause damage to the overlying infrastructure such as shear deformation or cracking. The surface infrastructure stability is dominantly controlled by the differential subsidence rather than the absolute magnitude of subsidence ( $\mathrm{Li}$ et al., 2006). The modelling results reveal that as the underground mining activities proceed toward the ground surface, the differential settlements will be aggravated and threaten the stability of the surface tailings dam. Higher horizontal stress and lower friction angle will cause greater dam foundation differential settlements. The determination of the threshold for the maximum allowable differential settlements could help determine the adequate crown pillar thickness from the perspective of surface infrastructure stability.

- The modelling results also indicate that stoping activities trigger the reactivation of both nearby faults. The parallel fault has a greater reactivation range and larger maximum shear displacement than the one intersecting with the vein. Also, the influence of fault friction angles is more dominant on fault shear displacements compared with that of in-situ stresses. 


\section{Chapter 5}

\section{Hanging wall overbreak assessment and control}

\subsection{Hanging wall overbreak assessment}

Stope overbreak is a major concern when mining steeply dipping narrow-vein deposits. Stope overbreak may compromise the stability of underground excavations and overlying surface crown pillars, leading to additional rock support requirements, otherwise hindering crown pillar recovery. The most direct concern about stope overbreak is the mixing of ore with barren waste or minerals below the cut-off grade, reducing mining profitability. Stope overbreak can also significantly increase mining operation costs, e.g., mucking, haulage, crushing, hoisting, milling, waste treatment, and low-grade ore upgrading. Thus, it is essential to evaluate and mitigate stope overbreak during mining procedures to maximize production and increase revenue.

In this chapter, the overbreak of stope hanging wall (HW) is evaluated as it is much more dominant than that of the footwall when mining steeply dipping narrow-vein deposits, which could represent the unplanned dilution potential (Henning \& Mitri, 2007). Firstly, empirical methods are used to evaluate HW stability and predict the overbreak volume. Then, a new methodology for predicting the overall HW overbreak during production is proposed and compared with the conventional modelling method. The impact of HW overbreak on surface subsidence is analyzed. Finally, horizontal sill pillar measures are applied and optimized to control stope overbreak.

\subsubsection{Empirical method}

The conventional stability graph is a qualitative design tool for stope stability assessment. It can provide mine planners with a preliminary tool for stope dimensioning. Mathews and his coworkers developed the stability graph method for open stope design at Golder Associates for predicting stable stope spans at depths below $1000 \mathrm{~m}$ (Mathews et al., 1981).

The stability graph is a plot of stability number $N^{\prime}$ against hydraulic radius $H R$ as shown in Figure 5.1. The stability number is calculated as:

$$
N^{\prime}=Q^{\prime} \times A \times B \times C
$$

Where:

$Q^{\prime}$ is the modified rock mass rating with the stress reduction factor set to one, 
$A$ is the stress factor,

$B$ is the joint orientation factor,

$C$ is the stope surface orientation factor.

The hydraulic radius, also called shape factor (Laubscher, 1977), is defined by the following equation:

$$
H R=\text { Area } / \text { Perimeter }
$$

Where:

"Area" refers to the area and "Perimeter" refers to the perimeter of the stope surface being analyzed, e.g., hanging wall. Note the method can be equally applied to the footwall face of the stope. As illustrated in Figure 5.1, three zones are defined in the stability graph to describe the stability of stope walls. They are:

(1) Stable - the excavation will stand with no artificial support, and localized support can be used to control slabbing.

(2) Unstable - the excavation will experience localized caving but tend to form a stable arch. Support measures such as cable bolts are recommended to maintain the stope stability.

(3) Caving - the stope will not stabilize until the void is filled.

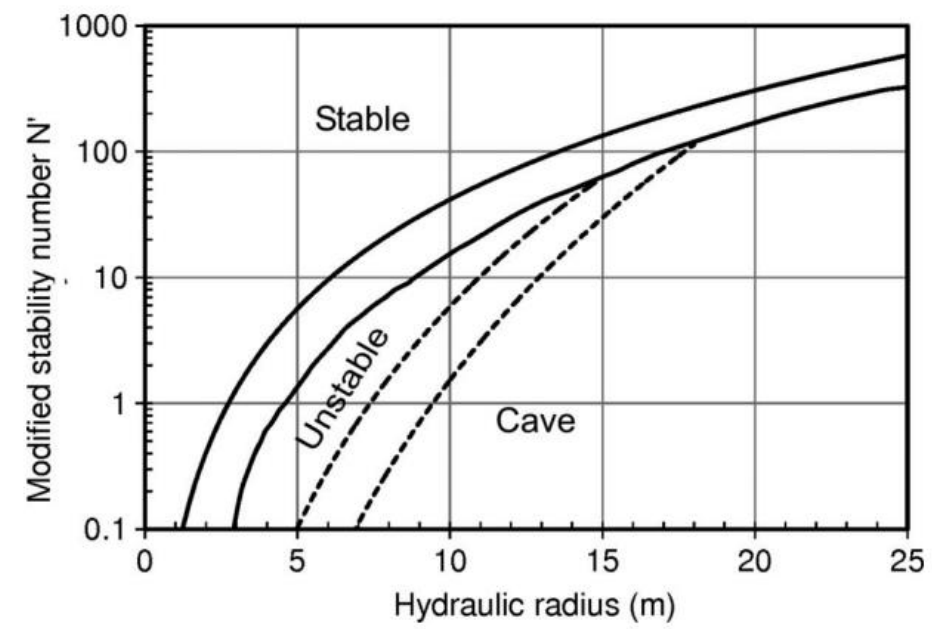

Figure 5.1: Stability graph proposed by Mathews et al. (1981) 
To quantify stope overbreak properly, Clark \& Pakalnis (1997) proposed the Equivalent Linear Overbreak Slough (ELOS) as illustrated in Fig. 5.2. The ELOS is calculated by the following equation.

ELOS = Volume of slough / Stope wall surface area

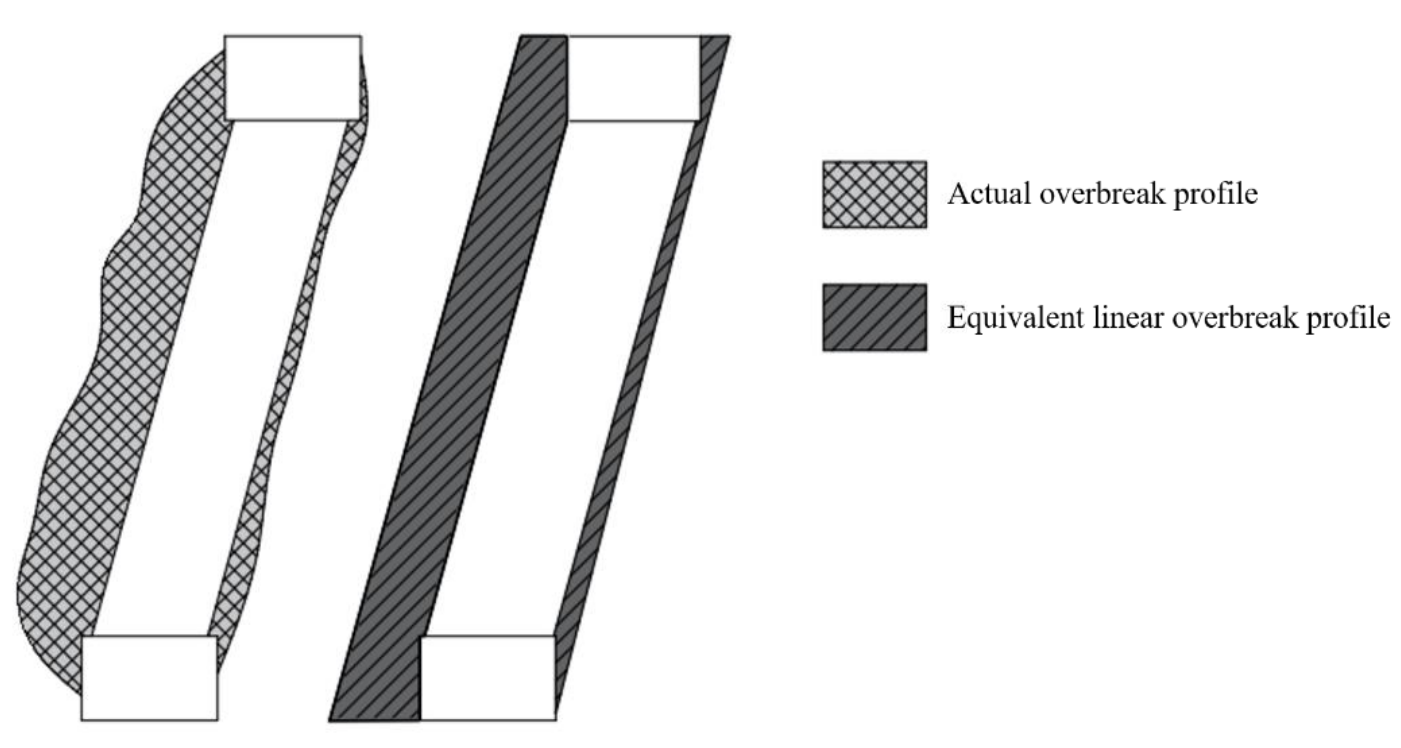

Figure 5.2: Equivalent linear overbreak/sloughage (ELOS)

Meanwhile, ELOS was incorporated into the qualitative stability graph method to predict overbreak/slough volume as shown in Fig. 5.3. The database of empirical dilution design graph was developed from case histories of narrow veins. 


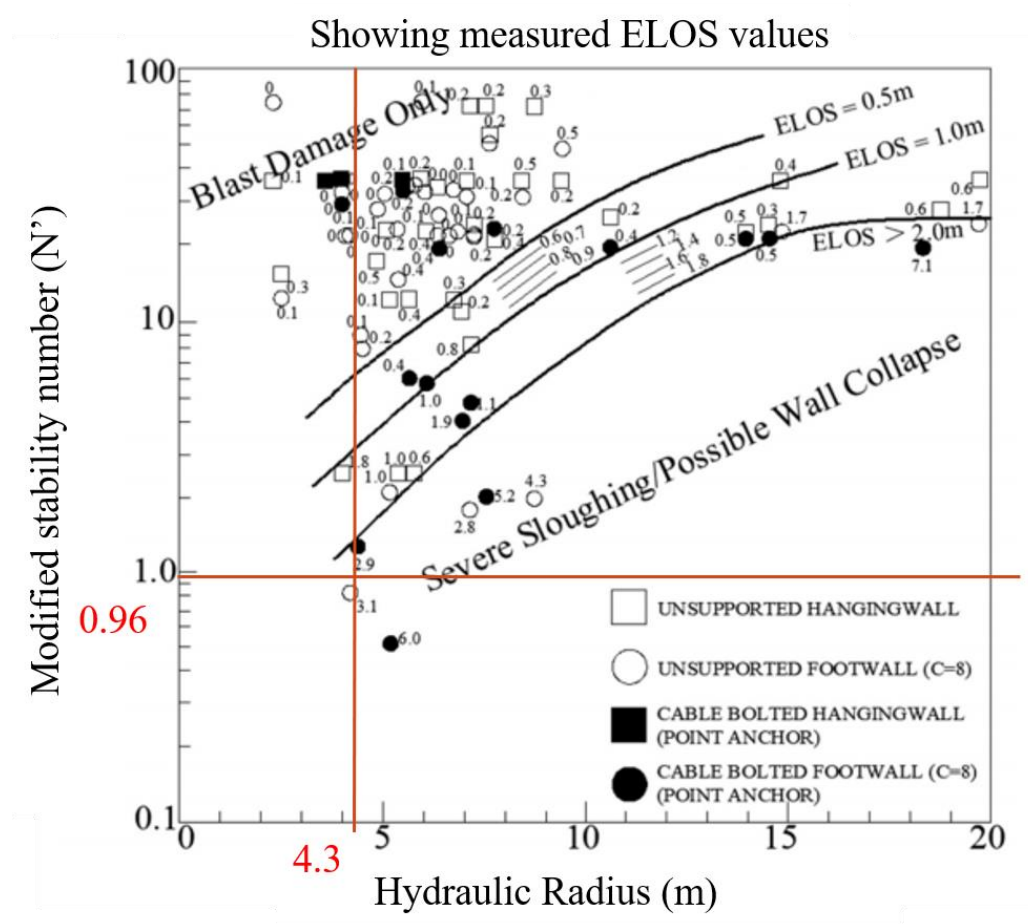

Figure 5.3: Empirical dilution design graph (from Clark \& Pakalnis, 1997)

In this study, stope stability and potential HW overbreak of the case study vein are initially assessed based on the empirical methods and dilution design graphs. The procedure to calculate the stability number $N^{\prime}$ and hydraulic Radius $H R$ :

- The modified $Q^{\prime}$ values used in this calculation are sourced from the geotechnical model of the north area, as well as previous consultant's reports. No calibrated data exists for the studied area and the rock mass classification is not part of this study. Available data from previous technical reports indicate a range of $Q^{\prime}$ value with upper and lower bounds. The lower bound of $Q^{\prime}$ value might be based on underground observation when rock mass is damaged by excavation activities.

- Factor $A$ is calculated according to previous 3D modelling results of Chapter 4. The induced maximum principal stress $\sigma_{1}$ is measured around the hanging wall of the stope.

- Factor $B$ is set to a value of 0.3 with the assumption that the critical joint set is parallel to the stope wall.

- Factor $C=8-6 \cos \Phi$ for all hanging walls in which $\Phi$ is the dip of the hanging wall. 
The following paragraphs present the details on how stope stability and potential hanging wall overbreak are evaluated based on the empirical graph methods:

Factor $A$ accounts for the influence of induced stress on the studied stope surface. It is based on ratio of UCS to induced $\sigma_{1}$ and varies from 0.1 to 1 . The initial A factor proposed by Mathews et al. (1981) was modified several times due to the limitations including no consideration for low compression and tension states in the original version. Mitri et al. (2011) recommended a modified stress factor $A^{\prime}$ to deal with these limitations, as shown in Fig. 5.4a. Based on the previous modelling results, the minimum principal stress around the stope hanging wall is approximately 3 $\mathrm{MPa}$, and hence the modified stress factor $A^{\prime}$ for the hanging wall is calculated as follows:

$$
A^{\prime}=\frac{\sigma_{1}}{U C S}=\frac{3 M P a}{50 M P a}<0.1
$$

Factor $B$ accounts for joint orientations relative to stope walls. This factor is determined using the graph presented in Fig. 5.4b. Joints orientations are assumed to parallel the stope walls. Thus, $B$ is determined to be 0.3 for the HW.

Factor $C$ accounts for two modes of failure (buckling/slabbing or sliding) and the effect of gravity. For hanging wall stability, the failure mode of buckling/slabbing due to gravity will be applied in the analysis. The graph in Fig. 5.4c will be applied to determine the proper value of the $\mathrm{C}$ factor. The $C$ factor is obtained to be 6.4, with the average hanging wall dipping angle of 75 degrees.

The modified $Q^{\prime}$ for the hanging wall rock is 5 according to the previous technical reports. Therefore, the stability number is calculated as follows:

$$
N^{\prime}=Q^{\prime} \times A \times B \times C=5 \times 0.1 \times 0.3 \times 6.4=0.96
$$

The hydraulic radius $H R$ is the stope wall area over the surface perimeter. According to the projected Avoca mining method, the sublevel spacing is $15 \mathrm{~m}$, and $20 \mathrm{~m}$ of void will be left during stoping. Thus, $H R$ is calculated as below:

$$
H R=H \times L \div 2(H+L)=20 \times 15 \div 2(20+15) \approx 4.3 \mathrm{~m}
$$




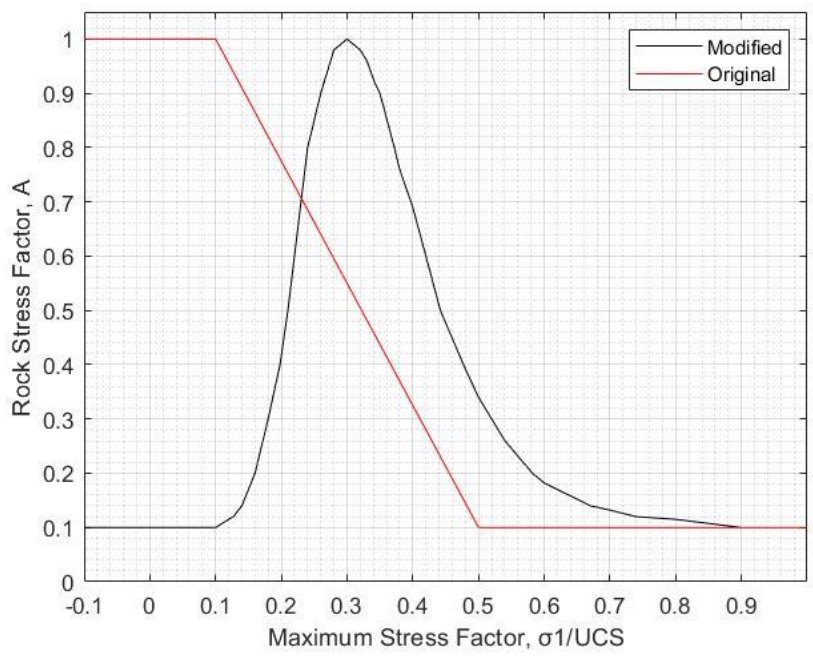

(a) Factor $A$ (Mitri et al., 2011; Mathews et al., 1981)

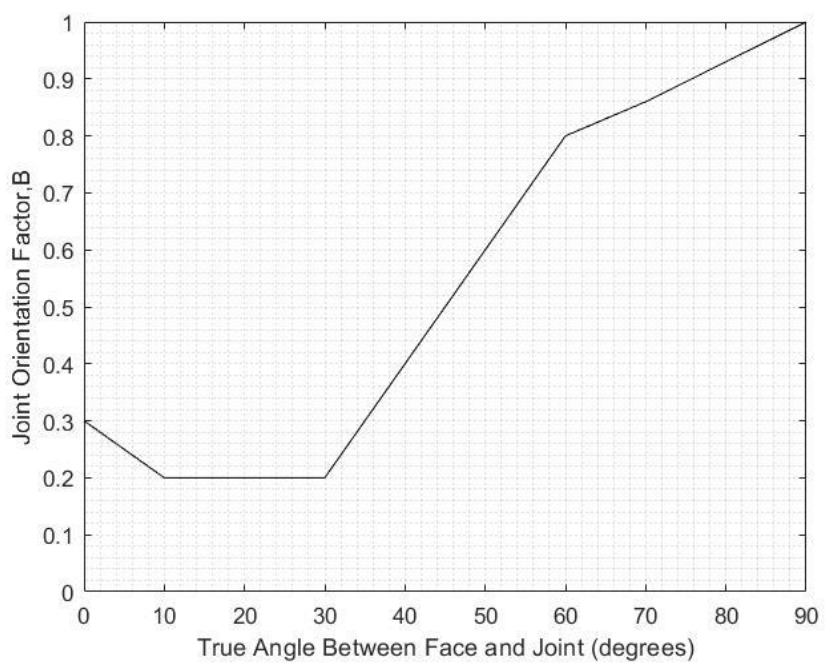

(b) Factor B (Mathews et al., 1981) 


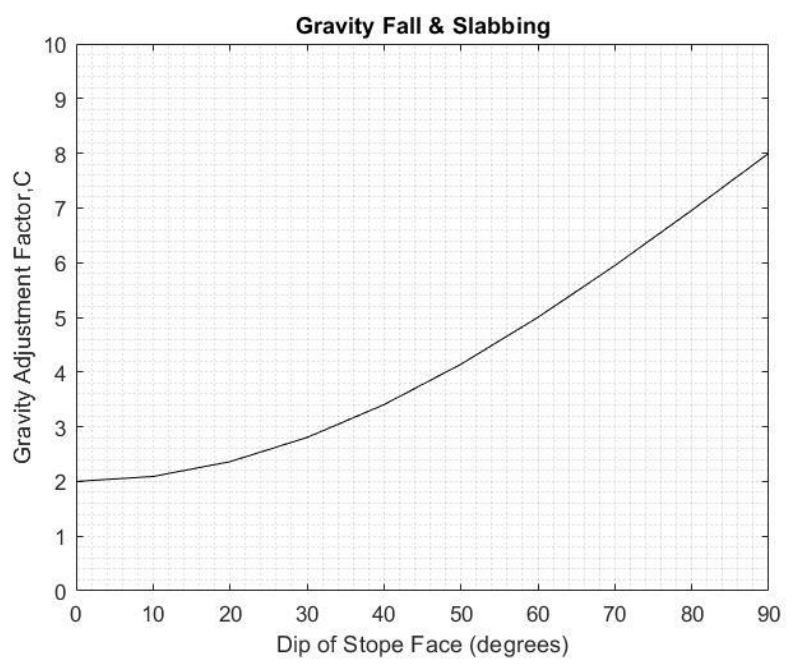

(c) Factor $C$ (Mathews et al., 1981)

\section{Figure 5.4: Empirical charts for determining A, B and $C$}

Fig. 5.1 indicates that the studied HW falls within the potentially unstable area. Same results can be obtained from Fig. 5.3 as shown by the intersection of red lines. Fig. 5.3 also shows that HW ELOS values of $2.9 \mathrm{~m}$ and $3.1 \mathrm{~m}$ are found in historical cases, of which the geometric and geotechnical conditions are similar with that of the case study stope. Thus, the empirical dilution graph estimates an ELOS of $3 \mathrm{~m}$ for the studied stope.

Empirical stability graphs are widely accepted in preliminary studies of open stope mines. However, some inherent deficiencies are inevitable when using empirical methods. Suorineni (2010) systematically reviewed the development and different variants of the stability graph method. He reported that no variant accounts for orebody thickness in the definitions of the stability states; hence it should be used with caution when applied to narrow vein orebodies. Although many authors have made expansions and modifications of the database (Potvin, 1988; Hutchinson \& Diederichs, 1996; Suorineni, 1998; Trueman et al., 2000; Mawdesley et al., 2001), empirical charts are only applicable to cases similar to those from which they were developed. Besides, it is also difficult to account for other site-specific factors such as the impacts of nearby faults, which could influence stope stability by expanding low-stress zones. Moreover, as mining activities proceed upwards, lower-level stoping activities will create stress shadow around upper stopes, weakening the clamping/confinement forces that help keep the host rock mass from 
detachment into the stope. Such effect on upped stope instability triggered by lower stope mining cannot be accounted for using empirical graph methods.

\subsubsection{Proposed numerical modelling methodology}

To avoid the disadvantages of empirical stability graph methods, many numerical modelling studies have been carried out to estimate ore dilution and HW overbreak using site-specific geometric and geotechnical data of mines. However, most early modelling studies, as well as current work, only focus on the stope overbreak assessment of an isolated type stope with no previous mined-out areas (Urli \& Esmaieli, 2016; Heidarzadeh et al.,2019; Vallejos \& Díaz, 2020; Hefni et al., 2020). Alternatively, the stope overbreak is not actually modelled during stoping simulation, e.g., overbreak areas attach to stope wall rather than being mucked out in the modeling (El Mouhabbis et al., 2009).

The overbreak that occurs in lower-level stopes extends the relaxation/unstressed zone, showing well-known stress shadow effect, which could enlarge the HW overbreak volume in the current level. Henning \& Mitri (2008) analyzed HW dilution data measured by the Cavity Monitoring System (CMS) at the Bousquet \#2 mine. It was found primary stopes above different heights of backfilled zones exhibit the different overbreak volume due to differing stress settings. Therefore, the stress shadow impact of lower-level stoping activities on the current-level stope overbreak must be considered. Analyzing an isolated stope without mined-out zones below could underestimate the overall overbreak volume during production.

With the aim of modelling HW overbreak more realistically with the mining sequence, a methodology for overbreak assessment using numerical modelling is proposed and applied for the case study vein. The detailed procedure is as follows.

(1) The stope is excavated first, and the resultant HW overbreak area is detected and mucked out, i.e. yielded elements on the stope HW are removed from the model;

(2) The stope and overbreak areas are then backfilled together before moving to upper level mining;

(3) HW overbreak volume at each mining level is analyzed and quantified.

A 2D modelling of the case study vein is conducted using the FLAC3D code, as a fine-mesh 3D model for overbreak assessment of such scale would require extreme computational efforts. As 
shown in Fig. 5.5, the model comprises the vein and nearby parallel fault, following the actual layout of the case study mine. The minimum mesh size is $0.5 \mathrm{~m}$ around the vein. The in-situ stresses and material parameters used for this model are consistent with the previous 3D modelling study in Table 4.1. The horizontal-to-vertical stress ratios are 1.5 and 1.8 in $\mathrm{x}$ - and $\mathrm{y}$ - directions, respectively. The vein is excavated bottom-up and backfilled at $15 \mathrm{~m}$ intervals, which are simulated in the modelling. The yielded areas in the stope HW will be treated as overbreak according to Hoek-Brown failure criterion and removed after stope excavation. Overbreak is assumed to cave into the stope and mucked out during production.

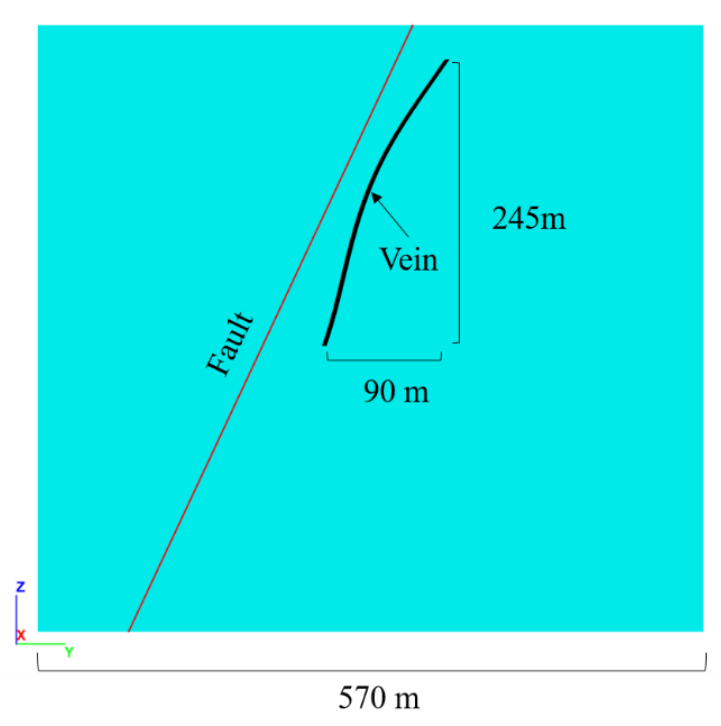

(a) Front view

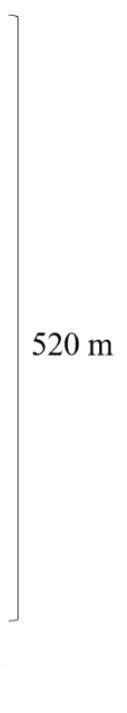

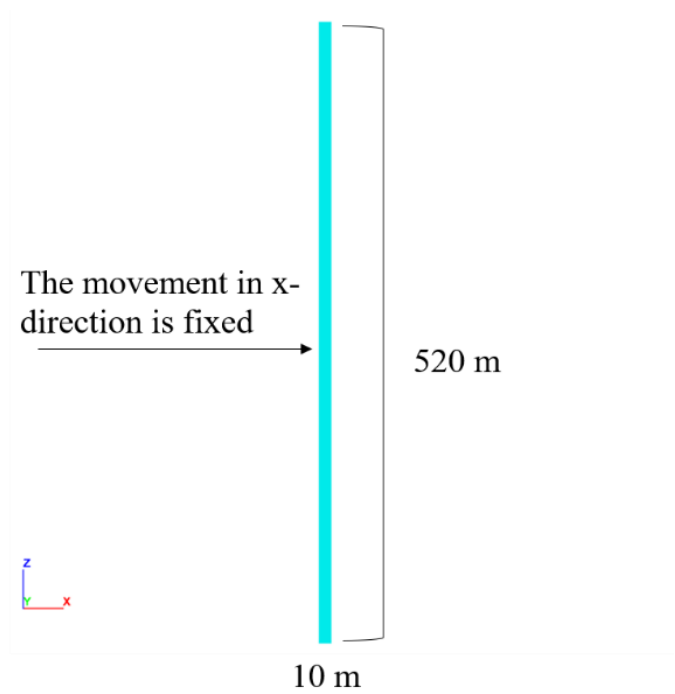

(b) Side view

\section{Figure 5.5: Modelling 2D overbreak problem in FLAC3D}

\subsection{Modelling results}

\subsubsection{HW overbreak estimation}

The predicted HW overbreak results using the proposed methodology are shown in Figure 5.6. The overbreak area is estimated based on Hoek-Brown failure criterion. To allow comparison, the conventional method is also tested following the same mining procedure but keeping the overbreak area in place at each stage. It can be observed from Fig. 5.6 that the HW overbreak (red areas) using the new method is larger than the one using the conventional modelling method used by ElMouhabbis et al. (2009) among others. 


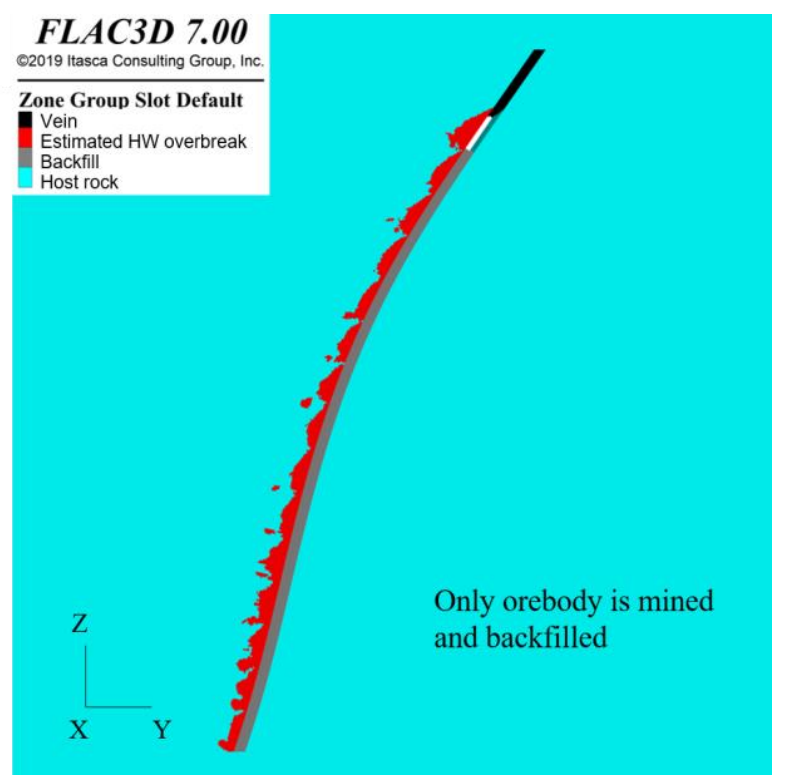

(a) Conventional method

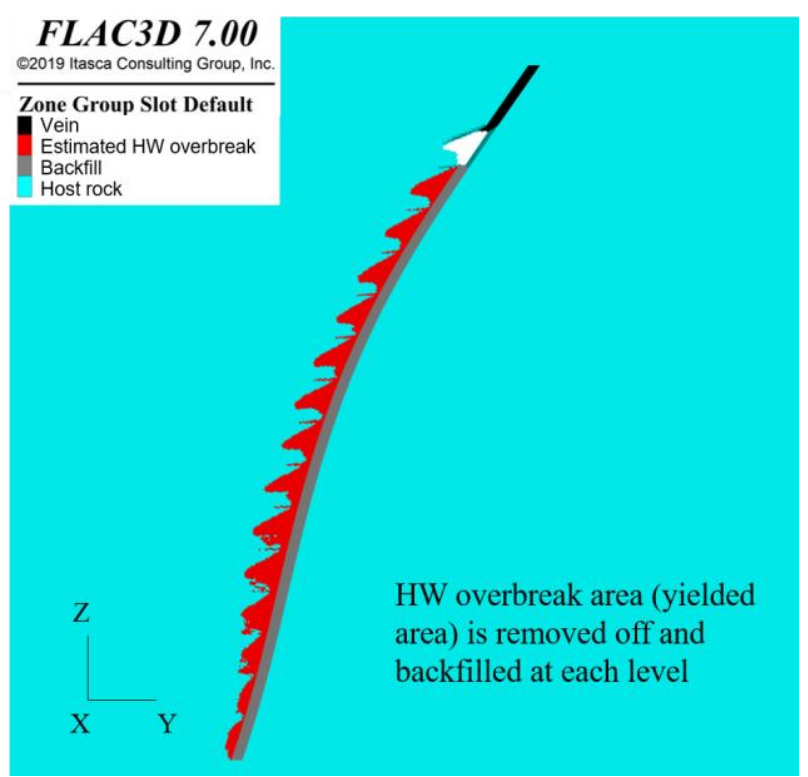

(b) New method

Figure 5.6: Predicted HW overbreak areas using two methods

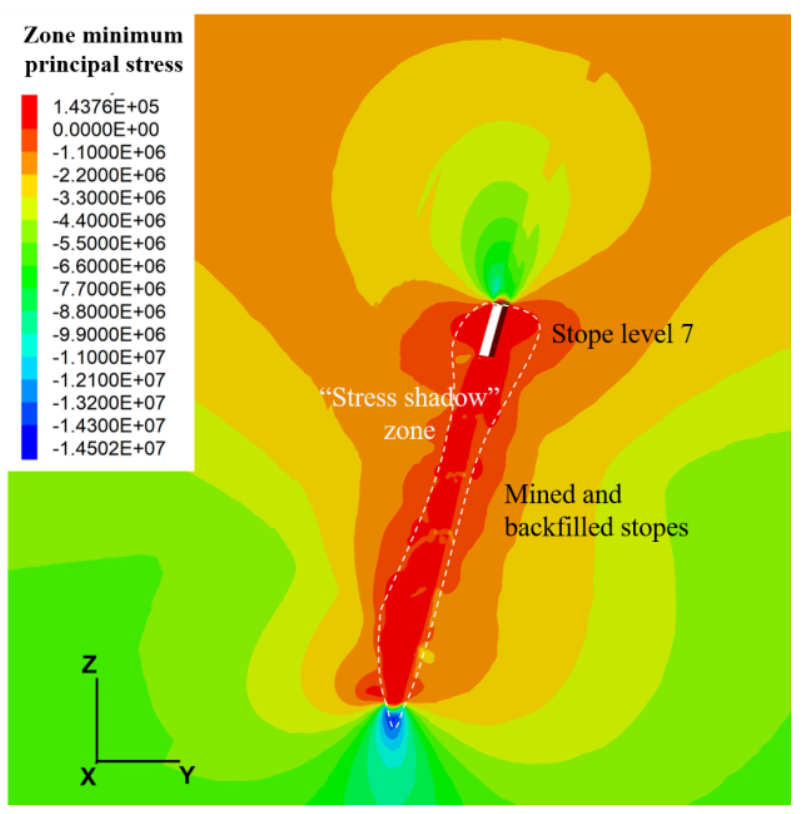

(a) Conventional method

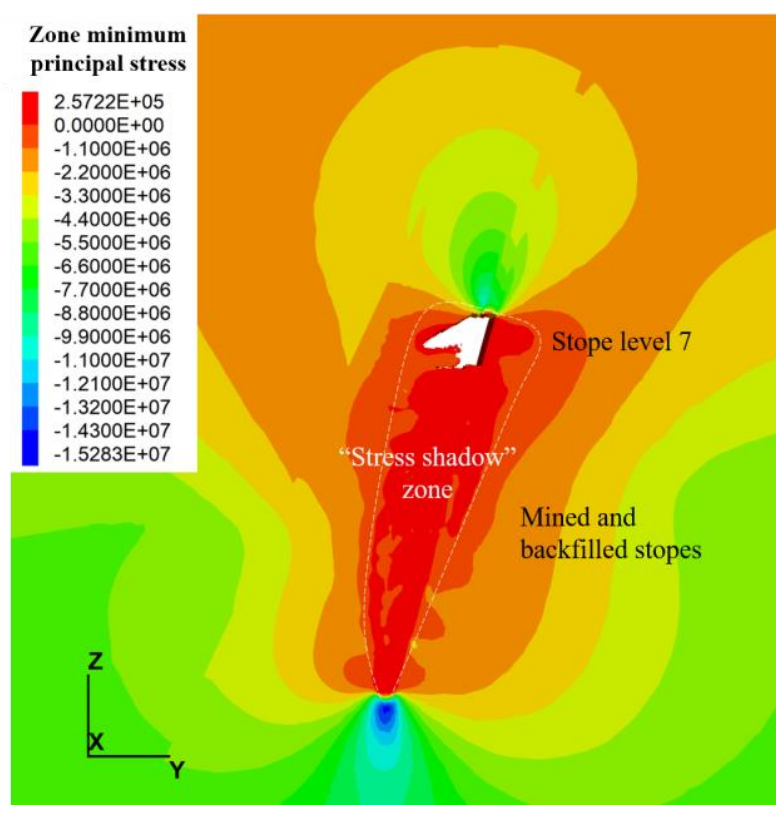

(b) New method

Figure 5.7: Stress shadow zones caused by stoping activities (unit: Pascal)

Figure 5.7 shows the minimum principal stress contours when mining stope level 7 using two modelling methods. The positive principal stress values represent tension due to different convention in FLAC3D. The in-situ stress relaxation area caused by previous stoping activities, is 
referred to here as "stress shadow" zone, which is delineated by white dashed line in Fig. 5.7. Compared with Fig. 5.7a, the obtained stress shadow zone using the new method is significantly larger in Fig. 5.7b. The enlarged stress relaxation zone leads to higher HW overbreak at following stope levels.

Figure 5.8 plots the predicted HW ELOS against different mining stages using two methods. It is found that the predicted HW overbreak (red line) by implementing the new method is higher than the conventional method (blue line) that we do not remove off the yielded HW area at each level. As summarized in Table 5.1, the average HW ELOS of $5.8 \mathrm{~m}$ is obtained using the new method, which is higher than that of $3.5 \mathrm{~m}$ using the conventional method.

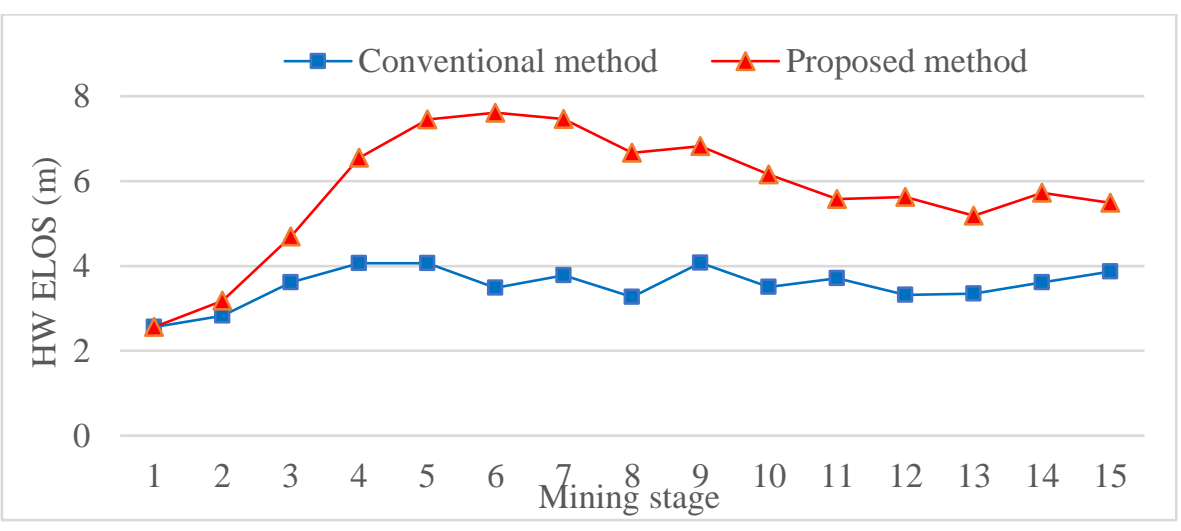

Figure 5.8. Comparison of the predicted HW ELOS between conventional and new methods

Table 5.1: Predicted HW ELOS values obtained from two methods

\begin{tabular}{ccccccccccccccccc}
\hline Mining stage & 1 & 2 & 3 & 4 & 5 & 6 & 7 & 8 & 9 & 10 & 11 & 12 & 13 & 14 & 15 & Average \\
\hline $\begin{array}{c}\text { HW ELOS - } \\
\text { Conventional (m) }\end{array}$ & 2.6 & 2.8 & 3.6 & 4.1 & 4.1 & 3.5 & 3.8 & 3.3 & 4.1 & 3.5 & 3.7 & 3.3 & 3.3 & 3.6 & 3.9 & 3.5 \\
$\begin{array}{c}\text { HW ELOS - } \\
\text { New (m) }\end{array}$ & 2.6 & 3.2 & 4.7 & 6.6 & 7.5 & 7.6 & 7.5 & 6.7 & 6.8 & 6.2 & 5.6 & 5.6 & 5.2 & 5.7 & 5.5 & 5.8 \\
\hline
\end{tabular}

\subsubsection{Impact of HW overbreak on ground settlements}

Table 5.2 compares the ground differential settlement results at different mining stages using two modelling methods. The results show that compared with conventional approaches, the new method provides a higher estimation of ground differential settlements induced by underground 
stoping activities. This is because that new method leads to enlarged stress shadow zones underground, which aggravates ground subsidence and compromises global stability of the mine.

\section{Table 5.2: Predicted differential settlements obtained using two methods}

\begin{tabular}{|c|c|c|c|c|c|c|}
\hline \multicolumn{2}{|c|}{ Mining stage } & 11 & 12 & 13 & 14 & 15 \\
\hline \multirow{2}{*}{$\begin{array}{l}\text { Differential } \\
\text { settlement } \\
(\mathrm{cm})\end{array}$} & $\begin{array}{l}\text { Conventional } \\
\text { method }\end{array}$ & 0.85 & 1.27 & 1.42 & 1.56 & 1.70 \\
\hline & New method & 1.43 & 1.76 & 1.95 & 2.13 & 2.33 \\
\hline
\end{tabular}

\subsection{HW overbreak control measures}

To minimize HW overbreak, horizontal sill pillar measures are proposed and examined in the modelling. The implementation of sill pillar might reduce the stress shadow created by lower-level mining activities by separating stoping levels. Horizontal sill pillars are often placed between stopes as support elements in steeply dipping deposits, allowing mining at multiple levels concurrently to increase production rates. Sill pillars can be recovered at the end of life of the mine plan.

Currently, pillar strength formulas, empirical design charts, and numerical modelling approaches are available for sill pillar design. Martin and Maybee (2000) systematically reviewed existing empirical strength formulas and design charts. Oke and Kalenchuk (2017) summarized hard rock pillar design methods in literature, providing guidelines to help practitioners select the most applicable pillar design chart or equation for their specific application. However, existing research only focuses on the rock pillar stability itself rather than its optimal placement from the perspective of reducing stope overbreak.

In effect, sill pillar is conventionally placed in the middle of the narrow vein (Stewart et al., 2005; Niemi \& Marjerison, 2006), but this regular placement pattern may not be the optimal solution. In this study, a horizontal sill pillar will be simulated at different mining levels from levels 5 to 8 to examine the impact of sill pillar measures on the overbreak volume. The results will help optimize sill pillar placement. Figure 5.9 shows the HW overbreak results in different sill pillar placement schemes. The pillar thickness is equal to that of a level interval, i.e. $15 \mathrm{~m}$. 


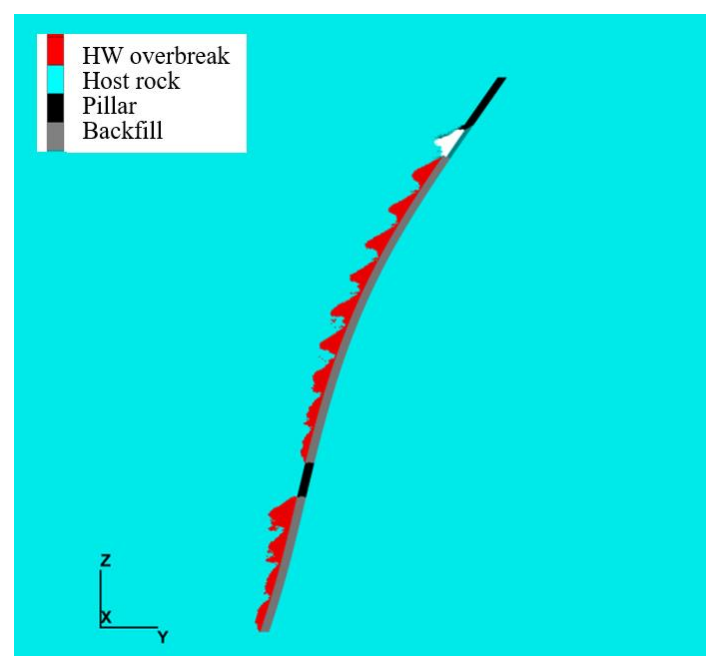

(a) Sill pillar at level 5

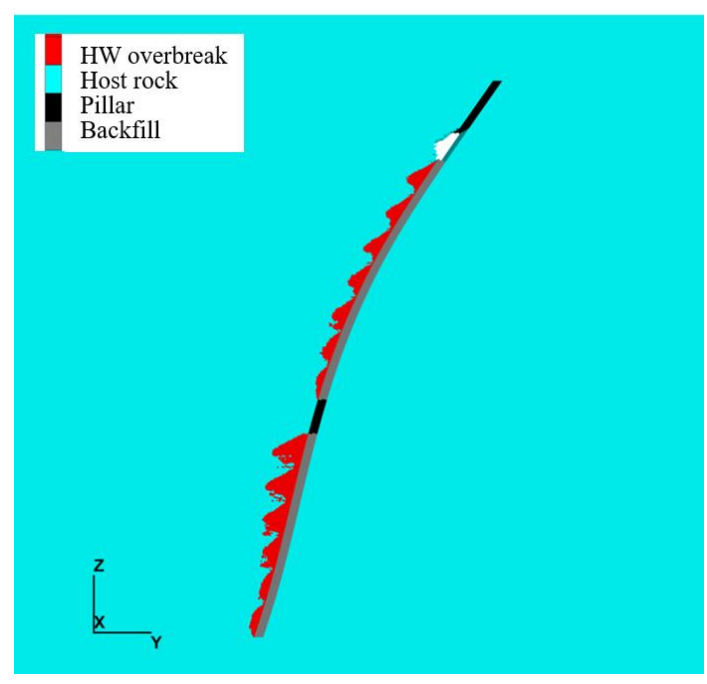

(c) Sill pillar at level 7

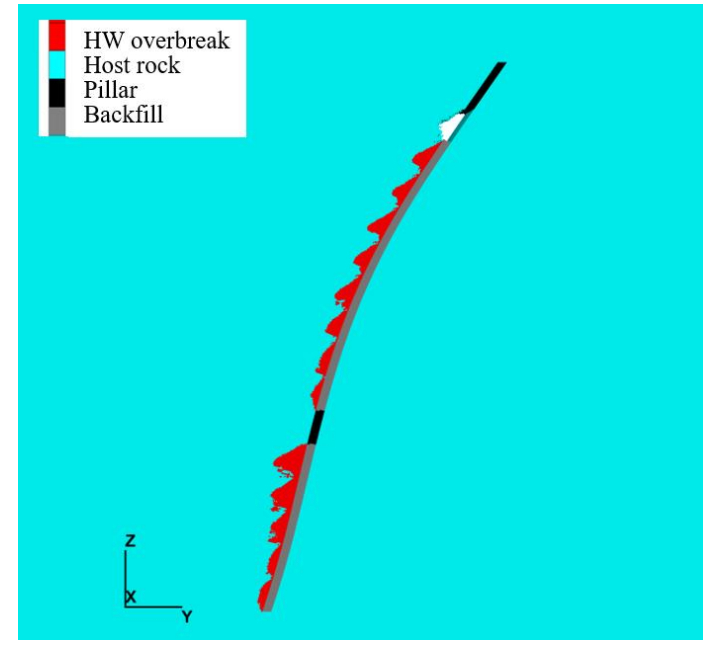

(b) Sill pillar at level 6

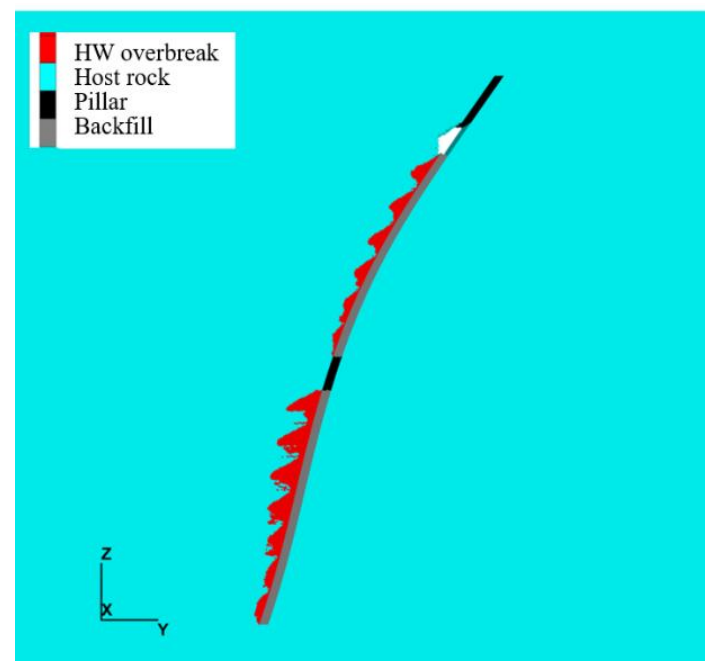

(c) Sill pillar at level 8

Figure 5.9: HW overbreak results with different sill pillar placement schemes

Figure 5.10 plots HW ELOS for different sill pillar locations. Compared with HW ELOS results without sill pillar, the other four cases show considerably less ELOS from mining levels above the sill pillar, i.e. HW ELOS decreases from $6.6 \mathrm{~m}$ at level 4 to $1.96 \mathrm{~m}$ at level 6 when the sill pillar is placed at level 5.

As can be seen from the minimum principal stress results in Fig. 5.11, the sill pillar reduces the stress shadow created by the lower level mining, hence the stope immediately above the sill pillar can thereby be considered an isolated stope, which experiences lower HW ELOS compared with 
other stoping levels. It is also noticed that the ELOS of the isolated stope immediately above the pillar is slightly lower than that of the isolated stope at level 1, as depicted by black dash lines in Fig. 5.10. This may be attributed to the height of backfill column beneath each stope; the stress relief on upper stopes is reduced as the lower mining zone is increasingly replaced with backfill.

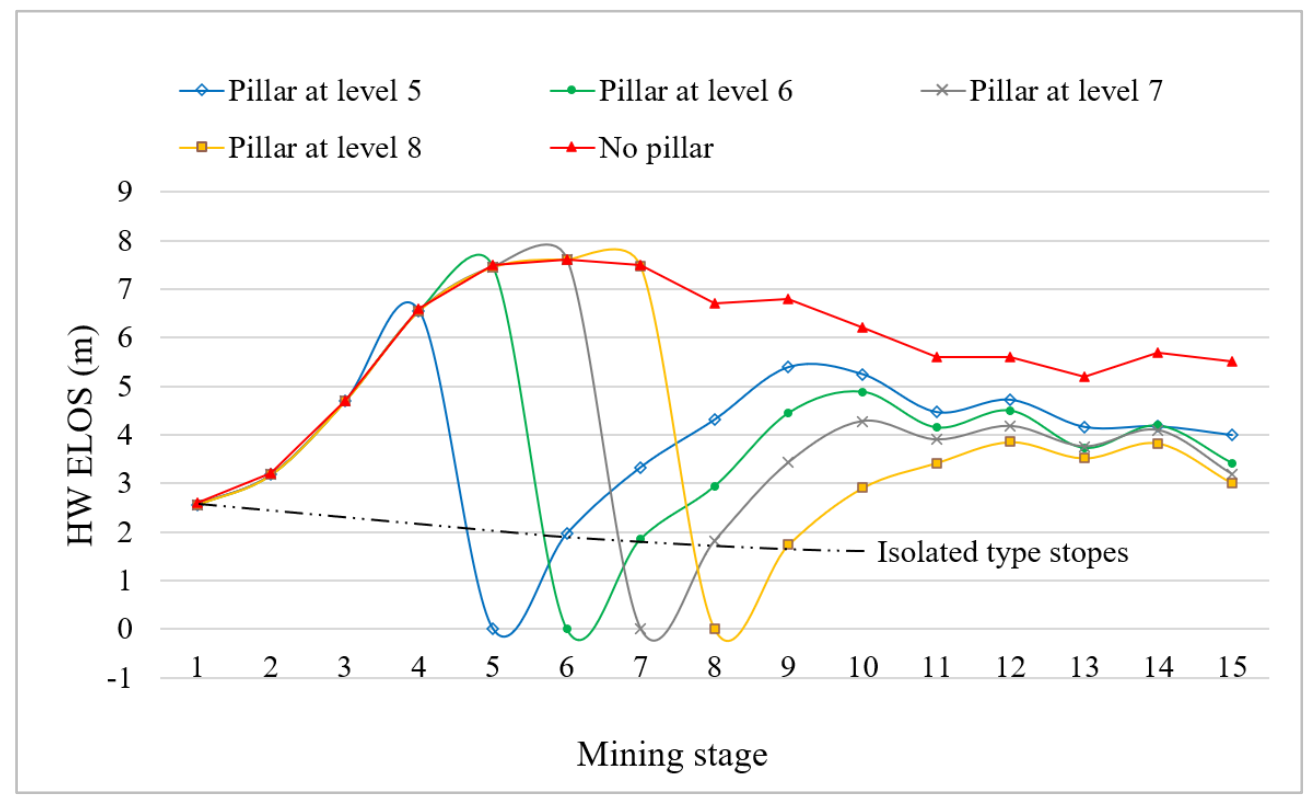

Figure 5.10: HW ELOS versus mining levels in different models

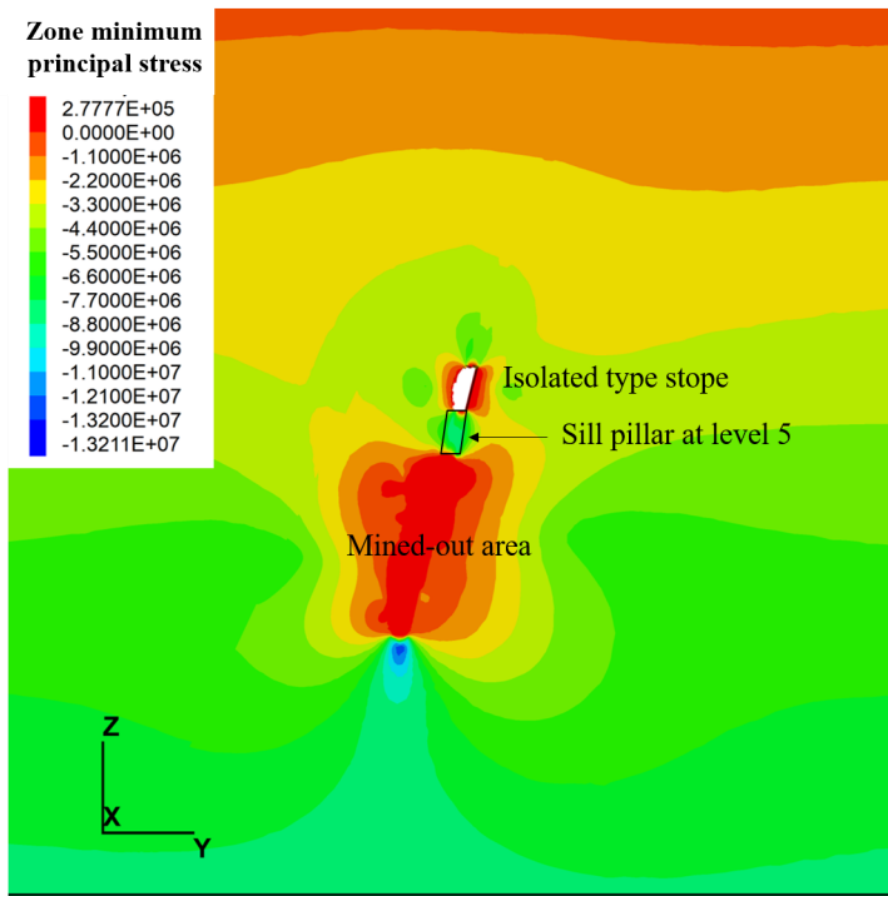

Figure 5.11: Sill pillar separates stoping levels to reduce stress shadow due to lower zone mining (unit: Pascal). Note: Positive principal stress values represent tension. 
Table 5.3 summarizes HW ELOS values when implementing the horizontal sill pillar at different levels. It can be observed that the average HW ELOS decreased significantly in all cases with the sill pillar. Also, it is found that leaving a sill pillar at the lower level 5 or 6 instead of the middle level is optimal as the average ELOS dropped from $5.8 \mathrm{~m}$ to $3.9 \mathrm{~m}$ representing overbreak volume reduction of $33 \%$.

Table 5.3: HW ELOS values when implementing sill pillars at different levels

\begin{tabular}{|c|c|c|c|c|c|c|c|c|c|c|c|c|c|c|c|c|c|}
\hline \multicolumn{2}{|c|}{ Mining stage } & 1 & 2 & 3 & 4 & 5 & 6 & 7 & 8 & 9 & 10 & 11 & 12 & 13 & 14 & 15 & Average \\
\hline \multirow{5}{*}{$\begin{array}{l}\text { HW } \\
\text { ELOS } \\
\text { (m) }\end{array}$} & $\begin{array}{l}\text { Pillar at } \\
\text { level } 5\end{array}$ & 2.6 & 3.2 & 4.7 & 6.6 & N/A & 2.0 & 3.3 & 4.3 & 5.4 & 5.2 & 4.5 & 4.7 & 4.2 & 4.2 & 4.0 & 3.9 \\
\hline & $\begin{array}{c}\text { Pillar at } \\
\text { level } 6\end{array}$ & 2.6 & 3.2 & 4.7 & 6.6 & 7.5 & N/A & 1.9 & 2.9 & 4.5 & 4.9 & 4.2 & 4.5 & 3.7 & 4.2 & 3.4 & 3.9 \\
\hline & $\begin{array}{c}\text { Pillar at } \\
\text { level } 7\end{array}$ & 2.6 & 3.2 & 4.7 & 6.6 & 7.5 & 7.6 & N/A & 1.8 & 3.4 & 4.3 & 3.9 & 4.2 & 3.8 & 4.1 & 3.2 & 4.3 \\
\hline & $\begin{array}{c}\text { Pillar at } \\
\text { level } 8\end{array}$ & 2.6 & 3.2 & 4.7 & 6.6 & 7.5 & 7.6 & 7.5 & N/A & 1.7 & 2.9 & 3.4 & 3.9 & 3.5 & 3.8 & 3.0 & 4.4 \\
\hline & $\begin{array}{l}\text { No } \\
\text { pillar }\end{array}$ & 2.6 & 3.2 & 4.7 & 6.6 & 7.5 & 7.6 & 7.5 & 6.7 & 6.8 & 6.2 & 5.6 & 5.6 & 5.2 & 5.7 & 5.5 & 5.8 \\
\hline
\end{tabular}

\subsection{Summary}

HW overbreak reduces ore grade and increases the amount of material that needs to be hauled and sent to the mill. It can also lead to additional rock supports and can hinder pillar recovery. Therefore, it is important to evaluate and minimize HW overbreak for boosting mining profitability. The empirical stability graph (Mathews et al., 1981) and the dilution design graph (Clark \& Pakalnis, 1997) are utilized for the initial assessment of the stope stability. However, existing empirical methods, as well as modelling methods mainly focus on the assessment of isolated stope while neglecting the influence of stress shadow zone created by lower-level mining activities. To fill this gap, a new methodology for HW overbreak estimation using numerical modelling is proposed and compared with the conventional one. Finally, the horizontal sill pillar measures are examined and optimized to reduce overall stope overbreak during production. The main observations are summarized below:

- The empirical stability graph method proposed by Mathews et al. (1981) is used to assess stope stability, and the results show that the studied stope HW is potentially unstable. Clark 
and Pakalnis (1997) incorporated ELOS into stability graph method to predict the overbreak volume, which indicates the HW ELOS for the studied stope is around $3 \mathrm{~m}$.

- The proposed new methodology obtains an average HW ELOS of $5.8 \mathrm{~m}$, which is higher than $3.5 \mathrm{~m}$ using the conventional method. The HW ELOS of the current stope are affected by stress shadowing of lower level mined out areas, which is more realistic than analyzing an isolated stope solely.

- By applying the proposed methodology, the estimated ground surface differential settlements are higher at each mining stage. This indicates that HW overbreak will aggravate ground surface settlement.

- The estimated overbreak is much higher if the yielded areas on stope HW were all mucked out, implying the importance of immediate stope backfilling to avoid hanging wall caving. Similar trends were previously reported in the field by Henning \& Mitri (2008); the measured 172 stope overbreak histories at the Bousquet \#2 mine showed a positive correlation between stope volume and stope exposure time.

- To minimize stope overbreak, a horizontal sill pillar is left to separate the orebody into two mining zones. It is observed that the average HW ELOS decreases significantly after leaving a sill pillar. Also, leaving a sill pillar at a lower mining level instead of the middle of the orebody is more effective. 


\section{Chapter 6}

\section{Conclusions and recommendations}

\subsection{Conclusions}

Although crown pillar stability in a mining context has been studied for more than 30 years, the design guidelines for surface crown pillars are still limited. Particularly, for complicated crown pillar cases with overlying infrastructure, empirical and analytical design methods are inadequate to determine the safe crown pillar dimensions to prevent stope caving, as well as ensure the stability of overlying surface infrastructure. Therefore, the primary goal of this study is to develop crown pillar design strategies using numerical modelling. Firstly, a mine case study of a shallow deposit with an overlying TSF is examined for crown pillar stability dimensioning and assessment. The finite difference code FLAC3D 7.0 is used to carry out model parametric studies on the crown pillar due to variations in in-situ stresses and fault properties. Based on the modelling results, critical factors such as in-situ stress regime, nearby fault reactivation and mining-induced ground surface subsidence are investigated. The adequate crown pillar thickness could be determined according to both crown pillar yielding and ground settlement results. In addition, a new methodology for HW overbreak estimation using numerical modelling is proposed. The new method proved to be more realistic compared with conventional methods. Finally, horizontal sill pillar placement in the orebody is examined and optimized to reduce HW overbreak and boost mine profitability.

\subsubsection{Surface crown pillar design}

The case study shallow deposits are situated under a TSF. High horizontal stresses and two major faults exist in mining area. For such complex scenario, empirical methods are unreliable to determine an adequate crown pillar thickness as the stability of both underground excavations and overlying surface infrastructure need to be considered. To deal with this problem, 3D numerical modelling is employed to carry out parametric studies on the crown pillar. Two criteria are used for crown pillar dimensions design: crown pillar yielding and overlying dam foundation subsidence. The key conclusions are summarized below.

- In comparison with the empirical results that the safe minimum crown pillar thickness is above $63.8 \mathrm{~m}$, the numerical modelling results show that the crown pillar starts to yield in 
the thickness varying from $43 \mathrm{~m}$ to $72 \mathrm{~m}$. The surface displacement monitoring measures are recommended if the crown pillar thickness is less than $72 \mathrm{~m}$ considering the worst-case scenario, but the crown pillar thickness could be as small as $43 \mathrm{~m}$ depending to the mining conditions

- Three crown pillar yielding states were characterized to assess surface crown pillar stability: yielding zone initiation, yielding zone coalescence, and completely yielding. The modelling results reveal that crown pillar tends to yield with higher deviatoric stress and lower fault friction angle.

- The surface infrastructure stability is dominantly controlled by the differential subsidence rather than the absolute magnitude of subsidence. The modelling results indicate that the differential settlements triggered by underground mining activities may threaten the stability of overlying tailings dam. The more intensive horizontal stresses and lower friction angle are applied, the greater dam foundation differential settlements occur.

- It can be found that stoping activities trigger the reactivation of both regional faults, but the fault parallels the vein has larger maximum shear displacements than the cross fault. Also, fault friction angle is a more dominant factor controlling shear displacements compared with in-situ stress.

\subsubsection{HW overbreak assessment}

A new methodology for dilution/stope overbreak assessment is proposed using numerical modelling. The HW overbreak areas are removed and backfilled in modelling procedures to fully consider the stress shadow effect of preceding stoping during production. Besides, horizontal sill pillar measures are examined and optimized to minimize HW overbreak. The following conclusions are made based on the modelling results:

- The empirical dilution design graph proposed by Clark \& Pakalnis (1997) is used to assess estimate stope overbreak volume, but only few case histories similar to the studied stope are recorded in the database. The estimated HW ELOS is around $3 \mathrm{~m}$ based on two similar case histories. 
- The proposed methodology for HW overbreak estimation is more realistic and accurate in terms of the HW overbreak developing tendency during production, compared with that from the empirical and conventional modelling approaches, as the latter two only focus on the stability assessment of isolated type stope.

- By applying the proposed methodology, the estimated ground surface differential settlement is higher at each mining stage. This indicates that HW overbreak can compromise ground stability and aggravate surface subsidence.

- The modelling results show that the horizontal sill pillar measures considerably reduce the overbreak volume as it blocks the stress shadowing of mined-out areas. Also, implementing horizontal sill pillar at lower levels of the vein rather than the conventional central part is more effective. 


\subsection{Recommendations for future work}

In the absence of field measurements on in-situ stresses and faults, the model parametric study shows that the safe minimum crown pillar thickness varies from $43 \mathrm{~m}$ to $72 \mathrm{~m}$. To obtain a more accurate estimation, horizontal stress ratios and fault parameters should be measured in-situ. For example, the actual fault behavior can be observed and measured to obtain the fault parameters. Boreholes can also be drilled near the ground surface to obtain the shallow in-situ stress regime from borehole deformation analysis.

Considering the overlying tailings dam stability, the dam foundation differential settlement results can be interpreted to guide crown pillar sizing. The determination of ground subsidence thresholds and criteria by geotechnical specialists should be quite useful.

It should be noted that the model used for HW overbreak estimation in this study is 2-dimensional, and thereby, the obtained results are conservative as the stope excavations are not supported by rock mass at two ends of the model. Thus, model calibration is required before being put in use. 3D modelling is recommended following the same methodology in the future.

Finally, the proposed modelling procedure for HW overbreak estimation is suggested to be followed when simulating mining sequences in other mine-wide modelling studies. As discussed before, the HW overbreak during stoping shows significant impact on ground settlement and hinders global stability. Thus, the implementation of proposed modelling procedure that considers stope overbreak can lead to more realistic and accurate results. 


\section{Reference}

Abdellah, W. R. E., Hefni, M. A., \& Ahmed, H. M. (2020). Factors influencing stope hanging wall stability and ore dilution in narrow-vein deposits: part 1. Geotechnical and Geological Engineering, $38(2), 1451-1470$.

Barton, N., Lien, R., \& Lunde, J. (1974). Engineering classification of rock masses for the design of tunnel support. Rock mechanics, 6(4), 189-236.

Bétournay MC (2002). Underground mining and its surface effects. Interstate Technical Group on Abandoned Underground Mines, Fourth Biennial Abandoned Underground Mine Workshop, Davenport, Iowa, May 1-3.

Beauchamp, K. J., Carter, T. G., Cooper, R. A., Ferguson, R., \& Kaczmarek, S. (2006). Addressing Mine Hazards under Transportation Corridors-The Timmins Experience. Golder Associates, Sudbury.

Brebbia, C. A., \& Dominguez, J. (1994). Boundary elements: an introductory course. WIT press.

Can, E., Kuşcu, Ş., \& Kartal, M. E. (2012). Effects of mining subsidence on masonry buildings in Zonguldak hard coal region in Turkey. Environmental Earth Sciences, 66(8), 2503-2518.

Carter, T. G. (1992) A new approach to surface crown pillar design. In Proc. 16th Can. Rock Mechanics Symposium, Sudbury (pp. 75-83).

Carter, T. G. (2014). Guidelines for use of the scaled span method for surface crown pillar stability assessment. Ontario Ministry of Northern Development and Mines, Ontario, 1-34.

Cundall, P. A., \& Strack, O. D. (1979). A discrete numerical model for granular assemblies. geotechnique, 29(1), 47-65.

Curran, J. H., Corkum, B. T., \& Pashutinski, I. (1996). CPillar 3D analysis of crown pillar and roof stability-User's guide Version 3.0. Rock Engineering Group, University of Toronto.

Clark, L.M. \& Pakalnis, R.C. (1997). An empirical approach for estimating unplanned dilution from open stope hanging walls and footwalls. 99thAnnual General Meeting, CIM (CD-ROM). Vancouver, B.C: Canadian Institute of Mining, Metallurgy and Petroleum. 
Cai, Y., Verdel, T., \& Deck, O. (2014). On the topography influence on subsidence due to horizontal underground mining using the influence function method. Computers and Geotechnics, $61,328-340$.

Donnelly, L. (2000). Fault reactivation induced by mining in the East Midlands. Mercian Geologist, 15(1), 29-36.

El Mouhabbis et al. (2009) Effect of stope undercutting on its wall overbreak. In Proc 43rd US Rock Mechanics Symposium, held in Asheville, NC June 28th - July 1, Paper No. ARMA 09-200.

Franks, C. A. M., \& Geddes, J. D. (1986). Subsidence on steep slopes due to longwall mining. International Journal of Mining and Geological Engineering, 4(4), 291-301.

Georgieva, T. D., Anastasov, D., \& Gyrkov, I. (2016). Crown pillar behavior study using numerical modelling in Chelopech mine. Rock Mechanics and Rock Engineering: From the Past to the Future, 457.

Hoek, E. (1989) A limit equilibrium analysis of surface crown pillar stability. Proc. Int' 1 Conf. Surface Crown Pillar Evaluation for Active and Abandoned metal mines, Canmet; $3^{\wedge} 13$.

Hoek, E. \& Kaiser, P. (1995). Support of Underground Excavation in Hard Rock. Rotterdam: Balkema.

Hoek, E., \& Diederichs, M. S. (2006). Empirical estimation of rock mass modulus. International journal of rock mechanics and mining sciences, 43(2), 203-215.

Hefni, M. A., Abdellah, W. R. E., \& Ahmed, H. M. (2020). Factors Influencing Stope Hanging Wall Stability and Ore Dilution in Narrow-Vein Deposits: Part II. Geotechnical and Geological Engineering, 1-19.

Hutchinson, D. J., \& Diederichs, M. S. (1996). Cablebolting in underground mines (Vol. 477, p. 478). Richmond, BC, BiTech Publishers.

Henning, J. G. (2007). Review of crown pillar investigations in a historic mine camp. In 1st Canada-US Rock Mechanics Symposium. American Rock Mechanics Association.

Henning, J. G., \& Mitri, H. S. (2007). Numerical modelling of ore dilution in blasthole stoping. International Journal of Rock Mechanics and Mining Sciences, 44(5), 692-703. 
Henning, J. G., \& Mitri, H. S. (2008). Assessment and control of ore dilution in long hole mining: case studies. Geotechnical and Geological Engineering, 26(4), 349-366.

Heidarzadeh, S., Saeidi, A., \& Rouleau, A. (2019). Evaluation of the effect of geometrical parameters on stope probability of failure in the open stoping method using numerical modelling. International Journal of Mining Science and Technology, 29(3), 399-408.

Holla, L. (1997). Ground movement due to longwall mining in high relief areas in New South Wales, Australia. International Journal of Rock Mechanics and Mining Sciences, 34(5), 775-787. Itasca consulting Group, Inc. (2017). FLAC3D (Fast Lagrangian Analysis of Continua in 3Dimensions), Version 6.0.

Ji, H. G., Ma, H. S., Wang, J. A., Zhang, Y. H., \& Cao, H. (2012). Mining disturbance effect and mining arrangements analysis of near-fault mining in high tectonic stress region. Safety science, 50(4), 649-654.

Kumar, H., Deb, D., \& Chakravarty, D. (2016). Numerical Analysis of Sill and Crown Pillar Stability for Multilevel Cut and Fill Stopes in Different Geomining Conditions. Geotechnical and Geological Engineering, 34(2), 529-549.

Kalenchuk, K., Falmagne, V., Gelover, A., Montiel, I., \& Luzania, J. (2019). Risk evaluation, design, implementation, instrumentation, and verification for crown pillar extraction at Pinos Altos mine. Rock Mechanics and Rock Engineering, 52(12), 4997-5011.

Laubscher, D. H. (1977). Geomechanics classification of jointed rock masses-mining applications. Trans. Instn. Min. Metall, 86, A1-8.

Li, W., Mei, S., Zai, S., Zhao, S., \& Liang, X. (2006). Fuzzy models for analysis of rock mass displacements due to underground mining in mountainous areas. International journal of rock mechanics and mining sciences, 43(4), 503-511.

Li, X., Li, D., Liu, Z., Zhao, G., \& Wang, W. (2013). Determination of the minimum thickness of crown pillar for safe exploitation of a subsea gold mine based on numerical modelling. International Journal of Rock Mechanics and Mining Sciences, 57, 42-56. 
MA FH, S. U. N. L., \& LI, D. (2011). Numerical simulation analysis of covering rock strata as mining steep-inclined coal seam under fault movement $[\mathrm{J}]$. Transactions of Nonferrous Metals Society of China, 21, s556-s561.

Mathews, K. E., Hoek, E., Wyllie, D. C., \& Stewart, S. (1981). Prediction of stable excavation spans for mining at depths below $1000 \mathrm{~m}$ in hard rock. CANMET DSS Serial No: 0sQ80-00081., Ottawa.

Mawdesley, C., Trueman, R., \& Whiten, W. J. (2001). Extending the Mathews stability graph for open-stope design. Mining Technology, 110(1), 27-39.

Martin, C. D., \& Maybee, W. G. (2000). The strength of hard-rock pillars. International Journal of Rock Mechanics and Mining Sciences, 37(8), 1239-1246.

Mitri, H. S., Hughes, R., \& Zhang, Y. (2011). New rock stress factor for the stability graph method. International journal of rock mechanics and mining sciences (1997), 48(1), 141-145.

Niemi, E., \& Marjerison, J. (2006). Extraction of a Remnant Sill Pillar Under Challenging Ground Conditions at the Stillwater Mine, Nye, MT. In Golden Rocks 2006, The 41st US Symposium on Rock Mechanics (USRMS). American Rock Mechanics Association., 57, 42-56.

Oke, J., \& Kalenchuk, K. (2017). Selecting the Most Applicable Hard Rock Pillar Design Method. In 51st US Rock Mechanics/Geomechanics Symposium. American Rock Mechanics Association.

Potvin. Y. (1988) Empirical open stope design in Canada, Ph.D. thesis, University of British Columbia.

Peng, S. S., Khair, A. W., \& Luo, Y. (1987). Topographical effects of surface subsidence — a case study. In Proceedings, 1987 National Symposium on Mining, Hydrology, Sedimentology and Reclarmation, Springfield (pp. 223-228).

RocScience Inc. (2000) UNWEDGE v 2.3. CPILLAR v 3.0. 31 Balsam Avenue, Toronto, Ontario, Canada, M4E 3B5.

Skempton, A. W., \& MacDonald, D. H. (1956). The allowable settlements of buildings. Proceedings of the Institution of Civil Engineers, 5(6), 727-768. 
Sheorey, P. R. (1994) A theory for in situ stresses in isotropic and transversely isotropic rock. Int. J. Rock Mech. Min. Sci. \& Geomech. Abstr. 31(1), 23-34

Suorineni, F.T. (1998). Effects of faults and stress on open stope design. Ph.D. Thesis, University of Waterloo.

Suorineni, F. T. (2010). The stability graph after three decades in use: experiences and the way forward. International journal of mining, Reclamation and Environment, 24(4), 307-339.

Stewart, P. C., Slade, J., \& Trueman, R. (2005). The effect of stress damage on dilution in narrow vein mines. In 9th AusIMM Underground Operators Conference 2005 (Vol. 2005, No. 1, pp. 211 222). Australasian Institute of Mining \& Metallurgy.

Sainoki, A. \& Mitri, H.S. (2014) Dynamic behaviour of mining-induced fault slip. International Journal of Rock Mechanics and Mining Sciences, 66, pp.19-29.

Trueman, R., Mikula, P., Mawdesley, C., \& Harries, N. (2000). Experience in Australia with the application of the Mathews' method for open stope design. CIM bulletin, 93(1036), 162-167.

Urli, V., \& Esmaieli, K. (2016). A stability-economic model for an open stope to prevent dilution using the ore-skin design. International Journal of Rock Mechanics and Mining Sciences, 82, 7182.

Vallejos, J. A., \& Díaz, L. (2020). A New Criterion for Numerical Modelling of Hangingwall Overbreak in Open Stopes. Rock Mechanics and Rock Engineering, 1-23.

Yardimci, A. G., Tutluoglu, L., \& Karpuz, C. (2016). Crown Pillar Optimization for Surface to Underground Mine Transition in Erzincan/Bizmisen Iron Mine. In 50th US Rock Mechanics/Geomechanics Symposium. American Rock Mechanics Association. 